RESEARCH

\section{SERIES}

NUMBER 112

November 2020

\section{TALKING ABOUT SEX AND SEXUAL BEHAVIOUR OF YOUNG PEOPLE IN IRELAND ANNE NOLAN AND EMER SMYTH}

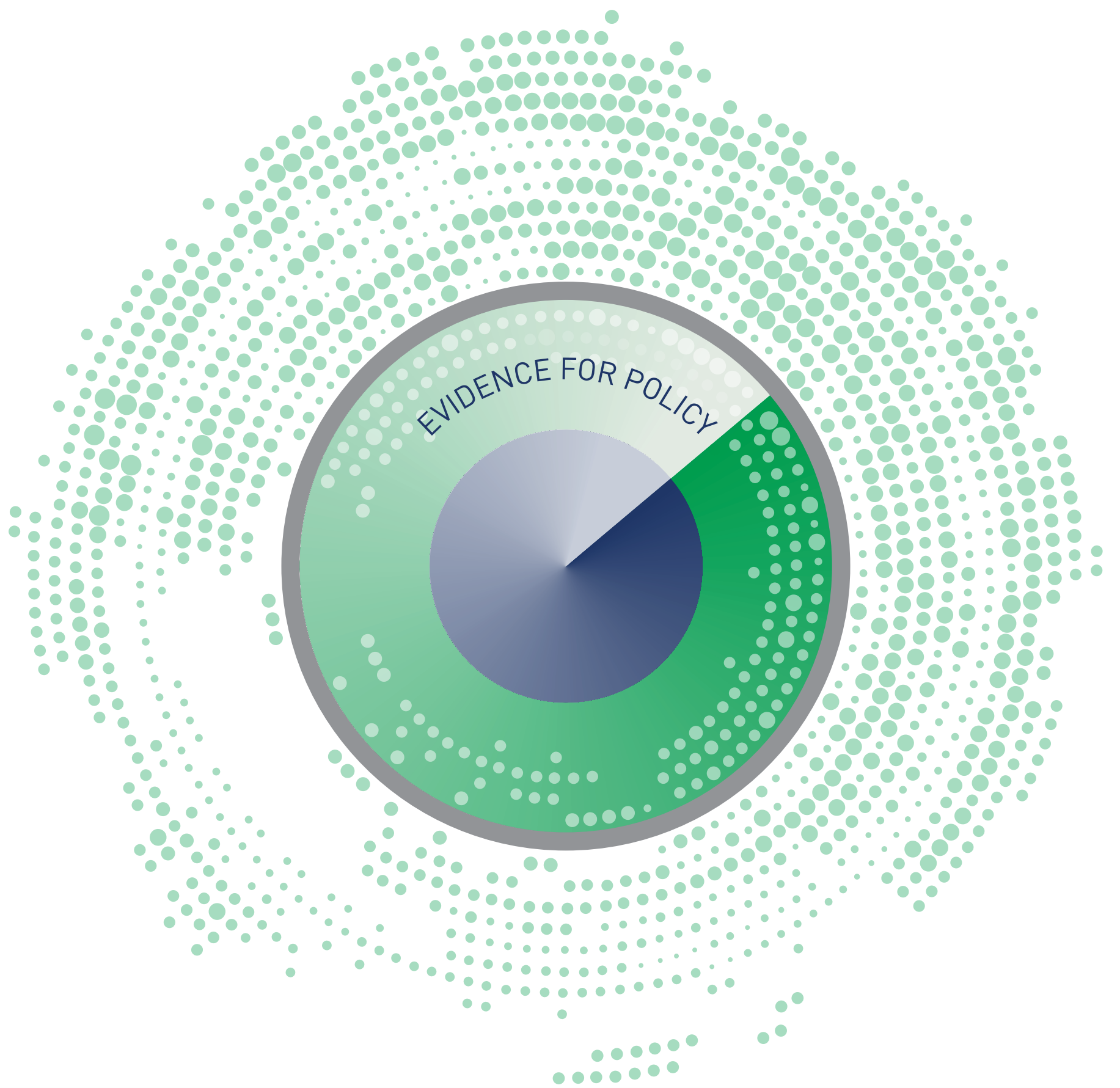




\title{
TALKING ABOUT SEX AND SEXUAL BEHAVIOUR OF YOUNG PEOPLE IN IRELAND
}

\author{
Anne Nolan \\ Emer Smyth
}

Note - Minor correction made to the first paragraph on page 8, following initial publication. Text now reads "4-9 years of age".

November 2020

\section{RESEARCH SERIES}

\section{NUMBER 112}

Available to download from www.esri.ie

(C) The Economic and Social Research Institute

Whitaker Square, Sir John Rogerson's Quay, Dublin 2

ISBN 978-0-7070-0540-9

DOI: https://doi.org/10.26504/rs112

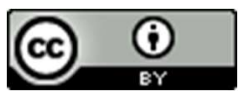

This Open Access work is licensed under a Creative Commons Attribution 4.0 International License (https://creativecommons.org/licenses/by/4.0/), which permits unrestricted use, distribution, and reproduction in any medium, provided the original work is properly credited. 


\section{ABOUT THE ESRI}

The mission of the Economic and Social Research Institute is to advance evidencebased policymaking that supports economic sustainability and social progress in Ireland. ESRI researchers apply the highest standards of academic excellence to challenges facing policymakers, focusing on 12 areas of critical importance to 21st century Ireland.

The Institute was founded in 1960 by a group of senior civil servants led by Dr T.K. Whitaker, who identified the need for independent and in-depth research analysis to provide a robust evidence base for policymaking in Ireland.

Since then, the Institute has remained committed to independent research and its work is free of any expressed ideology or political position. The Institute publishes all research reaching the appropriate academic standard, irrespective of its findings or who funds the research.

The quality of its research output is guaranteed by a rigorous peer review process. ESRI researchers are experts in their fields and are committed to producing work that meets the highest academic standards and practices.

The work of the Institute is disseminated widely in books, journal articles and reports. ESRI publications are available to download, free of charge, from its website. Additionally, ESRI staff communicate research findings at regular conferences and seminars.

The ESRI is a company limited by guarantee, answerable to its members and governed by a Council, comprising 14 members who represent a cross-section of ESRI members from academia, civil services, state agencies, businesses and civil society. The Institute receives an annual grant-in-aid from the Department of Public Expenditure and Reform to support the scientific and public interest elements of the Institute's activities; the grant accounted for an average of 30 per cent of the Institute's income over the lifetime of the last Research Strategy. The remaining funding comes from research programmes supported by government departments and agencies, public bodies and competitive research programmes.

Further information is available at www.esri.ie 


\section{THE AUTHORS}

Anne Nolan is an Associate Research Professor at the ESRI, and Adjunct Professor at Trinity College Dublin (TCD). Emer Smyth is a Research Professor at the ESRI, and Adjunct Professor at TCD.

\section{ACKNOWLEDGEMENTS}

The research was funded by the Health Service Executive (HSE) Health and Wellbeing Division under a Research Programme on 'Health and Wellbeing in Childhood and Adolescence'. The authors thank the Central Statistics Office (CSO) for access to Growing Up in Ireland (GUI) data, and the members of the Research Programme Steering Committee for helpful comments and guidance throughout the research process. The report also benefited considerably from comments received from three reviewers.

GUI has been funded by the Government of Ireland through the Department of Children and Youth Affairs (DCYA) in association with the CSO. These data have been collected in accordance with the Statistics Act, 1993. The DCYA and CSO take no responsibility for the views expressed or the outputs generated from the research undertaken on the GUI data.

This report has been accepted for publication by the Institute, which does not itself take institutional policy positions. All ESRI Research Series reports are peer reviewed prior to publication. The authors are solely responsible for the content and the views expressed. 



\section{CONTENTS}

Executive Summary.

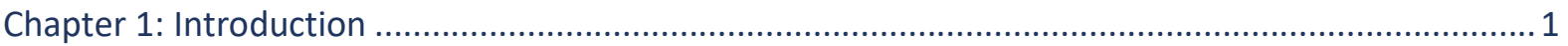

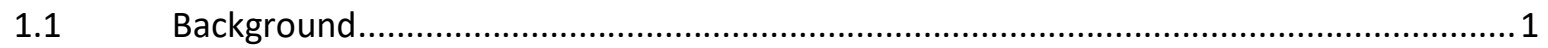

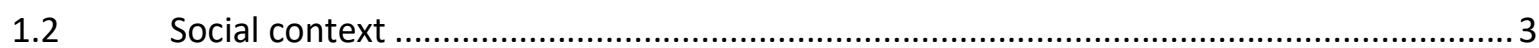

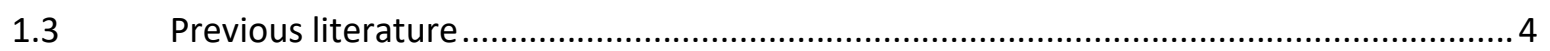

1.3.1 Existing Irish evidence on young people's sexual behaviour........................................ 5

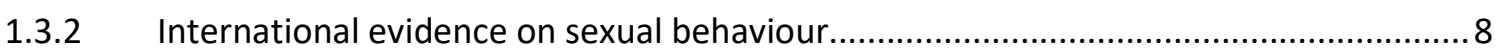

1.3.3 Schools, sex education and young people's sexual behaviour .....................................11

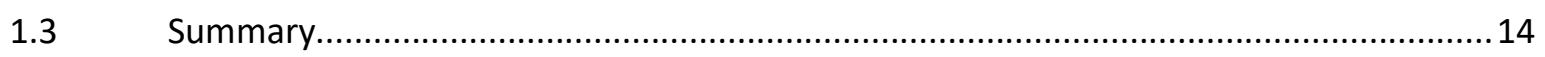

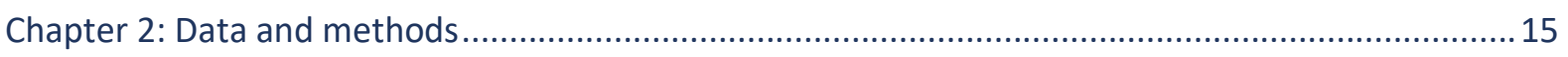

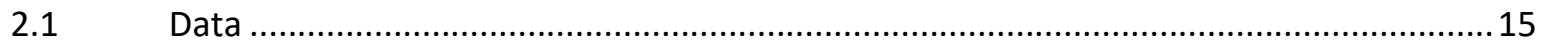

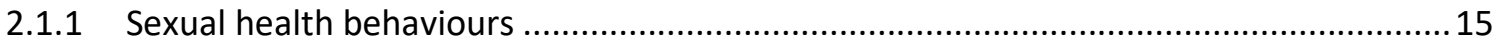

2.1.2 Independent variables: young people and their families.............................................. 18

2.1.3 Independent variables: school characteristics ................................................................20

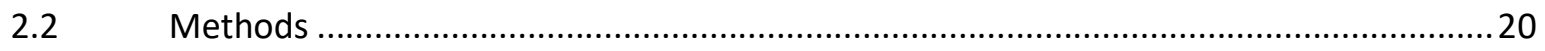

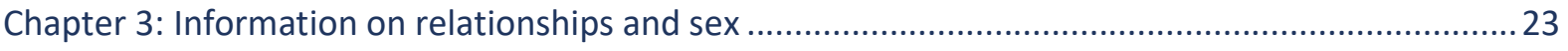

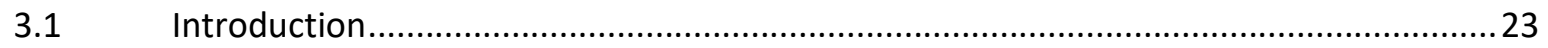

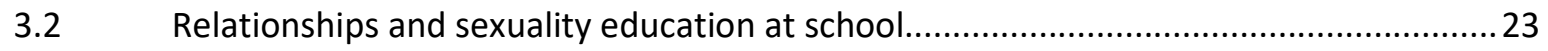

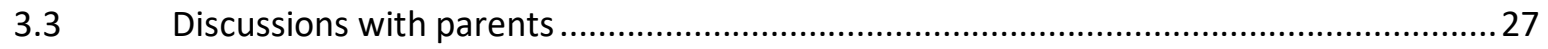

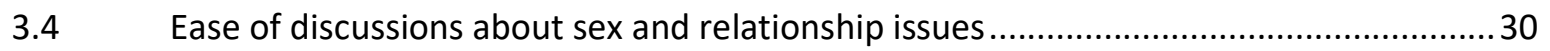

3.5 Parental reports of discussions about sex and relationship issues...................................32

3.5 Source of information about sex and relationship issues ................................................. 34

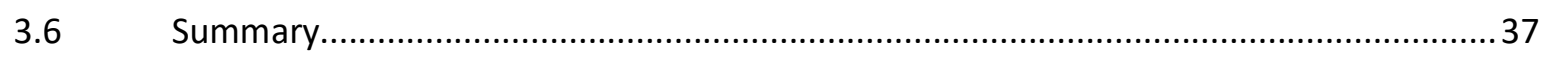

Chapter 4: Sexual competence and sexual health behaviours ........................................................... 39

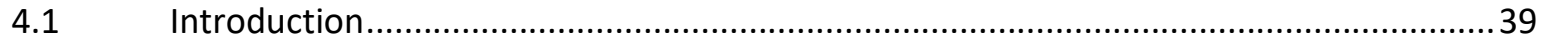

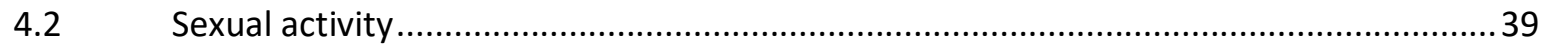

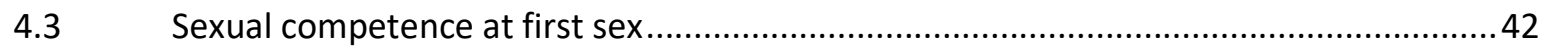

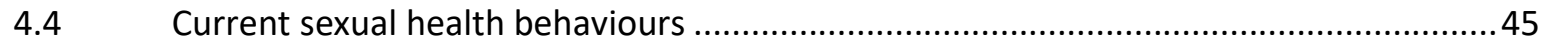

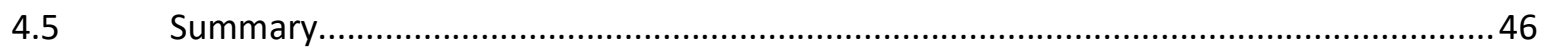

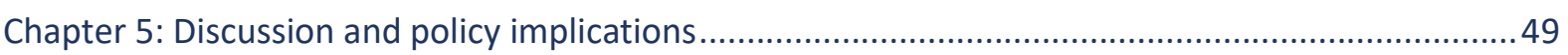

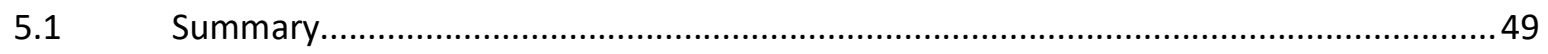

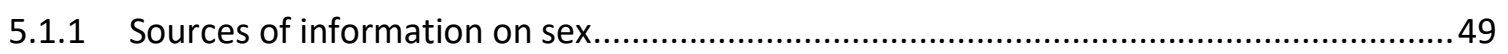

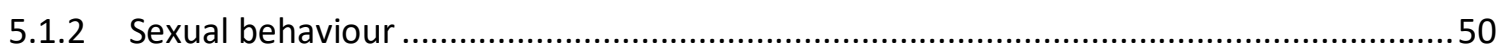

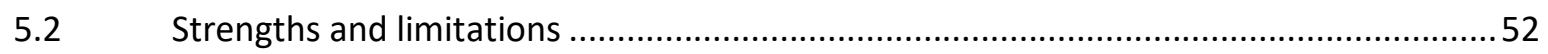




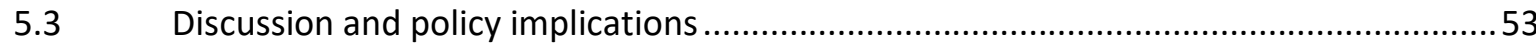

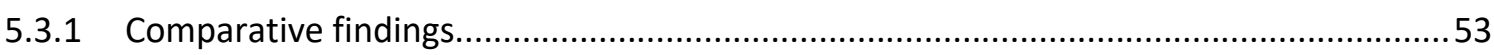

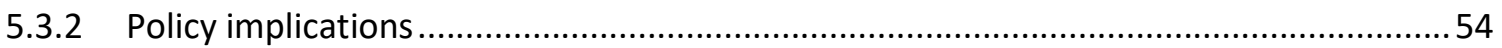

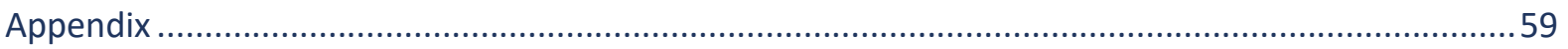

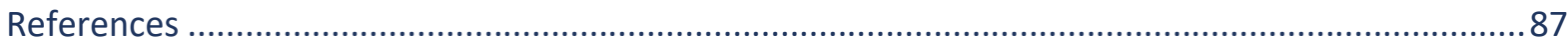




\section{LIST OF FIGURES}

Figure 3.1 Proportion who had received school-based RSE by school stage ..................................24

Figure 3.2 Proportion who had received school-based RSE by sex...............................................24

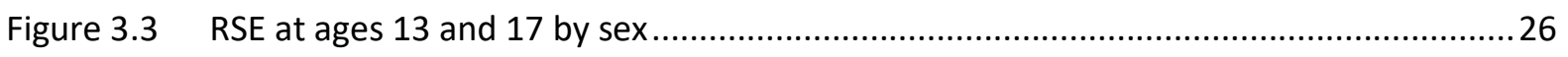

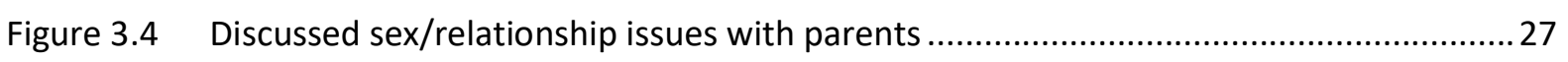

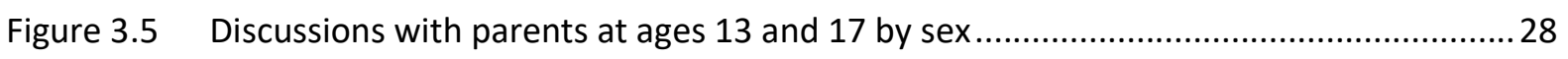

Figure 3.6 RSE at school and discussions with parents at ages 13 and 17 by sex ...........................30

Figure 3.7 Ease of talking openly about sex with mother and father .............................................. 31

Figure 3.8 Ease of talking openly about sex with mother and father by sex ................................. 31

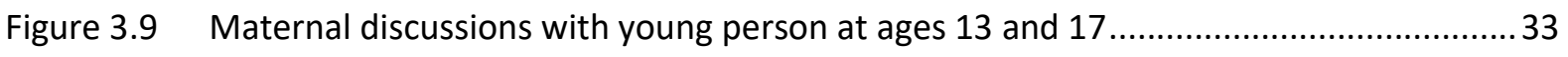

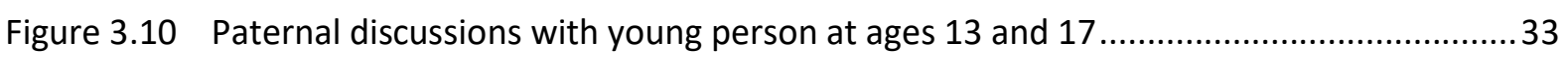

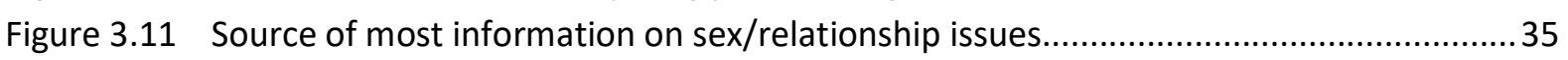

Figure 3.12 Source of information on sex/relationship issues by sex.............................................36

Figure 4.1 Prevalence of sexual intercourse by age, sex and school stage ..................................... 40

Figure 4.2 Prevalence of contraceptive use at first sex by age, sex and school stage ..................... 43

Figure 4.3 Prevalence of timing regret at first sex by age, sex and school stage............................ 44

Figure 4.4 Prevalence of condom use by age, sex and school stage ............................................. 45

Figure 4.5 Prevalence of always using contraception by age, sex and school stage .......................46 


\section{LIST OF TABLES}

Table 2.1 Summary statistics for variables relating to RSE, parental discussions and sources of information about sex.

Table 2.2 Summary statistics for sexual health behaviour variables.

Table A1 Multilevel logistic regression model of having received school-based relationships and sexuality education by age 13 (odds ratios).

Table A2 Multilevel logistic regression model of having received school-based relationships and sexuality education by age 17 (odds ratios)....

Table A3 Multilevel logistic regression models of having received school-based relationships and sexuality education at age 13 and/or 17 (odds ratios); base category - received RSE at both ages

Table A4 Logit regression model of parent/child discussions about sex, ages 13 and 17 (odds ratios)

Table A5 Logit regression model of 'never discussed sex/relationship issues with parents at ages 13 or 17 (odds ratios)

Table A6 Multilevel logistic regression model of likelihood of a 13-year-old not having received school-based relationships and sexuality education or discussed sex with their parents (odds ratios)

Table A7 Logistic regression model of receiving school-based RSE only at age 17 (odds ratios) ...65

Table A8 Logit regression model of ease of discussing sex with parents, age 17 (odds ratios)......66

Table A9 Logit regression model of mother's reports of discussions with young person at age 17 (odds ratios).

Table A10 Logit regression model of fathers' reports of discussions with young person at age 17 (odds ratios)

Table A11 Multinomial logit regression model of main source of information on sex, age 13 (odds ratios, relative to parents/family)

Table A12 Multinomial logit regression model of main source of information on sex, age 17 (odds ratios, relative to parents/family)

Table A13 Logistic regression models of indicating teacher was the main source of information on relationships/sex at ages 13 and 17 (odds ratios).

Table A14 Multilevel logistic regression model of the young person had had sexual intercourse at age 17 (odds ratios)

Table A15 Multilevel logistic regression model of having had oral sex and/or sexual intercourse at age 17 (odds ratios)

Table A16 Multilevel logistic regression model of whether most or all of their friends had had sex (odds ratios).....

Table A17 Multilevel logistic regression model of use of contraception at first sexual intercourse (odds ratios)

Table A18 Multilevel logistic regression model of regret at timing of first sexual intercourse (odds ratios)

Table A19 Multilevel logistic regression model of always using a condom at age 17 (odds ratios). 82

Table A20 Multilevel logistic regression model of always using contraception at age 17 (odds ratios) 


\section{ABBREVIATIONS}

\begin{tabular}{|c|c|}
\hline CAPI & computer-aided personal interview \\
\hline CSO & Central Statistics Office \\
\hline DEIS & Delivering Equality of Opportunity in Schools \\
\hline DES & Department of Education and Skills \\
\hline ETB & Education and Training Board \\
\hline GUI & Growing Up in Ireland \\
\hline HBSC & Health Behaviour in School-Aged Children (survey) \\
\hline HSE & Heath Service Executive \\
\hline ICCP & Irish Contraception and Crisis Pregnancy (study) \\
\hline IPPA & Index of Parent and Peer Attachment \\
\hline ISSHR & Irish Study of Sexual Health and Relationships \\
\hline LGBTQ+ & Lesbian, Gay, Bisexual, Transgender and Questioning \\
\hline NATSAL & (British) National Survey of Sexual Attitudes and Lifestyles \\
\hline NCCA & National Council for Curriculum and Assessment \\
\hline PCG & primary caregiver \\
\hline RSE & Relationships and Sexuality Education \\
\hline SCG & secondary caregiver \\
\hline SEN & special education need \\
\hline SES & socio-economic status \\
\hline SLÁN & Survey of Lifestyles, Attitudes and Nutrition \\
\hline SPHE & Social, Personal and Health Education \\
\hline STI & sexually transmitted infection \\
\hline UK & United Kingdom \\
\hline & United States of America \\
\hline
\end{tabular}





\section{EXECUTIVE SUMMARY}

Sexual activity is an important component of physical and mental health and wellbeing. Norms, behaviours and practices around sexual activity begin to be established during adolescence. The provision of appropriate sexual health education and information is a key facilitator of positive sexual health behaviours and relationships throughout the life course. This report uses data from the '98 cohort of Growing Up in Ireland (GUI) to examine when, where and how young people receive information on sex and relationships, and the role of this information in shaping sexual competence (or readiness) and behaviours among Irish adolescents.

\section{INFORMATION ON SEX AND RELATIONSHIPS}

- At age 13, 55 per cent of young people reported that they had received relationships and sexuality education (RSE) at school, and this proportion had increased to 92 per cent by age 17. At both ages, females were more likely to have received RSE than males, and those who were in later stages of education were more likely to have received RSE. There was significant variation in RSE receipt across individual second-level schools.

- At age 13, 45 per cent of young people reported that they had discussed sex and relationship issues with their parents. By age 17, this proportion had increased to just under 60 per cent. Better-quality relationships with parents were associated with a higher probability of reporting these discussions.

- A significant minority of 13-year-olds - a third of males and a quarter of females - reported no RSE or parental discussions about sex. This group was predominantly from disadvantaged social backgrounds. At age 17, while the proportion reporting no RSE or parental discussions was less than 5 per cent, young males were more likely to belong to this group.

- There was a clear gender divide in reports of ease of discussions with parents about sex; young women found it easier to talk to their mothers, while young men found it easier to talk to their fathers. However, nearly 60 per cent of young men reported finding it difficult or very difficult to talk to their fathers about sex.

- Similar patterns were evident in parents' reports of whether they had discussed five key issues with their child: sex and sexual intercourse; sexual feelings; contraception; safer sex; and sexual orientation. Less than 50 per cent of fathers had discussed each of these issues with their son or daughter by age 17, and rural fathers were significantly less likely to discuss these issues with their children than urban fathers. 
- At age 13, parents/family were the main source of information about sex, but at age 17 , friends were the most commonly cited source (at nearly 50 per cent). Teachers were cited by approximately 10 per cent of young people at both ages. At age 17, nearly a quarter of young men and 20 per cent of young women cited the internet/TV/films/books as their main source. Those who were more alienated from their peers were significantly more likely to cite the internet as their main source.

\section{SEXUAL COMPETENCE AND BEHAVIOURS}

- At age 17, 33 per cent of young people reported having had sexual intercourse. The proportion who had had sexual intercourse varied across second-level schools. However, none of the school characteristics captured by GUI, such as gender mix, ethos and size, accounted for this variation.

- Sexual competence or readiness is captured in GUI by reports of contraceptive protection at first sex, and reports of feeling that sex had 'occurred at the right time'. Nearly 90 per cent of young people who have had sexual intercourse reported using contraception when first having sex. Nearly a quarter of young people expressed regret over the timing of first sex, and this proportion was substantially higher among young women (31 per cent, almost all of whom wished they had waited longer) than young men (16 per cent, most of whom wished they had waited longer).

- The source of information was significant, with those sourcing most of their information on sex from their friends significantly less likely to report having used contraception when they first had sexual intercourse.

- For those that are sexually active, just under 80 per cent reported 'always' using contraception, and 56 per cent reported using a condom 'all the time'. There was little variation in these proportions by individual, school or peer group characteristics.

\section{IMPLICATIONS FOR POLICY}

Focusing first on RSE, the findings indicate that schools differ in the timing of RSE provision, but not for reasons due to school size, ethos or gender mix, suggesting that policy and leadership at the school level plays an important role in the timing of RSE provision. This is consistent with previous Irish research, which highlighted the importance of school leadership and teacher professional development in successful RSE provision but pointed to constraints in the form of teacher discomfort, the low status of RSE, exam pressures and a significant reliance on external providers for RSE classes.

The study findings point to little relationship between receiving RSE or not and 
young people's sexual behaviour and competence. However, GUI did not collect information on the quantity or, perhaps more importantly, the quality of the sex education received. The requirement within second-level education is for six RSE class sessions per year. Evidence suggests that only a quarter of schools are meeting this target. Consultation undertaken for the recent National Council for Curriculum and Assessment (NCCA) review of RSE has highlighted some issues around the quality of provision. Young people were especially critical of the focus on biological processes to the neglect of broader issues of relationships and emotions alongside a concern with risks rather than a positive view of sexual relationships. The current review of RSE alongside the prominent place afforded to wellbeing within the Junior Cycle curriculum provides an opportunity to consider how information and support on sex are provided to young people in the school context.

However, RSE is only one aspect of the portfolio of skills and competencies that can assist young people to protect their sexual health and ensure positive sexual experiences. The government's National Sexual Health Strategy highlights the responsibility of parents in providing their children with the information, education and support necessary to prepare them for a lifetime of positive sexual health and wellbeing. This research shows that the quality of the relationship between parents and their children is a key determinant of both whether discussions about sex and relationships take place and how easy young people find it to speak to their parents about sex. Initiatives to support parents in developing positive communication skills may be expected to have broader benefits in terms of discussions about sex and relationships.

The study findings highlight a significant group of young people who are not receiving information or advice from their parents on relationships and sex. Young men are much less likely to discuss sex with their parents than young women, and males from low-income families living in rural areas emerge as a potentially vulnerable group in relation to the lack of advice and information from parents. In the absence of parental discussion, young people appear to turn to their friends for information, increasingly so as they move through adolescence. However, the findings point to some risks associated with (over-)reliance on friends, with lower levels of contraceptive use at first sexual intercourse among this group.

Overall, the findings are positive in relation to sexual competence and behaviour, with low levels of regret about the timing of first intercourse and high levels of contraceptive or condom use at first sex. Young women were more likely than young men to express regret about the timing of sexual initiation, a quarter doing so compared to one in six of young men: a pattern that may reflect gendered social norms. 
Rates of contraceptive use at first sex are high, though at 90 per cent not universal. There appears to be a lower level of usage for subsequent sexual experiences, with less than four-fifths always using contraception and much fewer (56 per cent) always using a condom. The findings therefore suggest the necessity for a multipronged approach involving school-based RSE, parental support and public health campaigns to support safe sex practices among young people. 




\section{CHAPTER 1}

\section{Introduction}

\section{$1.1 \quad$ BACKGROUND}

Sexual activity is an important component of physical and mental health and wellbeing. The World Health Organization (WHO) defines sexual health as 'a state of physical, mental and social well-being in relation to sexuality. It requires a positive and respectful approach to sexuality and sexual relationships, as well as the possibility of having pleasurable and safe sexual experiences, free of coercion, discrimination and violence' (WHO, 2006). This definition has been adopted by the Irish government in its current National Sexual Health Strategy (Department of Health, 2015b).

Norms, behaviours and practices with regard to sexual activity begin to be established during adolescence. The development of positive sexual health behaviours lays the foundation for healthy relationships throughout the life course. ${ }^{1}$ Risky sexual behaviours are associated with other risky health behaviours (de Looze et al., 2014; Hale and Viner, 2012; Jackson et al., 2012b), which can lead to poorer health outcomes in later life. People younger than 25 years of age are at highest risk for adverse sexual health outcomes, such as sexually transmitted infections (STIs) and unplanned pregnancies (Mercer et al., 2013). Data on STI notifications among 15-24-year-olds in Ireland show increasing incidence (HSE Health Protection Surveillance Centre, 2019). In addition, young people aged 1524 account for a disproportionate number of cases: 49 per cent of chlamydia cases, 39 per cent of herpes simplex cases and 32 per cent of gonorrhoea cases (HSE Health Protection Surveillance Centre, 2019).

The National Sexual Health Strategy 2015-2020 is the strategic framework for the sexual health and wellbeing of the Irish population and was launched in October 2015 (Department of Health, 2015b). The strategy adopts a life course approach to sexual health which acknowledges the importance of developing healthy sexuality throughout childhood and adolescence and builds on that foundation for positive sexual health and wellbeing into adulthood and older age. In addition, one of the core aims of the national strategy for children and young people, Better Outcomes, Brighter Futures, is to ensure a positive and respectful approach to relationships and sexual health (Department of Children and Youth Affairs, 2014).

The life course approach recognises that experiences in earlier life shape adult health and wellbeing. It focuses on the importance of a healthy start to life and targets the needs of people at critical periods throughout their lifetime (https://www.euro.who.int/en/health-topics/Life-stages). 
One of the three key goals of the National Sexual Health Strategy is to ensure that everyone has access to appropriate sexual health education and information. ${ }^{2}$ In terms of the provision of Relationship and Sexuality Education (RSE) to children and young people, the strategy recognises the role of parents, schools and the outof-school environment in impacting the subsequent behaviour of young people and encouraging later sexual initiation, higher prevalence of protective behaviours and greater confidence in negotiating sexual relationships. In schools, the RSE programme has been a required component of the curriculum at primary and second levels since 1995/1996, and in 2003 was integrated into the broader Social, Personal and Health Education (SPHE) programme (Department of Health, 2015b).

Under the current RSE programme, schools and educational stakeholders, including parents, have a major role in determining the approach taken within schools (Young et al., 2018). A major review of RSE in primary and second-level schools was undertaken from June 2018 to March 2019. Consultations with key stakeholders (students, parents, teachers, principals) revealed a number of key points. Students said their learning in RSE was too little, too late and not relevant to their needs, while all stakeholders said that RSE needed to be more than information about biological aspects of growing up and sexual activity. It was noted that a holistic approach, that balances discussion about the risks and dangers associated with relationships and sexual activity with discussion about the positive, healthy and enjoyable aspects of relationships, needed to be developed (National Council for Curriculum and Assessment, 2019).

In this context, an analysis of the role of RSE in promoting positive sexual health behaviours is timely. In this report, we focus on the role of RSE in schools (and discussions around sex and relationships with parents) in developing sexual competence and positive sexual health behaviours among adolescents. The concept of 'sexual competence' has been developed to consider the broader contextual attributes of first sexual intercourse (willingness, timing regret, use of contraception, etc.), rather than simply age of occurrence (Palmer et al., 2019). Two key sets of research questions are addressed in this study:

- What are the experiences of young people in relation to RSE? Does it vary by school type? Where do young people source most of their information on sex and relationship issues? What is the role of parental discussions?

- How does sexual competence at sexual initiation vary across the young adult population? For those who are currently sexually active, how do sexual health 
behaviours vary across the young adult population? Does RSE at school and from other sources impact sexual competency and sexual health behaviours?

Among the 17-year-olds, 88 per cent identified as 'heterosexual/straight', 5 per cent as 'bisexual' and a little over 2 per cent as 'gay/lesbian', with the remainder unsure or preferring not to say. Because of the small numbers involved in the nonheterosexual groups, the analyses cannot examine potential differences in sexual competence and behaviour by sexual orientation. Thus, the information presented in the remainder of the report relates to all young people, regardless of sexual orientation.

The report is structured as follows. In the remainder of this chapter, we survey the recent literature, both Irish and international, that has focused on how young people receive information on sex and relationships, sexual competency and sexual health behaviours. Chapter 2 introduces the data, from the Growing Up in Ireland (GUI) study, the key variables examined and the methods used. Chapter 3 examines how young people receive information on sex and relationships, focusing on school-based RSE, discussions with parents and main sources of information on sex. Chapter 4 focuses on sexual competency and sexual health behaviours. Chapter 5 summarises and discusses the policy implications arising from the research.

\subsection{SOCIAL CONTEXT}

Before surveying the relevant literature on the issues examined in this report, it is worth reflecting on the broader social context that has shaped sexual attitudes and behaviours in Ireland over time. The latter part of the 20th century was characterised by significant change in Irish attitudes towards sexual issues. Fahey et al. (2007) note that for much of the 20th century, Catholic moral teaching was the dominant framework through which most Irish people learnt about and experienced sex. Beginning in the 1960s, this dominant framework was largely replaced by a secular moral framework based on individual responsibility. Major changes in legislation in relation to artificial contraception (1993), divorce (1996), same-sex marriage (2015) and abortion (2018) reflected these changing attitudes.

Layte et al. (2006) note that the rise in non-marital fertility is a good indicator of changes in sexual attitudes and behaviours that Ireland has experienced since the 1960s. In the 1960s, the proportion of births outside marriage averaged just over 2 per cent. The proportion increased steadily during the next decades (accounting for just under a quarter of births in the 1990s), and by 2017 was 38 per cent (just 
under the EU average of 42 per cent). ${ }^{3}$ Irish attitudes in relation to sexual issues are now broadly comparable with other western European countries on a number of dimensions, including attitudes towards homosexuality (van den Akker et al., 2013) and LGTBI rights (European Commission, 2019).

While sexual attitudes and behaviours may be converging towards western European liberal norms, the issue of consent has recently become a policy focus both in Ireland and elsewhere. In 2016, a special Eurobarometer survey investigated attitudes towards gender-based violence across the EU. Respondents were asked whether having sexual intercourse without consent was justified in nine different circumstances. Overall, 27 per cent of EU adults, and 21 per cent of Irish adults, agreed that sex without consent was justified for at least one of the nine reasons (European Commission, 2017). ${ }^{4}$ Focusing specifically on younger people, the 2018 My World survey in Ireland found that 47 per cent of young adults (18-25 years) reported that they had been touched against their will or without their consent and 20 per cent said they had been forced or pressured to have sex. Females ( 56 per cent) were much more likely than males ( 23 per cent) to report that they had been touched against their will or without their consent. They were also more likely to report that they had been forced or pressured to have sex ( 25 per cent for females, 10 per cent for males) (Dooley et al., 2019).

\subsection{PREVIOUS LITERATURE}

There is an extensive literature on various aspects of sexual activity, behaviour and identity among young adults. A major area of focus concerns early initiation of sexual activity (Lewis et al., 2017; Mercer et al., 2013), given the research that suggests that earlier age of intercourse is strongly associated with lowered competence at first intercourse, as evidenced by less willingness and planning and less use of contraception and protection (Wellings et al., 2001). This results in a higher risk of poor outcomes such as unplanned pregnancy, early child-bearing, higher rates of STIs, lower sexual function and experience of non-volitional sex, all of which can have long-lasting effects on health and wellbeing (Layte et al., 2006; Palmer et al., 2019). However, as GUI does not collect information on the age of initiation of sexual activity, we focus here on how young people receive information on sex and relationships, sexual competency and sexual health behaviours. Before surveying the literature on these issues, however, it is worth

See Table 2.23 in https://www.cso.ie/en/releasesandpublications/ep/pvsar/vitalstatisticsannualreport2017/births2017/. In 2017, the EU-27 average was 42 per cent https://ec.europa.eu/eurostat/statistics-explained/index.php?title=Marriage_and_divorce_statistics.

4 Across the EU, at least one in ten respondents thought that intercourse without consent was justified if the person was drunk or using drugs (12 per cent), voluntarily went home with someone (11 per cent), wore revealing, provocative or sexy clothing, or did not clearly say no or physically fight back (both 10 per cent). The corresponding figures for Ireland were 11 per cent, 9 per cent, 9 per cent and 8 per cent. 
briefly outlining the scope of existing research on the Irish population, and the adolescent population in particular.

\subsubsection{Existing Irish evidence on young people's sexual behaviour}

The most comprehensive nationally representative study of the 18-64 adult population, the Irish Study of Sexual Health and Relationships (ISSHR), was carried out in 2004 (Layte et al., 2006). In terms of sex education, there was a clear cohort effect; 88 per cent of men and 93 per cent of women aged 18-24 had received some form of sex education, in comparison with 12 per cent of men and 19 per cent of women aged 55-64. For all age groups, sex education in school was the most common source. ${ }^{5}$ For men aged 18-24, just 21 per cent had received sex education in the home, although the proportion among women was higher (38 per cent). Those from higher social class and educational groups were more likely to have received sex education, and the differential was largely explained by lower levels of sex education at home for those with a lower education and/or social class. Those from more disadvantaged social groups also held less liberal attitudes towards sex, which may have inhibited their willingness to give, or their comfort in giving, sex education. The research identified worrying levels of knowledge about sex; for example, among women, 56 per cent of under-25s could not correctly identify a woman's most fertile period.

Focusing on aspects of sexual competency at first sexual intercourse, approximately 90 per cent of men and women aged 18-24 had used contraception. ${ }^{6}$ In terms of regret, women were more likely to express regret over the timing than men, and there was a clear age trend among both men and women. Younger age groups were significantly more likely to say they 'should have waited longer'. In a subsequent statistical analysis of regret, Layte and McGee (2007) found that within all age groups and for both sexes, having sex before age 17 was associated with a higher likelihood of subsequent regret. Men and women having sex before age 17 were 2.9 and 3.6 times more likely, respectively, to believe that they should have waited longer. Women who had early intercourse were 1.8 times more likely than men who had early intercourse to feel that they should have waited longer. However, regret after early sexual initiation was not universal and while young age per se contributed to higher levels of regret, it was not solely responsible. Regression analysis showed that less planning, lower autonomy, a less stable relationship with their partner and a shorter subsequent relationship with their first partner all contributed to higher subsequent regret irrespective of age of first intercourse. 
Focusing on sexual health behaviours among those who were sexually active, the ISSHR study showed that 93 per cent of men and 94 per cent of women aged 1824 (not intending to conceive) used contraception at the last event. Condoms were the most popular method; 82 per cent of men and 74 per cent of women aged 18 to 24 used a condom on the most recent occasion (Layte et al., 2006).

Following on from the ISSHR, the 2010 Irish Contraception and Crisis Pregnancy (ICCP) survey (which surveyed over 3000 individuals aged 18-45) showed that fewer parents surveyed in 2010 had talked to their children about sex and related topics (70 per cent) compared with 2003 (82 per cent) (McBride et al., 2012; Rundle et al., 2004). In 2010, more adults aged 18 to 25 had received sex education (86 per cent) compared with adults aged 36 to 45 (57 per cent). Younger people were more likely to use contraception on the occasion of first sexual intercourse: 89 per cent of 18 to 25 year olds and 80 per cent of 26 to 35 year olds reported using contraception the first time they had sexual intercourse, compared with 61 per cent of 36 to 45 year olds. However, specific groups of people were identified as being 'at risk' for not using contraception at first sexual intercourse. These included men, individuals with a pre-Leaving Certificate education, those in the lower social classes and those who had sex for the first time before the age of 17. Inconsistency in contraceptive use was strongly related to the type of relationship that the person had with their partner. Sex in casual relationships or recently formed relationships was far more likely to occur without protection, largely because respondents were not prepared, sex was unexpected or the individual had been drinking or taking drugs. ${ }^{8}$ Around 10 per cent of respondents to the ICCP survey did not use contraception when they last had intercourse.

Other surveys that have captured elements of sexual health and behaviours, albeit not focused on sexual health and/or the young adult population, include the 1998 and 2002 Survey of Lifestyles, Attitudes and Nutrition (SLÁN) and the annual Healthy Ireland surveys. SLÁN asked all sexually active respondents aged under 50 a question about frequency of contraceptive use over the past year and what kinds of contraception they used over the past year (Shiely et al., 2004). Across the two surveys, 94 per cent of those aged 20-24 always/sometimes used contraception. The annual Healthy Ireland survey of the adult population (aged 16+) fielded a separate module on sexual health in the 2015, 2016 and 2017 surveys (it was dropped in wave 4, 2018) (Department of Health, 2015a, 2016, 2017, 2018)..$^{9}$ In 2015, 24 per cent of the adult population had used a condom the last time they had sex, but 47 per cent had not used any form of contraception the last time they

An earlier ICCP study, carried out in 2003, was designed to establish baseline measures for crisis pregnancy prevalence in addition to a broad range of sexual health indicators related to crisis pregnancy (McBride et al., 2012).

8 However, the proportion of people attributing their non-use of contraception to alcohol and drugs had decreased over the seven-year period.

9 By wave 3 (2017), the focus was on HIV/STI testing: 11 per cent of 17-24-year-olds had a HIV test in the previous year, and 13 per cent had an STI test (Department of Health, 2017). 
had sex (this had declined to 45 per cent by 2016). Of those aged 17-24, however, just 7 per cent of men and 8 per cent of women had used no form of contraception at last sex (but this proportion had increased to 11 per cent by 2016).

Focusing specifically on adolescents, the Health Behaviour in School-Aged Children (HBSC) study gathered data on sexual initiation and behaviours among 15-17-yearolds in 2010, 2014 and 2018. The HBSC study is a WHO cross-national research project (covering 43 countries) that aims to increase the understanding of young people's health, wellbeing and behaviours, including sexual behaviours (Young et al., 2018). Young et al. (2018) examined sexual intercourse, age of initiation and contraception use among a sample of nearly 4500 Irish adolescents aged 15-18 years from the 2010 HBSC study. Over a quarter of boys and a fifth of girls had had sexual intercourse. ${ }^{10}$ Older age was predictive of sexual initiation for both boys and girls, as were alcohol, tobacco and cannabis involvement, living in poorer neighbourhoods and having good communication with friends. Involvement in music and drama was protective. Household social class and level of affluence were not associated with sexual initiation after these other factors were taken into account. The authors also examined early initiation (before 14 years of age), with adolescents living in rural areas more likely to report initiation. Burke et al. (2018) used data from the 2014 wave of the HBSC study to examine the predictors of age of sexual initiation, focusing on the 15-17-year-olds who reported ever having sex (22 per cent of all 15-17 year olds overall). They found that sociodemographic, lifestyle and behavioural factors were stronger predictors of age of sexual initiation among sexually active girls than boys. Together the predictors considered accounted for 23 per cent of variation in age of sexual initiation for sexually active girls and 11 per cent of the variation for boys.

Condom use at last intercourse was reported by 80 per cent of the 2010 sample (Young et al., 2018). Boys' condom use was associated with older age, higher family affluence, bullying others, more frequent physical activity and health-protective behaviours. For girls, condom use was predicted by belonging to a non-Traveller community, healthy food consumption, higher quality of life and being bullied, whereas taking medication for physical and psychological symptoms was associated with non-use of condoms.

A number of detailed qualitative studies of parents in Ireland provide useful information on the factors that inhibit and enable age-appropriate communication between parents and children/adolescents regarding the body, relationships, sexuality and growing up (Hyde et al., 2009; Conlon, 2018). Hyde et al. (2009) examined how a sample of 43 parents communicated on the topic of relationships

10 In 2018, the proportions reporting sexual intercourse were similar: 28 per cent of 15-17-year-old boys, and 20 per cent of 15-17-year-old girls (Költő et al., 2020). 
and sexuality with their pre-adolescent and adolescent children. They found that parents used a variety of strategies to talk to their children about sex and relationships, but often a 'wake-up call', i.e. reacting to an event, pre-empted a discussion. Focusing on 93 parents (mainly mothers) of young children aged 49 years of age, Conlon (2018) found that parents expressed a willingness to be more open in talking with their children from a young age and hoped that this would generate a culture of normalisation regarding the body, sexuality and relationships. Many parents expressed a lack of confidence in talking about these issues, in part a legacy of their own limited experience with positive information when they themselves were children.

\subsubsection{International evidence on sexual behaviour}

A large body of evidence on various aspects of sexual health and behaviour has emerged from the British National Survey of Sexual Attitudes and Lifestyles (NATSAL) surveys, carried out in 1990-1991, 1999-2001 and 2010-2012. ${ }^{11}$ Much of the evidence focuses on the determinants of sexual initiation, and early sexual initiation (Lewis et al., 2017; Mercer et al., 2013). However, Palmer et al. (2019) note that the context in which first sex occurs generally receives less attention than chronological age at first intercourse. They note that an exclusive focus on age neglects individual differences in physical, social and psychological maturity, as well as the emphasis placed by young people themselves on the circumstances in which first sex occurred in evaluating their experiences. The concept of sexual competence, first developed by researchers working on NATSAL 2 (Wellings et al., 2001), represents an alternative approach to timing of first sexual intercourse, considering the contextual attributes of the event rather than simply age of occurrence. Sexual competence or readiness is identified using self-report of four variables: contraceptive protection, autonomy of decision (not influenced by alcohol or peer pressure), consensuality (both partners equally willing), and absence of regret ('right time for me'). Lack of sexual competence at first sex has been shown to be associated with poor subsequent sexual health, as defined by self-reported STI diagnosis, Human Papilloma Virus (HPV) positive status, lower sexual function, unplanned pregnancy and experience of non-volitional sex.

Using data from NATSAL 3, Palmer et al. (2019) found that, among the sample of 17-24-year-old respondents who had had sex, over half of women and more than 40 per cent of men were not sexually competent at first intercourse. While age at first intercourse was associated with sexual competence, it did not fully explain all the variability in sexual competence. The stability of the first partnership was associated with a more positive first sexual experience. Both area-level deprivation and own education level were associated with sexual competence (lower socioeconomic status may indicate lower levels of perceived control over one's life). The

11 NATSAL 4 is currently in development (although findings will not be released until 2024) (Wellings et al., 2019). 
most commonly reported negative feature of first sex was that it was felt not to have occurred at 'the right time' ( 40 per cent of women and 27 per cent of men). Approximately 10 per cent of young people did not use a reliable contraceptive method at first sex.

Earlier data from NATSAL 2 showed that overall, 42 per cent of those aged 16-44 were classified as sexually competent at first intercourse, and this proportion showed an increasing trend with age cohort (i.e. younger cohorts were more sexually competent at first intercourse) (Wellings et al., 2001). Level of education, source of information about sex, age of menarche for women, and living in a singleparent household for men remained statistically significant determinants of sexual competence in multivariate regressions. Of those aged 16-24 who had sex, 80 per cent of men and women reported condom use at first intercourse. First intercourse using no contraception was reported by 7.4 per cent of men aged 16-19 and 9.8 per cent of women. They also highlighted gender differences in the experience of first sex (willingness, timing), with women more likely to report that they wished they had waited longer and to report not having been equally willing. In terms of sources of sex education, school-based lessons were the main source of information about sexual matters for young people (aged 16-24). ${ }^{12}$

A series of studies based on data from the HBSC surveys has examined patterns of sexual initiation and sexual competence among European adolescents. Ramiro et al. (2015) examined sexual initiation, very early sexual initiation (13 years of age or younger) and condom use among 15-year-olds across 20 European countries (not including Ireland) over the period 2002-2010 (using three waves of the HBSC study). They found that overall prevalence of early and very early sexual intercourse initiation was quite stable in Europe between 2002 and 2010, while condom use increased. Using data from the 2013/2014 HBSC in Bulgaria, France, Ireland and Scotland, Moreau et al. (2019) examined regret over the timing of first sexual intercourse. They found that approximately 20 per cent of the 15-year-olds who had had sex expressed regret over the timing, i.e. that they wished it had happened later, or they did not want to have sex at that time. ${ }^{13}$ Girls were over four times more likely to express regret than boys, and those from less affluent families were also more likely to report regret over the timing of first sex. De Looze et al. (2019) used data from 33 countries (including Ireland) that participated in the 2013/2014 HBSC to examine associations between gender equality and contraceptive use (condom only, pill only and dual methods) at last intercourse for over 8000 adolescents aged 14-16. They found that higher levels of gender

12 Respondents could choose from four sources: parents, lessons at school, friends, other.

13 While the proportion expressing regret in Ireland (nearly 25 per cent) was significantly higher than that reported by French teenagers (less than 16 per cent), the difference was no longer statistically significant after adjustment for other covariates (gender, family socioeconomic status, age of partner, etc.). 
equality were positively associated with contraceptive use among both males and females, although the effects were stronger for females.

Focusing on the role of source of information on sex in influencing sexual health behaviours, Palmer et al. (2019), using data from NATSAL 3, found that young women who had discussed sexual matters with their parents and those who reported school to be their main source of information were more likely to have been sexually competent at first sex. However, these associations were not observed in young men. Macdowall et al. (2015) examined the association between source of information about sex and sexual behaviours using data on 1724 -year-olds from NATSAL 3. They found that gaining information mainly from school was associated with lower reporting of a range of negative sexual health outcomes, particularly among women. Citing a parent as the main source was also associated with fewer negative outcomes, but to a lesser extent. Sabia (2006) found that school sex education had no effect on sexual behaviours, using data from the US Survey of Adolescent Health.

Using a similar methodology to NATSAL 2, Schubotz et al. (2004) examined the most important source of sex education for young people in Northern Ireland. ${ }^{14}$ In contrast to young people in Britain, for whom school was identified as the most important source of information about sexual matters, 80 per cent of young people in Northern Ireland, both male and female, said they received most information about sex from their friends. School was the second most common source of information (74 per cent) (Schubotz et al., 2004). ${ }^{15}$ Sexually active young people who were able to discuss sexual matters with their parents were more likely to use contraception than young people who did not discuss such issues with their parents. They also found that young women who discussed sexual matters with their parents were more likely to delay their first intercourse. However, communication about sexual matters with parents seemed to have little or no effect on the timing of first sexual intercourse for young men. If anything, young men who said they did discuss sex with their families appeared to be slightly more likely to already have had sex before age 16 . Consistent with other research in Ireland and the UK, females were more likely than males to regret the timing of their first intercourse and more likely to have felt under pressure from their partners to have sex.

The role of family structures and processes in influencing adolescent sexual activity and behaviours has been the subject of a large body of research. For example, Bonell et al. (2006) examined the factors associated with sexual activity, contraceptive use and pregnancy by age 15/16 among adolescents from lone-

14 The Northern Ireland study fielded similar questions to NATSAL 2 but focused on a narrower age range, those aged 1625.

15 Respondents were asked to identify their top three sources. 
parent families in 27 schools across England. Adjusting for socio-economic status, they found that men and women from lone-parent families, or born to teenage mothers, were more likely to report sex by age 15/16 but not non-use of contraception at first sex. However, they found less conclusive evidence that parenting behaviours (parental strictness, parent-child communication, parental input into sex education) explained the effects of family type on young people's sexual behaviour and likelihood of conception.

In contrast, Wight et al. (2006), using data on over 5000 Scottish second-level students, found that family processes had a wider influence on young people's sexual behaviour than did family structure. Low parental monitoring predicted early sexual activity for both sexes, but for females it also predicted more sexual partners and not using a condom or other contraceptives. Having a lot of spending money also predicted early sexual activity for both sexes and, for males, having more sexual partners. No association was found between the level of comfort talking with parents about sex and sexual behaviour. In multivariate analyses, parental monitoring was the variable with the greatest influence on the widest number of sexual outcomes examined.

A common theme in many of the studies is that the wider socioeconomic context of the household has emerged as a key factor explaining multiple sexual health behaviours in adolescence. For example, socioeconomic disadvantage, together with low educational attainment, has been shown to be associated with low levels of contraceptive use at first sex. Data from NATSAL 2 have demonstrated that approximately 30 per cent of young people who left school at age 16 without qualifications used no contraception at first intercourse, compared with 11 per cent of those who left school at age 16 with a qualification (Wellings et al., 2001). Educational aspirations have also been found to be related to use of contraception: those intending to go to university were more likely to have used contraception at first intercourse (Blenkinsop et al., 2004). Data on 15-year-olds from the Scottish HBSC studies over the period 2002-2014 show an association between family affluence and condom use in both boys and girls (but not the birth control pill) (Neville et al., 2017).

\subsubsection{Schools, sex education and young people's sexual behaviour}

Schools can potentially influence sexual behaviour in two ways: firstly, intentionally, through the provision of information and advice on sex as part of the school curriculum; and secondly, and more indirectly, through the way in which the school climate (that is, the nature of relationships between teachers and students and among students) and the network of peers can shape young people's sense of themselves and the behaviour in which they engage. 


\section{International research}

There have been a number of studies across different countries on take-up and perceptions of school-based sex education and its association with young people's sexual behaviour. In one Australian study (Ezer et al., 2019), young people's knowledge about sexually transmitted diseases was found to be moderate to low, but was even lower among those who had not received sex education at school. In the USA, formal sex education was found to be associated with a delay in sexual intercourse and greater use of a condom/contraception at first intercourse (Lindberg and Maddow-Zimet, 2012). Similarly, in the British NATSAL studies, naming school as the main source of information was associated with older age at first sex, lower risk of unsafe sex and lower rates of STIs (Macdowall et al., 2015). Among women, those more reliant on school-based information had lower rates of non-volitional sex and of abortion (Macdowall et al., 2015).

Reviews of best practice in school sex education have highlighted the importance of a life-skills approach (for example, focusing on decision-making and risk assessment) phased in an age-appropriate way and embedded in a whole-school perspective (Pound et al., 2017). Findings on the impact of specific programmes (either within or outside school) to delay sexual activity and/or reduce risky behaviours have, however, been mixed (Jackson et al., 2012a; Peterson et al., 2019; Lopez et al., 2016a, 2016b). In the UK, a study found that young people who had discussed emergency contraception in school or had been taught about local family planning were more likely to have used contraception at first intercourse. However, there were no significant differences with comparison students in relation to regretted sexual activity (wishing they had waited) (Blenkinsop et al., 2004).

Young people are found to be critical of an approach that is overly focused on risks rather than acknowledging the positive aspects of sexual behaviour (Pound et al., 2017). They are also critical of the gendered and heterosexist nature of provision (Pound et al., 2016). Similarly, in Australia (Ezer et al., 2019), students reported mixed views on the relevance of these classes, with criticism of the limited information provided and of its heterosexist focus.

Fewer studies have examined whether other aspects of school experience influence sexual behaviour. An American study showed significant variation in the age of sexual initiation across schools (White and Warner, 2015). One Scottish study (Henderson et al., 2008) found significant between-school variation in whether 15- and 16-year-olds reported being sexually active. Similarly, Hale et al. (2014) found small but significant differences between schools in England in risky behaviour, including the likelihood of having unprotected sex. However, these studies did not fully identify the factors behind such variation between schools, although schools with a concentration of disadvantage had higher rates of early 
sexual activity (Henderson et al., 2008; White and Warner, 2015). Peer culture may play an important part, with young people reporting that most or all of their friends had had sex being more likely to be sexually active at 15/16 (Henderson et al., 2008). A relationship between school disengagement and early sexual activity has been found across a number of countries, including Scotland, Finland, France, Poland and the USA (Henderson et al., 2008; Madkour et al., 2010). Relatedly, higher levels of academic achievement are associated with delaying sexual initiation and increased use of contraceptives (House et al., 2010). Even controlling for individual grades, schools that are characterised by a stronger orientation to higher education participation have older age at sexual initiation (White and Warner, 2015). However, one Japanese study found that while individual satisfaction with school was associated with lower rates of sexual activity, no significant relationship was apparent with school-level aggregate satisfaction levels (Takakura et al., 2010).

\section{Irish research on sex education at school}

RSE was introduced in Irish schools as part of the Social, Personal and Health Education (SPHE) programme in 1995 on foot of an Expert Advisory Group on Relationships and Sexuality. An interim curriculum and guidelines for primary and second-level schools were issued in 1996 (Keating et al., 2018). The first evaluation of RSE (Morgan, 2000) found that a significant minority of schools had no provision in place prior to the introduction of the programme. Later research (Mayock et al., 2007) highlighted the importance of school leadership and access to professional development for teachers in successful implementation. Challenges centred on time constraints because of an overcrowded curriculum and exam pressures as well as teacher discomfort around discussing sex and the low status of SPHE as a school subject. Similar issues of teacher discomfort were evident at primary level (NCCA, 2008). Inspectorate reports suggested that some primary schools were not covering the more sensitive aspects of SPHE (DES, 2009) and that several secondlevel schools were overly reliant on external speakers for RSE, with significant variation across schools in the quality of provision (DES, 2013). A later survey of schools (DES, 2017) showed that a significant proportion of primary and secondlevel schools continue to be reliant on external providers for RSE classes.

The NCCA has recently completed a review of RSE (NCCA, 2019a), which involved a consultation process with stakeholders, teachers, parents and young people. The young people consulted were critical of RSE provision, feeling there was too much focus on biology rather than broader issues of relationships and emotions (NCCA, 2019b), a perspective that echoed findings from an earlier qualitative study (Hyde and Howlett, 2004). Like their counterparts in international studies, young people felt that there was little focus on LGBTQ+ orientations in RSE. The parents consulted also emphasised the importance of RSE focusing on respect, relationships and consent but parents of second-level students were more likely to 
mention the need to discuss risk, particularly STIs (NCCA, 2019a). Most parents indicated that they would prefer more communication from schools as to what their child was learning in RSE. The NCCA review highlighted considerable variation across schools in terms of the content and timing of RSE, with the dominant focus on risks rather than positive aspects of sexual relationships. The review highlighted the importance of provision being student-centred, holistic, inclusive, age/developmentally appropriate and based on a whole-school approach. It indicated the need to create an integrated curriculum for SPHE/RSE as one subject and to review the content of, and time allocated to, this domain. School leadership and teacher professional development were highlighted as crucial ingredients in the successful implementation of RSE.

The RSE review means that this study is timely in providing information on sources of information about sex and sexual behaviour among 17 -year-olds and relating these patterns to a range of individual, family, peer and school characteristics. The data used and variables analysed are discussed in detail in Chapter 2.

\subsection{SUMMARY}

This chapter has provided an overview of existing international and Irish research on sources of information and levels of sexual activity among young people. The study findings point to important differences by gender and family background factors in patterns of sexual initiation and adoption of safe sex practices. Research findings differ on whether school-based information has a direct impact on young people's sexual behaviour but nonetheless school emerges as an important arena for ensuring access to information for all young people. This study seeks to build on existing research by looking at the influences of family, school and peers on both sources of information and sexual behaviour. Given the recent review of school-based sex education and increased policy recognition of the importance of programmes on sexual consent, this study is timely as an evidence base for future policy development. 


\section{CHAPTER 2}

\section{Data and methods}

\subsection{DATA}

Growing Up in Ireland (GUI), the National Longitudinal Study of Children in Ireland, surveys two cohorts of children and young people. The '08 Cohort (previously known as the Infant Cohort) contains information on 11,134 nine-month-old children and their families who were first surveyed between September 2008 and April 2009 (Quail et al., 2011). The '98 Cohort (previously known as the Child Cohort) represents 8568 children and their families first surveyed between August 2007 and May 2008 when the children were nine years of age (Thornton et al., 2011). The sampling frame was the primary school system. Data from the ' 98 Cohort are used in this report. The second wave of data collection for the '98 Cohort was carried out between August 2011 and March 2012 (when the young people were approximately 13 years of age); wave 3 was carried out between April 2015 and August 2016 (when the young people were approximately 17/18 years ${ }^{16}$ of age) (Murphy et al. 2018).

Data were collected primarily via computer-aided personal interview (CAPI) with the primary caregiver (PCG) (who in most cases was the young person's mother), although as the young person aged into adolescence, more of the information was collected from the young person, on either a CAPI or a self-completion basis. Sensitive self-completion questionnaires were also conducted with parents and young people in all waves. In this report we concentrate on young people who were not twins or triplets and who were observed at all three waves (ages 9, 13 and 17). This results in a sample size of 5854 (although the analyses in Chapter 4 focus on the subsample who have had sexual intercourse, i.e. 1792 individuals).

At wave 1, the teacher and principal were also surveyed, while at ages 13 and 17 (if the young person was still in school), the principal was also surveyed. These questionnaires provide rich information on the type of school attended (including size, gender mix and social mix).

\subsubsection{Sexual health behaviours}

At age 17, GUI included a detailed module on sexual health behaviours in the sensitive self-completion questionnaire. Questions covered topics such as relationships and sexuality education (both in school and in terms of discussions

16 For simplicity, these young people are referred to as 17 -year-olds throughout the remainder of the report. 
with parents ${ }^{17}$ ); sexual orientation and gender identity; current boyfriends/girlfriends; sexual activities; and pressure to have sex. Those who reported that they had engaged in sexual intercourse were asked a further set of questions about the nature of their first sexual experience (nature of relationship, contraceptive use, timing regret) and questions about their current sexual behaviours (contraceptive and condom use, decision-making about contraceptive use). At age 13, young people were asked a subset of these questions, focusing mainly on Relationships and Sexuality Education (RSE) receipt, parental discussions and sources of sex education.

In this report, we focus on two aspects of sexual health behaviours that have received limited attention in previous Irish research. First, we examine experience of RSE received from parents/guardians and/or at school. A number of indicators of sex education are constructed:

- RSE in second-level school;

- ease of discussions with mother/father about sex;

- parental discussions about relationships/sex with the young person;

- main source of information about sex.

Second, we focus on those who have had sexual intercourse and examine two key aspects of sexual behaviour: sexual competence at first sex, and condom and contraceptive use for those who are currently sexually active. Sexual competence at first sex is indicated by two variables characterising contraceptive use and timing regret, while current sexual health behaviours are summarised by two variables reflecting condom and contraceptive use respectively.

Table 2.1 presents summary statistics for the RSE, parental discussion and sources of information variables examined in this report, while Table 2.2 presents summary statistics for the sexual competency and sexual health behaviour variables.

17 Parents were also asked (in their own sensitive self-completion questionnaire) about whether they had discussed relationship and sexuality issues with the young person, covering five issues: sex and sexual intercourse; sexual feelings, relationships and emotions; contraception; safer sex/sexually transmitted infections/venereal disease; sexual orientation (e.g. homosexuality, heterosexuality). 
TABLE 2.1 SUMMARY STATISTICS FOR VARIABLES RELATING TO RSE, PARENTAL DISCUSSIONS AND SOURCES OF INFORMATION ABOUT SEX

\begin{tabular}{|c|c|c|c|}
\hline Outcome & Definition & $\begin{array}{c}\% \\
\text { Age } \\
13\end{array}$ & $\begin{array}{c}\% \\
\text { Age } \\
17\end{array}$ \\
\hline RSE & $\begin{array}{l}=0 \text { if have not (yet) received RSE in second-level school } \\
=1 \text { if have received RSE in second-level school }\end{array}$ & $\begin{array}{l}44.8 \\
55.2\end{array}$ & $\begin{array}{c}7.8 \\
92.2\end{array}$ \\
\hline Sex-parents & $\begin{array}{l}=0 \text { if have not discussed sex/relationships with parents } \\
=1 \text { if have discussed sex/relationships with parents }\end{array}$ & $\begin{array}{l}54.8 \\
45.2\end{array}$ & $\begin{array}{l}40.4 \\
59.6\end{array}$ \\
\hline Ease - mother & $\begin{array}{l}=1 \text { if never discussed sex with mother } \\
=2 \text { if find it very difficult to discuss sex with mother } \\
=3 \text { if find it quite difficult to discuss sex with mother } \\
=4 \text { if find it neither easy nor difficult to discuss sex with mother } \\
=5 \text { if find it quite easy to discuss sex with mother } \\
=6 \text { if find it very easy to discuss sex with mother }\end{array}$ & - & $\begin{array}{l}21.9 \\
12.6 \\
15.5 \\
14.7 \\
23.3 \\
12.0\end{array}$ \\
\hline Ease - father & $\begin{array}{l}=1 \text { if never discussed sex with father } \\
=2 \text { if find it very difficult to discuss sex with father } \\
=3 \text { if find it quite difficult to discuss sex with father } \\
=4 \text { if find it neither easy nor difficult to discuss sex with father } \\
=5 \text { if find it quite easy to discuss sex with father } \\
=6 \text { if find it very easy to discuss sex with father }\end{array}$ & - & $\begin{array}{l}33.3 \\
22.2 \\
16.4 \\
13.1 \\
11.0 \\
4.1\end{array}$ \\
\hline $\begin{array}{l}\text { Source of sex } \\
\text { education }\end{array}$ & $\begin{array}{l}=1 \text { if parents/family } \\
=2 \text { if friends } \\
=3 \text { if teacher } \\
=4 \text { if internet/books/TV/films } \\
=5 \text { if nowhere }\end{array}$ & $\begin{array}{c}45.5 \\
23.1 \\
10.8 \\
4.3 \\
13.8\end{array}$ & $\begin{array}{c}17.7 \\
46.3 \\
9.3 \\
19.5 \\
4.6\end{array}$ \\
\hline $\begin{array}{l}\text { Mother - } \\
\text { discussions }\end{array}$ & $\begin{array}{l}=1 \text { if spoken to young person about sex and sexual intercourse } \\
=2 \text { if spoken to young person about sexual feelings, relationships and } \\
\text { emotions } \\
=3 \text { if spoken to young person about contraception } \\
=4 \text { if spoken to young person about safer sex/sexually transmitted } \\
\text { infections/venereal diseases } \\
=5 \text { if spoken to young person about sexual orientation (e.g. } \\
\text { homosexuality, heterosexuality) }\end{array}$ & $\begin{array}{l}59.0 \\
69.0\end{array}$ & $\begin{array}{l}71.5 \\
68.9\end{array}$ \\
\hline $\begin{array}{l}\text { Father - } \\
\text { discussions }\end{array}$ & $\begin{array}{l}=1 \text { if spoken to young person about sex and sexual intercourse } \\
=2 \text { if spoken to young person about sexual feelings, relationships and } \\
\text { emotions } \\
=3 \text { if spoken to young person about contraception } \\
=4 \text { if spoken to young person about safer sex/sexually transmitted } \\
\text { infections/venereal diseases } \\
=5 \text { if spoken to young person about sexual orientation (e.g. } \\
\text { homosexuality, heterosexuality) }\end{array}$ & $\begin{array}{l}30.5 \\
37.7 \\
20.6 \\
19.5 \\
32.0\end{array}$ & $\begin{array}{r}40.2 \\
45.9 \\
37.9 \\
34.9 \\
41.4\end{array}$ \\
\hline
\end{tabular}

Source: GUI, '98 Cohort, waves 2 (age 13) and 3 (age 17).

Notes: $\quad$ Population weights are employed. - indicates that the information was not collected in this wave. 


\begin{tabular}{|c|c|c|c|}
\hline Outcome & Definition & $\begin{array}{c}\% \\
\text { Age } 13\end{array}$ & $\begin{array}{c}\% \\
\text { Age } 17\end{array}$ \\
\hline \multicolumn{4}{|l|}{ Sexual competency } \\
\hline Contraceptive use & $\begin{array}{l}=0 \text { if no contraception used } \\
=1 \text { if contraception used }\end{array}$ & - & $\begin{array}{l}11.3 \\
88.7\end{array}$ \\
\hline No timing regret & $\begin{array}{l}=0 \text { if 'should have waited longer' or 'should not have waited so long' } \\
=1 \text { if 'it was about the right time' }\end{array}$ & - & $\begin{array}{l}23.1 \\
76.9\end{array}$ \\
\hline \multicolumn{4}{|c|}{ Sexual health behaviours } \\
\hline Condom use & $\begin{array}{l}=0 \text { if never, on some occasions, on most occasions ( } 3 / 4 \text { of the time) } \\
=1 \text { if on every occasion }\end{array}$ & - & $\begin{array}{l}44.1 \\
55.9\end{array}$ \\
\hline Contraceptive use & $\begin{array}{l}=0 \text { if sometimes, hardly ever, never use contraception } \\
=1 \text { if always use contraception }\end{array}$ & - & $\begin{array}{l}20.8 \\
79.2\end{array}$ \\
\hline
\end{tabular}

Source: $\quad$ GUI, '98 Cohort, wave 3 (age 17).

Notes: Population weights are employed. Information on sexual competency and sexual health behaviours was first collected at wave 3 (age 17). The sexual competency and sexual health behaviours questions are only asked of those who have had sexual intercourse ( $n=1792$ or $33.2 \%$ of the wave 3 sample). - Indicates that the information was not collected in this wave.

\subsubsection{Independent variables: young people and their families}

The advantage of GUI is the richness of the data on most aspects of the lives of young people and their families, recorded at ages nine, 13 and 17 . We make use of the data collected at ages 13 and 17 in this report. We examine the way in which our key outcome variables in relation to sex education, sexual competency and sexual health behaviours vary by sex, age and school stage in the first instance.

We also examine patterns in relation to the socio-economic status (SES) of the young person's family, as family SES has been shown to be an important predictor of adolescent health behaviours in previous research (see for example Richter et al., 2009). SES (or social background) refers to position in the social stratification system and is usually measured by education, occupation, employment, income and/or wealth. These components of SES may not be interchangeable and have different kinds of influences on sexual health behaviours and health. SES can reflect diverse underlying theoretical concerns such as material wellbeing, human capital, prestige and cultural resources (Pampel, Krueger et al., 2010). To capture these elements, we include variables for household equivalised income, education (of the PCG), lone-parent household and migrant status (of the PCG). Migrant status is included as there is a suggestion in previous research that health behaviours, including adolescent sexual behaviour, can differ significantly across ethnic/migrant groups (see for example Coleman and Testa, 2007).

Parents discussing relationships and sex with their children is likely to be more common and more open when there is a positive relationship already and where 
young people talk freely to their parents about different aspects of their lives (McElwain and Bub, 2018). Furthermore, the extent to which parents monitor their children's behaviour (for example, knowing their friends) may reduce the likelihood of young people engaging in early and/or risky sexual behaviour (Wight et al., 2006). To capture these dimensions, four measures of the quality of the parent-child relationship (at age 13) were used:

- the Pianta short-form child-parent relationship scale closeness subscale, which captures getting on well with the young person (Quail et al., 2014);

- the Pianta short-form child-parent relationship scale conflict subscale, which captures perceptions of difficulties in the relationship with the young person; ${ }^{18}$

- the parental monitoring subscale (Stattin and Kerr, 2000) captures parental knowledge of their children's lives;

- the child disclosure subscale (Stattin and Kerr, 2000) captures the willingness of young people to give their parents information about their activities and lives in general.

The first three measures are reported by the primary and secondary caregivers, while the fourth is reported by the young person themselves. For most of the multivariate models, indicators of the quality of relationship with the PCG are used (in order not to exclude those in lone-parent families). Indicators of relationship quality with the secondary caregiver are used where there is a specific focus on ease of discussion with or receipt of information from their father.

Young people's knowledge about sex and sexual behaviour may be influenced by their peer group, including whether they associate with older friends and/or whether their friends are already sexually active (Potard et al., 2008; van Leeuwen and Mace, 2018). The analyses of sources of information on sex consider the role of peer relationship quality (namely, trust and alienation)..$^{19}$ The analyses of sexual behaviour take account of whether some or all of the young person's friends are older than them and whether they consider that most or all of their friends have had sexual intercourse.

Previous research has shown that early puberty can be associated with earlier sexual initiation (Belsky et al., 2010). The analyses take account of whether the

18 At age 17, scores on the 'intimacy' and 'conflict' subscales of the networks of relationships inventory with mothers/fathers are also employed.

19 Scores from the 'trust' and 'alienation' peer subscales of the Inventory of Parental and Peer Attachment (IPPA) are used. 
young person had reached puberty (commencement of menstruation for females, the voice having broken for males) by the time of the survey at age 13 .

\subsubsection{Independent variables: school characteristics}

Schools can operate as a context for imparting information about relationships and sex and broader aspects of school process and climate can influence attitudes and behaviour (see Section 1.2). Analyses in this report take account of a number of objective characteristics of the school attended (measured at age 13):

- whether the school is in the Delivering Equality of Opportunity in Schools (DEIS) programme, which is taken as a proxy for a concentration of socio-economic disadvantage;

- whether the school is fee-paying, which is taken as a proxy for a concentration of socio-economic advantage;

- the gender mix of the school, distinguishing between coeducational, single-sex boys' and single-sex girls' schools;

- the size of the school, distinguishing between $<200,200-399,400-599$ and $600+$ student categories;

- the school sector, distinguishing between voluntary secondary, Education and Training Board (ETB) and community/comprehensive schools; a further dummy variable is included to identify schools with a Roman Catholic ethos.

As the cohort is based on age rather than educational stage, analyses of receipt of school-based RSE at 13 distinguish between those in first and second year of second-level education. At 17, we distinguish between those in fifth year, those in sixth year and those who have already left school.

In looking at young people's reliance on school-based sources of information, we use measures of their school engagement, including attitudes to school at 13 as well as the experience of positive interaction (praise or positive feedback) and negative interaction (reprimand) with teachers. To assess whether knowledge and behaviour reflect academic performance, we control for grades received at Junior Certificate, with scores allocated on the basis of subject level and grade and averaged over all exam subjects taken.

\subsection{METHODS}

Each of the chapters in this report begins by presenting descriptive information on overall behavioural patterns before using multivariate models to disentangle the relative effects of individual, family and peer factors on different aspects of 
information receipt, sexual competence and behaviour. At the first wave for Cohort ' 98 of the Growing Up in Ireland study, nine-year-old children were sampled within a set of schools selected to be representative of the total population of primary schools. Traditional regression techniques have involved the assumption that there is no autocorrelation within the data; that is, that students represent independent observations rather than being clustered within schools. However, it cannot be assumed that students in the same school are completely 'independent' of each other in this way. Groups rarely form at random and, once formed, the members of a group interact with each other to create even greater homogeneity (Jones, 1992). Using traditional regression procedures will therefore increase the risks of finding differences and relationships where none exist (Goldstein, 2003).

In contrast to regression procedures, multilevel modelling techniques take the clustering of individuals within groups into account (Goldstein, 2003). Such models provide more precise estimates of the effects of school characteristics, even where there is no significant variation between schools in the outcome examined. In this report, a series of two-level models are estimated, with young people grouped within second-level schools. Analyses presented in this report were carried out using Stata (a statistical software package). The number of students per secondlevel school ranged from 1 to 49. Because some schools have only a few students, the estimates of school effects should be interpreted as lower bound estimates since having more observations (students) per school would likely increase between-school variation. In multilevel models, the fixed-effect coefficients can be interpreted in the same way as traditional regression coefficients. In addition, a random intercept is estimated which indicates the scale of variation in the outcome between schools.

Chapter 3 analyses the patterns of, and factors influencing, receipt of school-based sex education using multilevel models. It also presents multivariate analyses of the influences on timing of discussion of sex with parents and the ease of that discussion from the young person's perspective. Chapter 4 examines the patterns of sexual competence and sexual behaviour before analysing the family, school and peer factors that may explain variation in these behaviours across young people. 



\section{CHAPTER 3}

\section{Information on relationships and sex}

\subsection{INTRODUCTION}

In this chapter we describe how, when and where young people receive information about relationships and sex. We examine not only whether they have received relationships and sexuality education (RSE) at school, but also whether they have spoken to their parents about relationships and sex, and how easy they find it to talk openly with their parents about sex. Finally, we examine where young people report receiving most of their information about sex.

For all outcomes, we examine how the receipt of information varies by key individual and family characteristics such as gender, educational year group and family socio-economic status. We also analyse the extent to which the receipt of RSE at school differs by the characteristics of the school (ethos, single-sex, etc.). For most of our measures, we have information collected at both the wave 2 (age 13) and wave 3 (age 17) interviews, allowing us to examine the evolution of exposure to RSE, parental discussions and sources of information between ages 13 and 17.

\subsection{RELATIONSHIPS AND SEXUALITY EDUCATION AT SCHOOL}

Young people were asked whether they had received RSE in school during the wave 2 (age 13) and wave 3 (age 17) interviews. Overall, 55 per cent of 13-year-olds reported that they had received RSE, while the corresponding figure at 17 years of age was 92 per cent (see also Table 2.1 in Chapter 2). However, these aggregate figures mask considerable variation across educational year groups (and additionally for the 17-year-olds, whether they have completed their second-level education). Figure 3.1 shows that, at age 13, the proportion who had received RSE ranged from 47 per cent of those who were in first year of second-level school ${ }^{20}$ to 62 per cent of those who were in second year in second-level school (and these differences were statistically significant). At age 17, the proportions who had received RSE ranged from 91 per cent of those who were in fifth year to 93 per cent of those who had left second-level school (and while the overall prevalence was much higher, these differences were again statistically significant). At both 13 and 17 , statistically significant differences were observed between young men and 
women, with young women more likely to have received RSE at both ages (see

Figure 3.2).

\section{FIGURE 3.1 PROPORTION WHO HAD RECEIVED SCHOOL-BASED RSE BY SCHOOL STAGE}

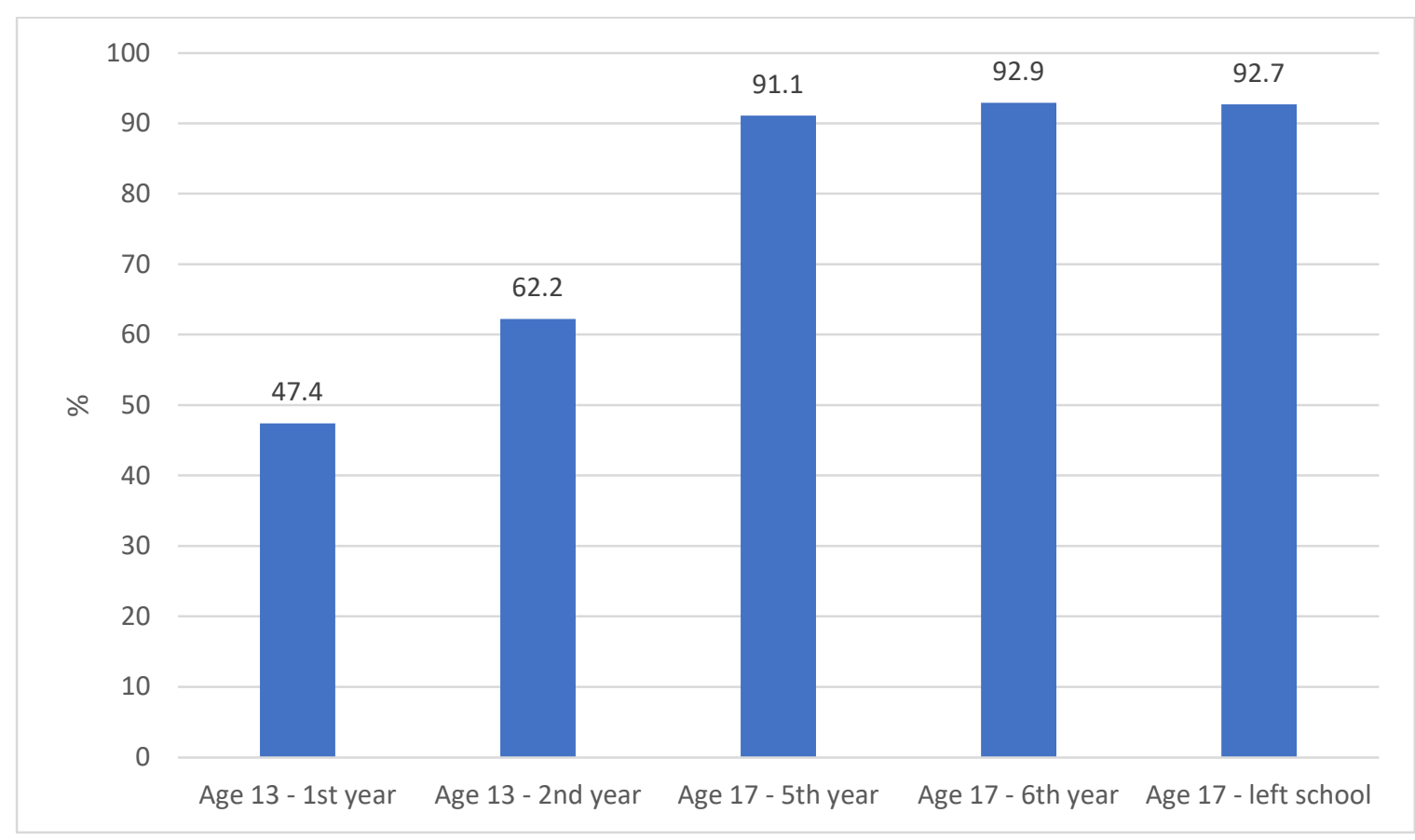

Source: GUI, '98 Cohort, waves 2 (age 13) and 3 (age 17).

Note: $\quad$ Population weights are employed.

\section{FIGURE 3.2 PROPORTION WHO HAD RECEIVED SCHOOL-BASED RSE BY SEX}

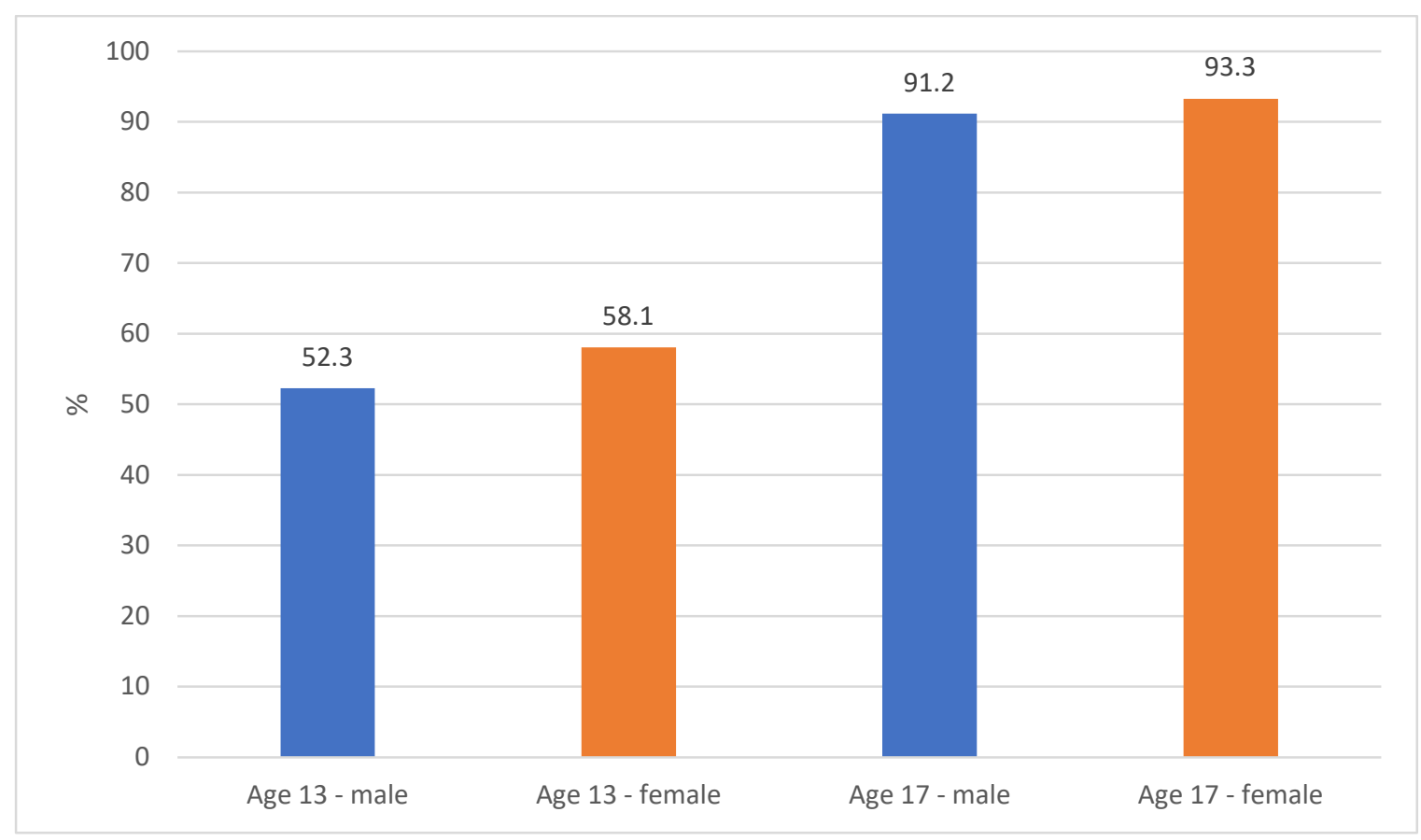

Source: GUI, '98 Cohort, waves 2 (age 13) and 3 (age 17).

Note: $\quad$ Population weights are employed. 
A multilevel multivariate logistic regression model was used to provide more precise estimates of school-level factors and to examine whether the receipt of RSE varied by the specific school attended (Appendix Table A1). There was little significant variation by individual and family characteristics, though females were somewhat more likely to have received RSE by 13 than males. Controlling for the age, gender, family type, migrant status, special education need (SEN), maternal education, household income and region of the young person, those in second year (rather than first year) were significantly more likely to have reported receiving RSE at age 13. There was no significant variation in RSE receipt by school characteristics such as whether the school was Delivering Equality of Opportunity in Schools (DEIS), non-DEIS or fee-paying, by gender mix, by school size, by school sector (voluntary secondary, Education and Training Board (ETB) or community/comprehensive) or whether the school had a Catholic ethos. However, whether the young person had received RSE varied significantly by the individual school they attended, suggesting that second-level schools differ in the timing of RSE. The scale of difference is comparatively modest, with around 6 per cent of the remaining total variation ${ }^{21}$ (controlling for the individual and school characteristics) at the school level.

At 17 years of age, receipt of RSE varied little by individual or family characteristics, though females were somewhat more likely to report receipt than males. Those who had already left second-level education were slightly more likely to have reported having received RSE at school (relative to those in fifth year) (but only at the 10 per cent significance level). There was no significant variation by school characteristics (though receipt was somewhat higher for those in DEIS schools, but only at the 10 per cent level). However, RSE receipt varied significantly across individual schools; the scale of difference between schools at 17 was greater than at 13 (19 per cent of total variation compared with 6 per cent) (see Appendix Table A2). This is at the higher end of school effects, with previous research showing that around a fifth of the variation in achievement levels is at the school level (see, for example, Smyth, 1999). Thus, access to RSE does appear to be driven by different policy and practice in individual second-level schools.

Finally, in this section we examine the concordance between reports of RSE at 13 and 17. Overall, 52 per cent of 17 -year-olds had reported receiving RSE at both ages 13 and 17, while a further 41 per cent had received it by age 17 despite having not received it by age 13 (these could be termed 'late' RSE receivers). Those who had received RSE at 13 but not (yet) at 17 (the 'early' receivers) accounted for 4 per cent of the sample. The proportion who reported not having received RSE (yet)

21 In multilevel logistic regression models, there is no direct estimation of the level-1 (individual) residuals. Therefore an approximation is given for the intraclass correlation (the amount of variation at the school level as a proportion of total variation). 
was 4 per cent. As shown in Figure 3.3, these proportions differed significantly between males and females, with males much more likely to report no RSE at both ages 13 and 17.

\section{FIGURE 3.3 RSE AT AGES 13 AND 17 BY SEX}

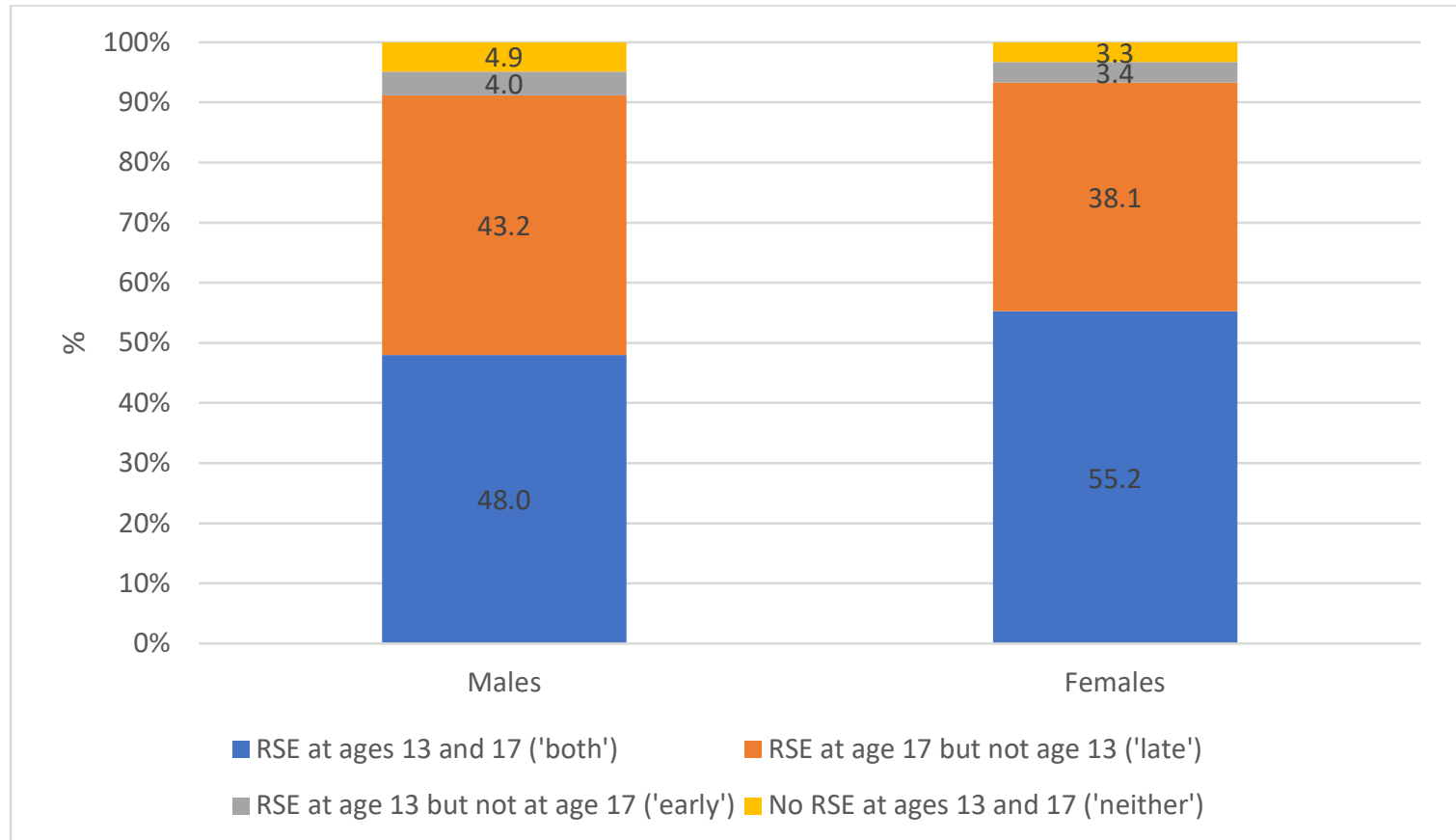

Source: GUI, '98 Cohort, waves 2 (age 13) and 3 (age 17).

Note: $\quad$ Population weights are employed.

In a multivariate multilevel model ${ }^{22}$ controlling for individual, family and school characteristics at age 17, the probability of not having received RSE at either age 13 or 17 (compared to receiving it at both ages) was lower for females and those in sixth year, as well as varying across individual schools. Being a 'late' receiver of RSE (i.e. not receiving it at age 13 but receiving it at age 17) was significantly lower for those who were older and those who were in sixth year or who had already left second-level school, but none of the school characteristics were statistically significant. However, late receipt varied by individual school. Receiving RSE at 13 but not 17 (an 'early' receiver) was less common among those in sixth year or who had left school as well as among those who attended a DEIS or fee-paying (compared to non-DEIS) school. As with the other groups, there was significant variation by individual second-level school (see Appendix Table A3).

22 Because Stata does not allow for multilevel multinomial models, these were estimated as a series of binary logistic regression models. 


\subsection{DISCUSSIONS WITH PARENTS}

In both the 13- and 17-year-old questionnaires, young people were asked 'have you ever discussed sex and/or relationship issues with your parent(s)/guardian(s)?'. Overall, 45 per cent of young people reported that they had discussed sex and/or relationship issues with their parents/guardians at age 13, and this had increased to 60 per cent by age 17 (see also Table 2.1). As is evident from Figure 3.4, young women were more likely to report that they had discussed sex/relationship issues with their parents than young men, at both 13 and 17 .

\section{FIGURE 3.4 DISCUSSED SEX/RELATIONSHIP ISSUES WITH PARENTS}

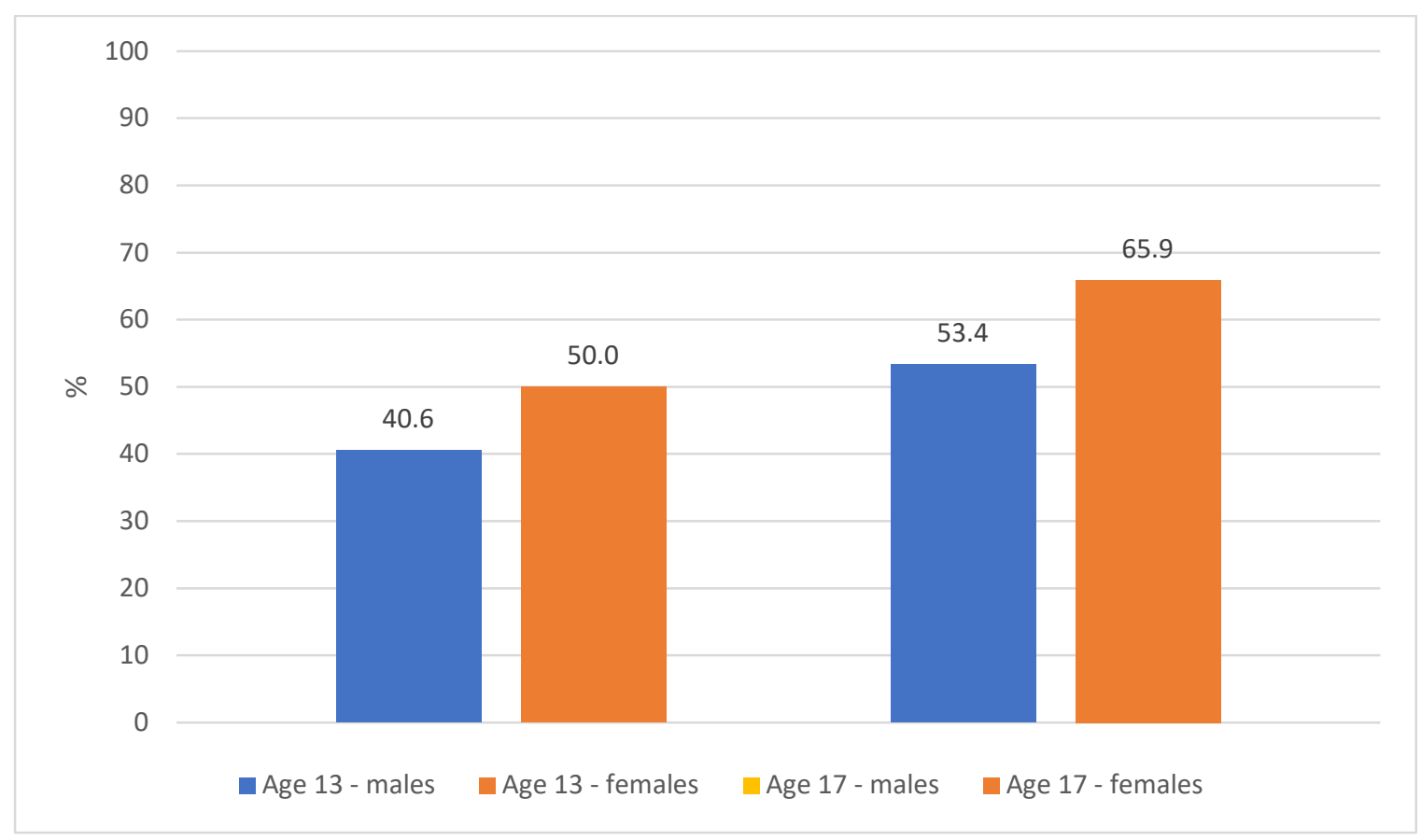

Source: $\quad$ GUI, '98 Cohort, waves 2 (age 13) and 3 (age 17).

Note: $\quad$ Population weights are employed.

Multivariate logit modelling ${ }^{23}$ shows that at age 13 , having discussed sex and/or relationship issues with parents was significantly more likely for young women and for those whose mothers had higher levels of education and who were from higher income families. Those who reported having a closer relationship with their mother were more likely to have discussed these issues but the pattern did not vary by level of conflict, the extent of parental monitoring of their behaviour or the extent to which they disclosed information to their parents. Interestingly, having reached

23 Multilevel models were not used here as parent-child discussions would not be expected to be directly influenced by the school attended. 
puberty by 13 (voice broken for males or having started menstruating for females) was significantly associated with discussion of sex/relationships, suggesting that puberty operated as a prompt for parental engagement on the issue. Previous research has suggested that parents may initiate or intensify communication about sexual matters once they think their children have become sexually active (Macdowall et al., 2015).

At age 17, the gender and family socioeconomic status (SES) effects identified at age 13 were no longer statistically significant. However, those in lone-parent families were more likely to report having discussed sex/relationships with their parents. As at 13, there was no variation by migrant status or region. Those who had a close relationship with their mother at 13 were more likely to have discussed sex/relationships by 17 . This was mediated through intimacy with the mother at 17. In other words, close relationships facilitated discussion only if they persisted throughout adolescence. As at 13 , conflict or parental monitoring did not have an impact but those who had reached puberty by 13 were more likely to have discussions about sex four years later (see Appendix Table A4 for full results).

\section{FIGURE 3.5 DISCUSSIONS WITH PARENTS AT AGES 13 AND 17 BY SEX}

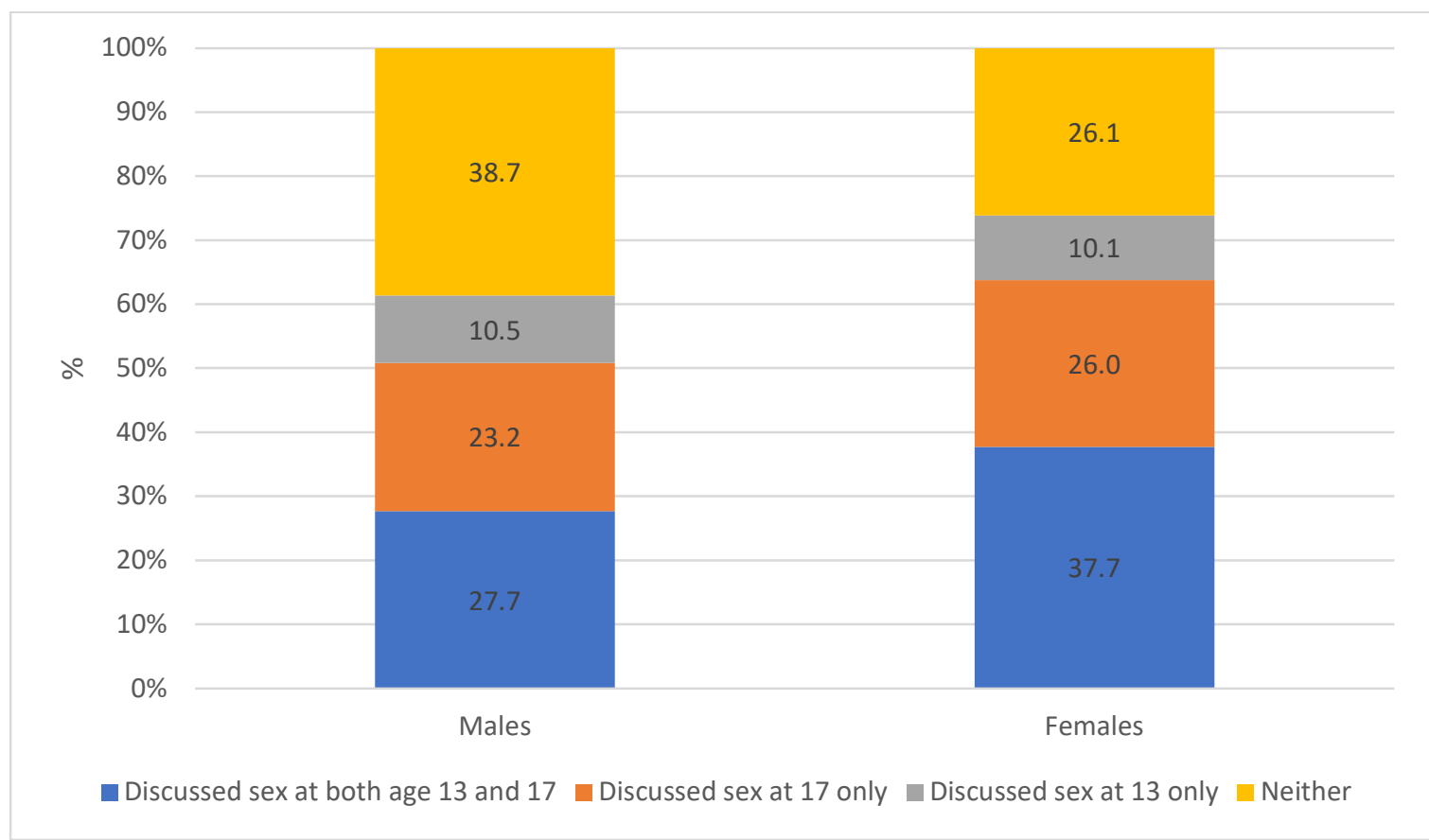

Source: GUI, '98 Cohort, waves 2 (age 13) and 3 (age 17).

Note: $\quad$ Population weights are employed.

Next we examine the concordance between reports of discussions with parents at ages 13 and 17. Overall, 33 per cent of the young people at age 17 reported that 
they had never discussed sex/relationship issues with their parents, while a similar proportion (33 per cent) reported discussing these issues with their parents at both 13 and 17. From Figure 3.5, it is evident that young men were significantly more likely than young women to have never discussed sex/relationship issues with their parents (39 per cent vs 26 per cent). In a multivariate regression controlling for individual and family characteristics, the probability of never having discussed sex/relationship issues with parents was significantly lower for young women, those with mothers born outside Ireland, and those from lone-parent families. Those with a closer relationship with their mother at both ages 13 and 17 were also significantly less likely to belong to this group (who had never discussed sex/relationship issues with their parents). See Appendix Table A5 for the full set of results.

The analyses so far have looked at whether young people received information and advice on sex and relationships at school or at home. The data can be combined to identify those who received RSE at school and/or talked to their parents, at both ages 13 and 17. Approximately 28 per cent of the cohort at 13 had received RSE at school and discussed sex and relationships with their parents, while a similar proportion (28 per cent) had not received RSE at school nor discussed sex and relationships with their parents. By age 17, these figures were 57 per cent and 4 per cent respectively.

As illustrated in Figure 3.6, there was a clear gender divide, with young men significantly more likely to belong to the group who had not received RSE in school nor discussed sex/relationship issues with parents at both ages 13 and 17 . Multilevel multivariate regression models were used to examine the factors associated with belonging to the group of young people who had not received school-based RSE and had not discussed sex with their parents at the age of 13 . Young women, those whose mothers were graduates and those in the highest income quintile were significantly less likely to fall into this group. The pattern did not only reflect family (dis)advantage, as those who were brought up in a loneparent family were significantly less likely to be in this group than those from twoparent households. Those who were in second year at the age of 13 were much less likely to be in the group who had not received any information from their school or family. School characteristics (such as gender and social mix) did not make a difference but there was significant variation across individual schools (see Appendix Table A6).

Looking at patterns at 17 , a multilevel multivariate model was used to examine the profile of young people who received only school-based advice at 17 (contrasting them against all other groups). This group was significantly more likely to be male, in the lowest two income quintiles and from a two-parent family, and to live in a 
rural area. The reliance on school-based advice did not vary across individual second-level schools but was somewhat more likely for those attending community/comprehensive or Catholic schools (see also Appendix Table A7).

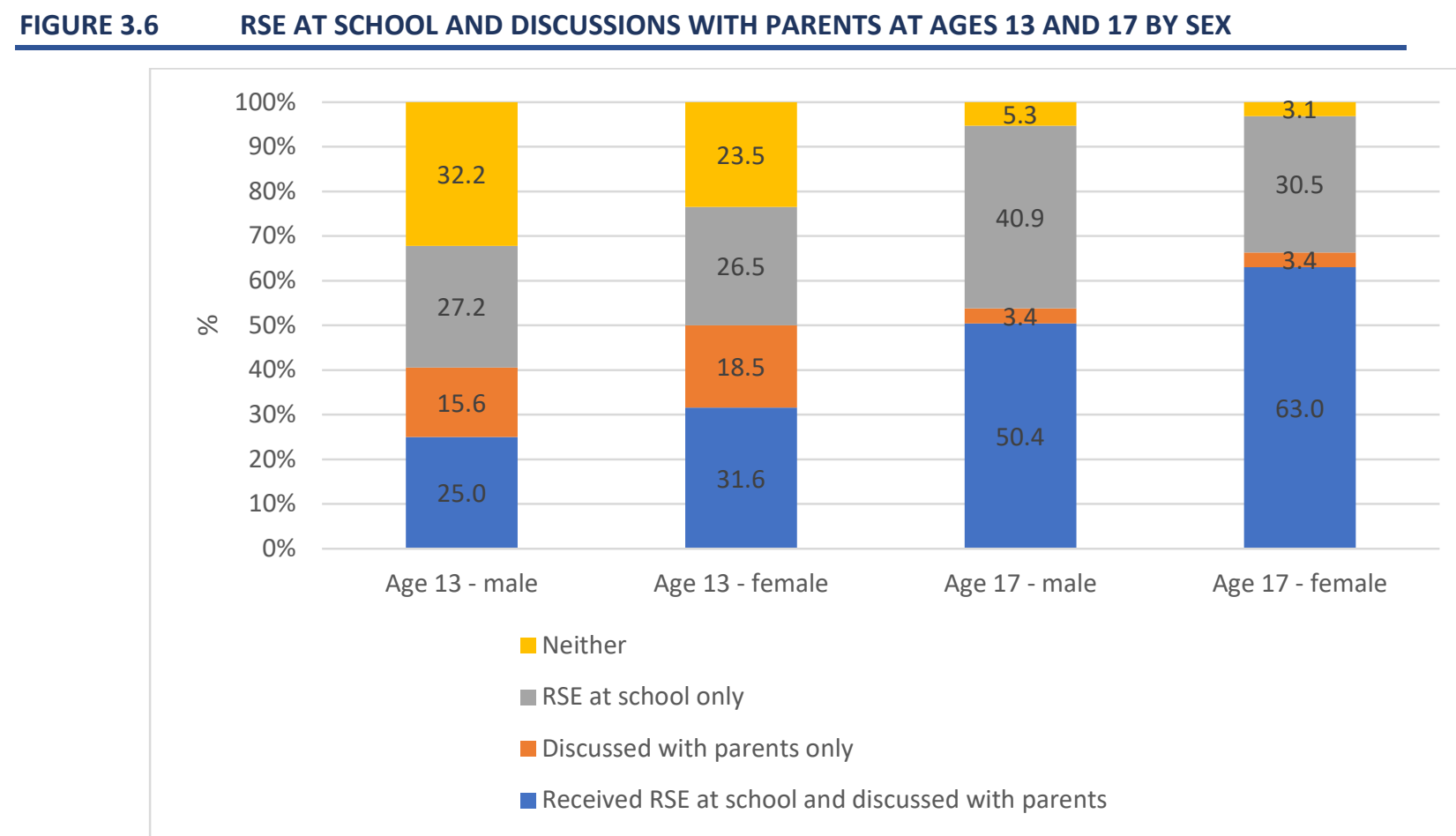

Source: GUI, '98 Cohort, waves 2 (age 13) and 3 (age 17).

Note: $\quad$ Population weights are employed.

\subsection{EASE OF DISCUSSIONS ABOUT SEX AND RELATIONSHIP ISSUES}

At age 17, the young people were asked to rate how easy they felt it was to talk openly with their parents about sex. As illustrated in Figure 3.7, overall the young people reported feeling more at ease talking openly about sex with their mothers rather than their fathers. Looking in more detail at these patterns across young men and women, young women reported it easier to talk to their mothers, while young men reported greater ease in talking to their fathers. Nonetheless, even among young men, nearly 60 per cent reported that it was quite difficult or very difficult to discuss sex with their fathers, or that the issue never came up (see Figure 3.8). 


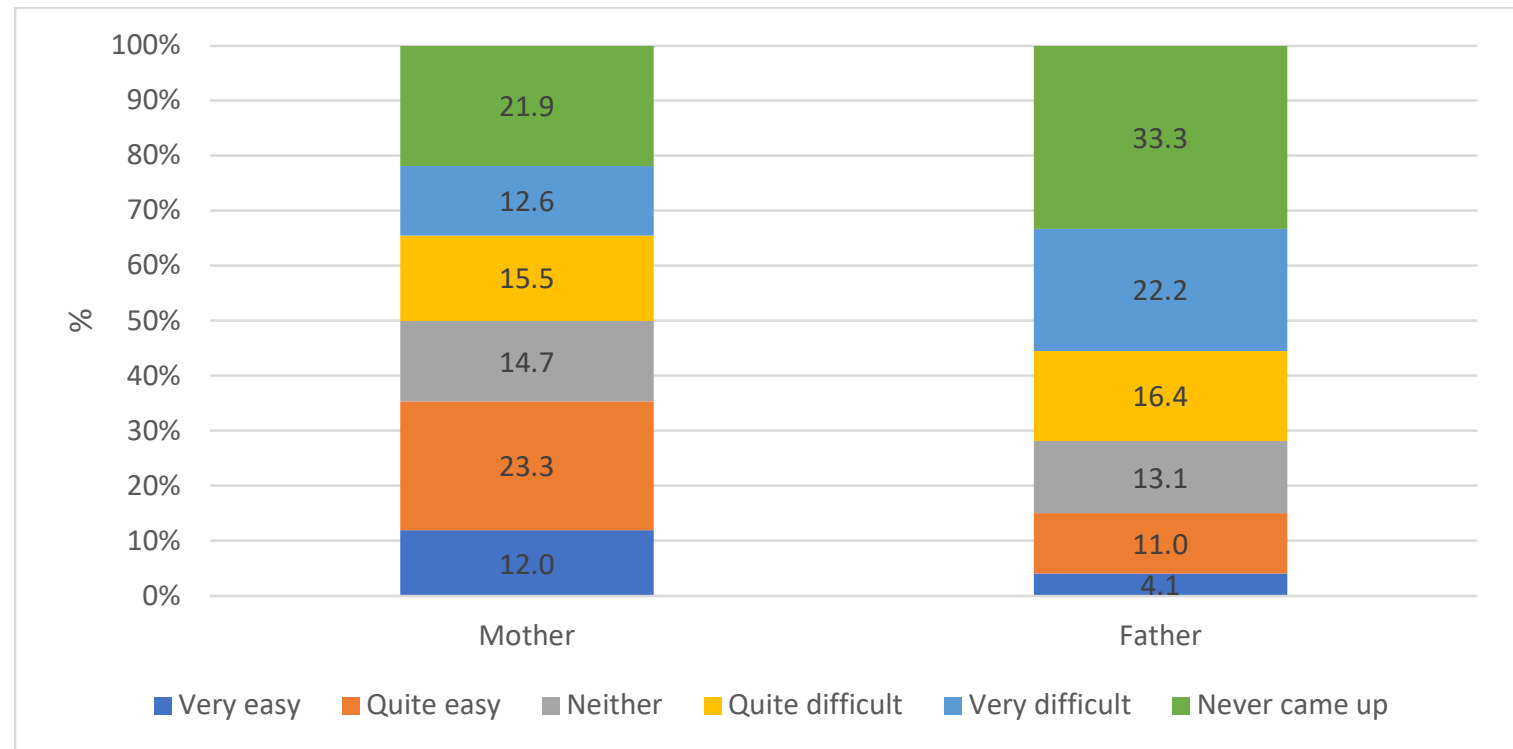

Source: GUI, '98 Cohort, wave 3 (age 17).

Note: $\quad$ Population weights are employed.

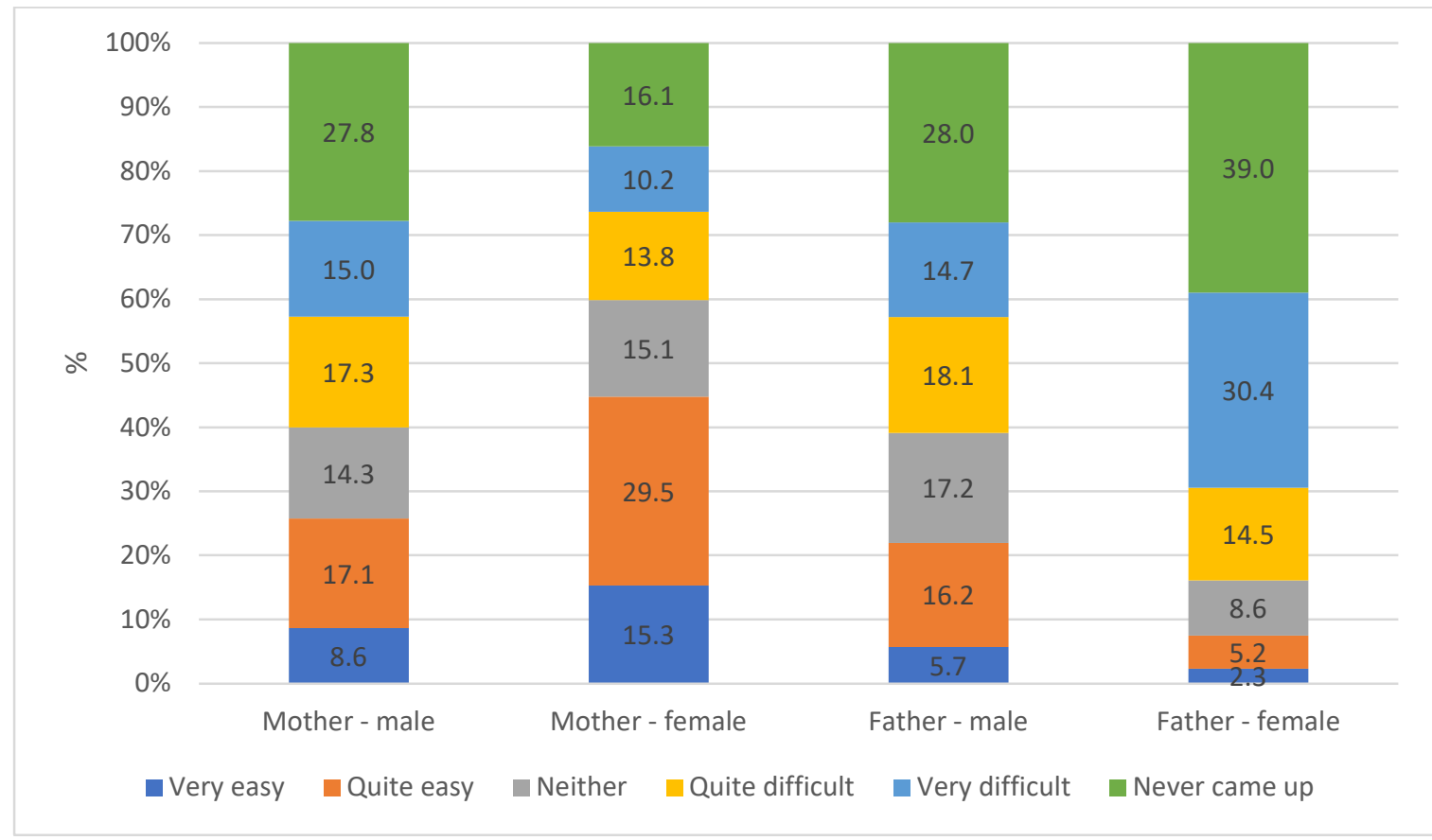

Source: GUI, '98 Cohort, wave 3 (age 17).

Note: $\quad$ Population weights are employed. 
In the multivariate models, young women reported finding it easier to talk to their mothers about sex, as did those from lone-parent families. There was some evidence that those from higher income families reported finding it more difficult to talk to their mothers about sex (but these results were only marginally statistically significant for those in the highest income quintile). Discussions were easier where young people had a more intimate relationship with their mother at age 17 and more difficult if the relationship was conflictual. Unlike the timing of discussion, the stage of pubertal development did not influence the ease of such conversations.

Young men found it easier to talk to their fathers about sex than young women. Those who had a more intimate and less conflictual relationship with their father at 17 found it easier to talk to him about sex. See Appendix Table A8 for the full set of results.

\subsection{PARENTAL REPORTS OF DISCUSSIONS ABOUT SEX AND RELATIONSHIP ISSUES}

In this section, we switch the focus from the young persons' reports to parental reports of discussions with their children about sex and relationship issues. When the young people were aged 13 and 17, mothers and fathers were asked about whether they had discussed five topics with their child: sex and sexual intercourse; sexual feelings, relationships and emotions; contraception; safer sex/sexually transmitted infections/venereal diseases; sexual orientation (e.g. homosexuality, heterosexuality). Figures 3.9 and 3.10 illustrate the prevalence of these discussions at ages 13 and 17. Not surprisingly, a higher proportion of mothers and fathers had discussed these issues with their child at age 17 than at age 13. Focusing on mothers' reports, at age 17 , the proportions range from approximately 70 per cent for safer sex to 80 per cent for sexual feelings, relationships and emotions. However, even at age 17, less than 50 per cent of fathers had discussed each of the five issues with their son or daughter. 


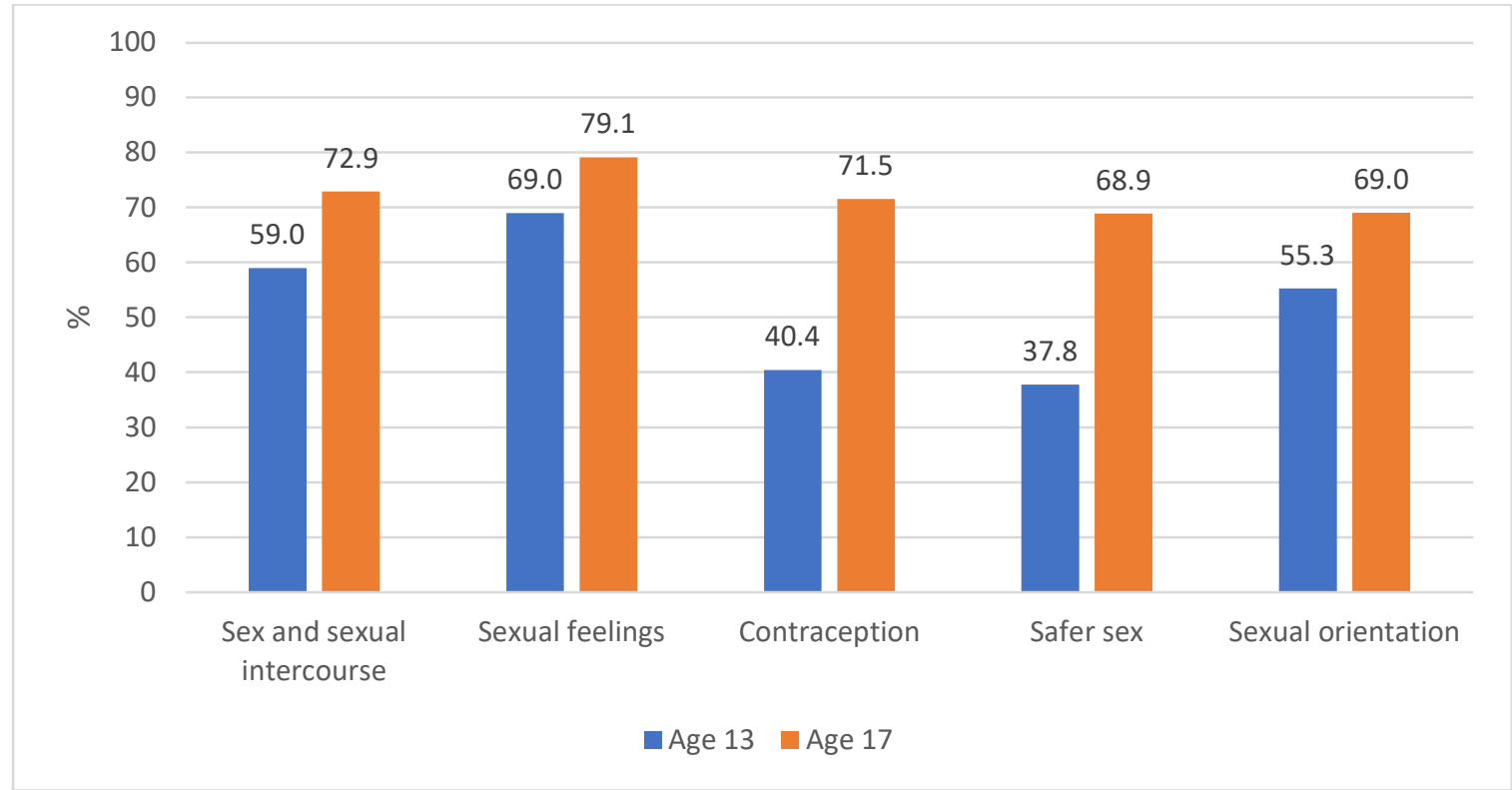

Source: GUI, '98 Cohort, waves 2 (age 13) and 3 (age 17).

Note: $\quad$ Population weights are employed.

FIGURE 3.10 PATERNAL DISCUSSIONS WITH YOUNG PERSON AT AGES 13 AND 17

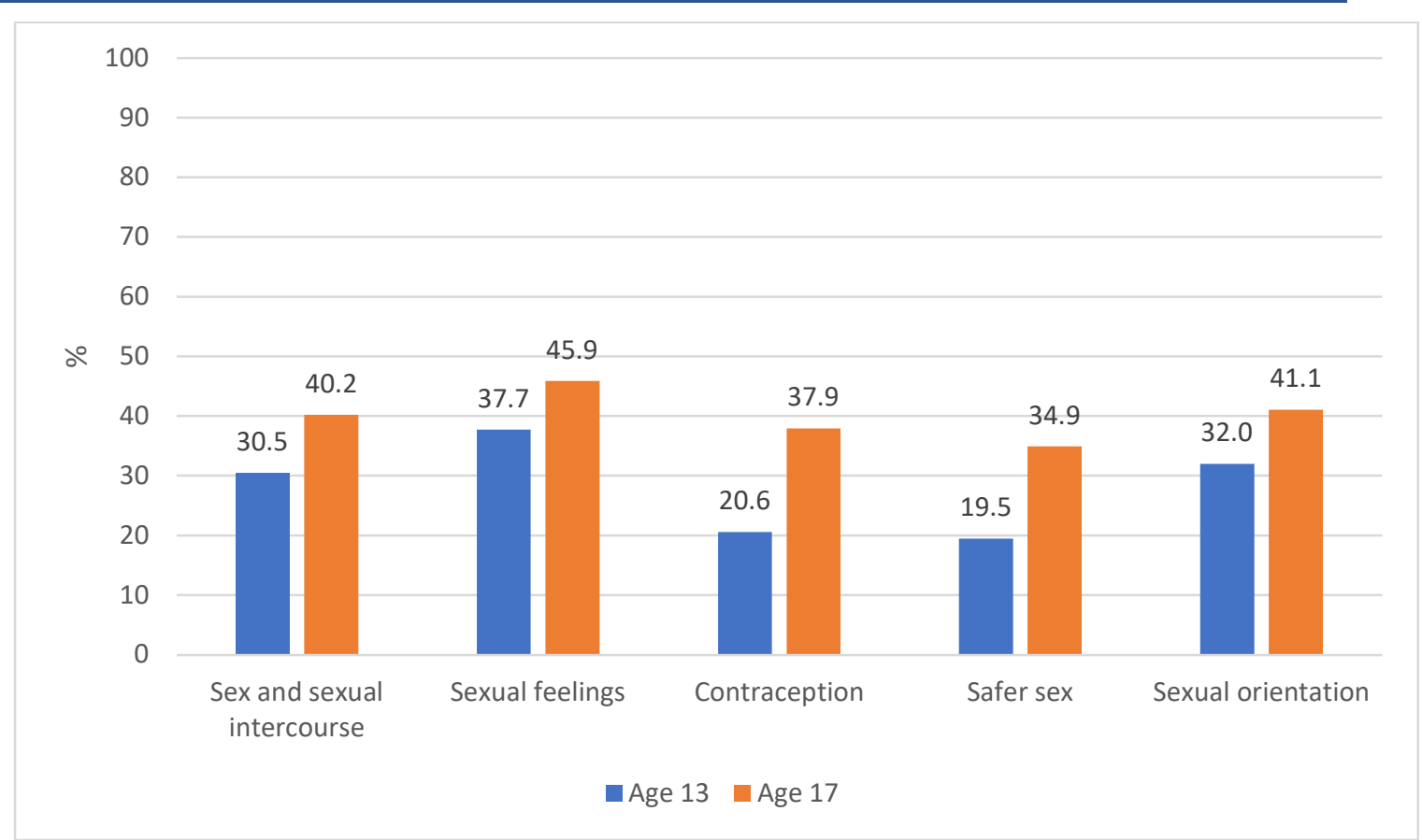

Source: GUI, '98 Cohort, waves 2 (age 13) and 3 (age 17).

Note: $\quad$ Population weights are employed. 
Aggregating across all topics, at age 13, 24 per cent of mothers had discussed all of these issues with their child, and this proportion had increased to 49 per cent by age 17. The corresponding figures for fathers were 11 per cent and 20 per cent respectively.

Focusing on parental reports at age 17, in multivariate models, summarised in Appendix Tables A3.9 and A3.10, mothers of young women were significantly more likely to report discussing all issues, while the opposite was true for fathers of young women (who were significantly less likely to discuss all issues than the fathers of young men). In general, there was little variation in parental reports (whether by mothers or fathers) by family social background, although mothers with higher levels of education were significantly more likely to report discussing sexual intercourse, sexual feelings and sexual orientation with their son or daughter. Those from lone-parent families were significantly more likely to have mothers who reported that they had discussed contraception, safer sex and sexual orientation by age 17 . The quality of the relationship between parents and child was important for both mothers' and fathers' reports, with those with closer relationships with their child at 13 and 17 more likely to report discussing all five issues. For fathers' reports, higher levels of parental monitoring were associated with a greater probability of discussing all issues. One of the strongest negative associations occurred for those living in rural areas; fathers of young people resident in rural areas were significantly less likely to have discussed each of the five issues with their child by age $17 .^{24}$

\subsection{SOURCE OF INFORMATION ABOUT SEX AND RELATIONSHIP ISSUES}

In this section we consider the main sources of information that are used by young people in relation to sex and relationship issues. Young people were asked to indicate the source where they receive most of their information, and this question was asked at both ages 13 and 17. Figure 3.11 shows that at age 13, the most frequently cited source was parents/family (including siblings), with approximately 46 per cent of young people nominating this source. The next highest was friends at 23 per cent, followed by 'nowhere' at just under 14 per cent. By age 17, friends had replaced parents/family as the most cited source, at 46 per cent compared to 18 per cent for parents/family. The internet, along with books, magazines, TV, films, etc. was the second most cited source at age 17, at nearly 20 per cent. At

24 A possible explanation is that rural fathers are more religious (and there is evidence that religiosity can affect attitudes towards sexual issues (Halman and van Ingen, 2015)). However, controlling for religiosity (i.e. whether the father considers himself a member of a religion) did not change the magnitude or statistical significance of the odds ratios for rural location. This suggests that other unobserved factors are associated with rural residence that explain rural fathers' reluctance to talk to their 17-year-old sons or daughters about these issues. 
both ages 13 and 17 , teachers were cited as the source of most information by approximately 10 per cent.

\section{FIGURE 3.11 SOURCE OF MOST INFORMATION ON SEX/RELATIONSHIP ISSUES}

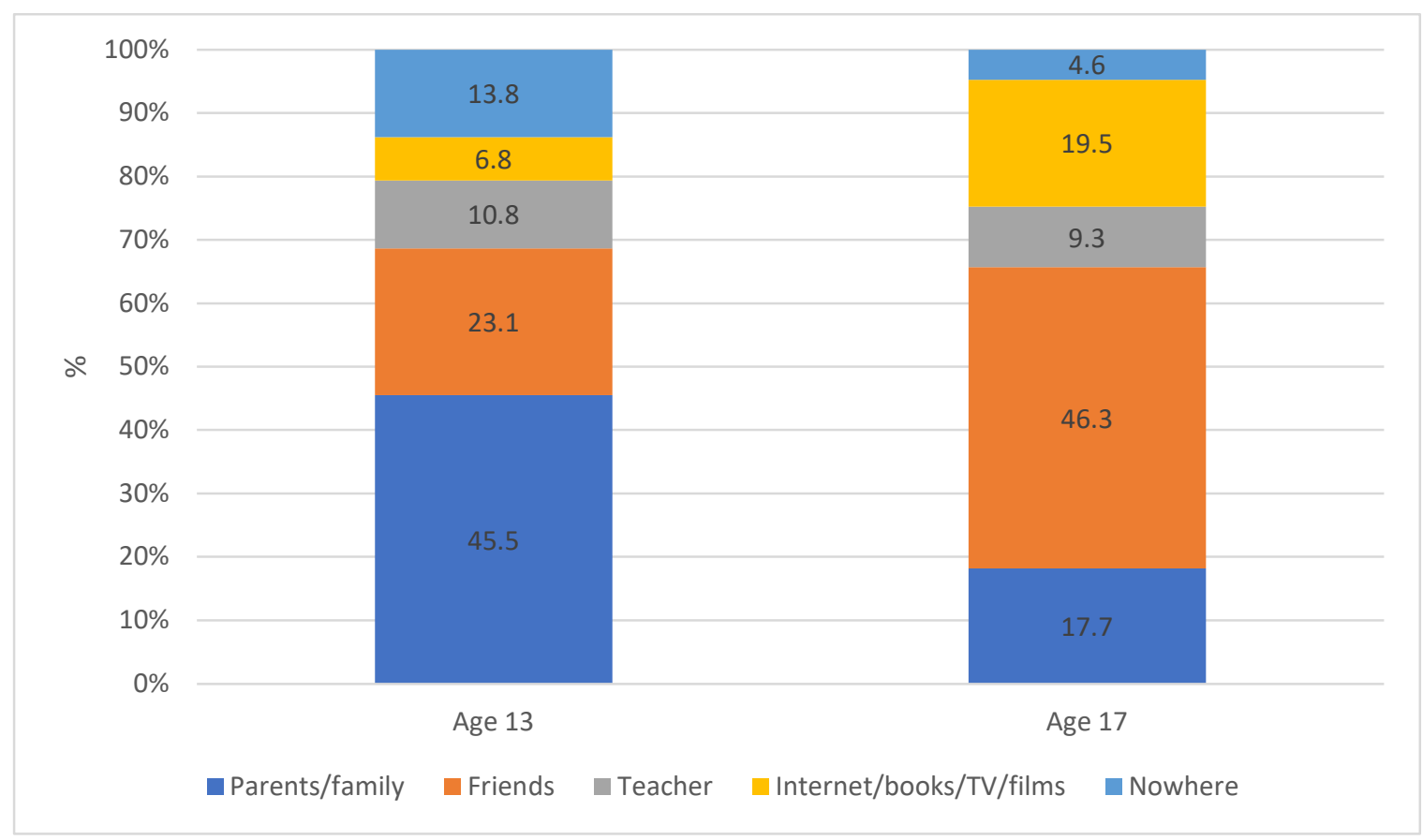

Source: $\quad$ GUI, '98 Cohort, waves 2 (age 13) and 3 (age 17).

Note: $\quad$ Population weights are employed.

As illustrated in Figure 3.12, there were significant differences in the main sources cited between males and females. A higher proportion of young women cited their parents/family as their main source (at both ages 13 and 17) than young males. Similarly, a higher proportion of young males cited the internet as their main source, particularly at age 17 , when nearly one quarter cited this as their main source. However, it is notable that over 8 per cent of young males at age 13 cited the internet as the source for most of their information on sex and relationship issues, and 17 per cent of 13-year-old boys reported that they did not get any information from any of these sources. 


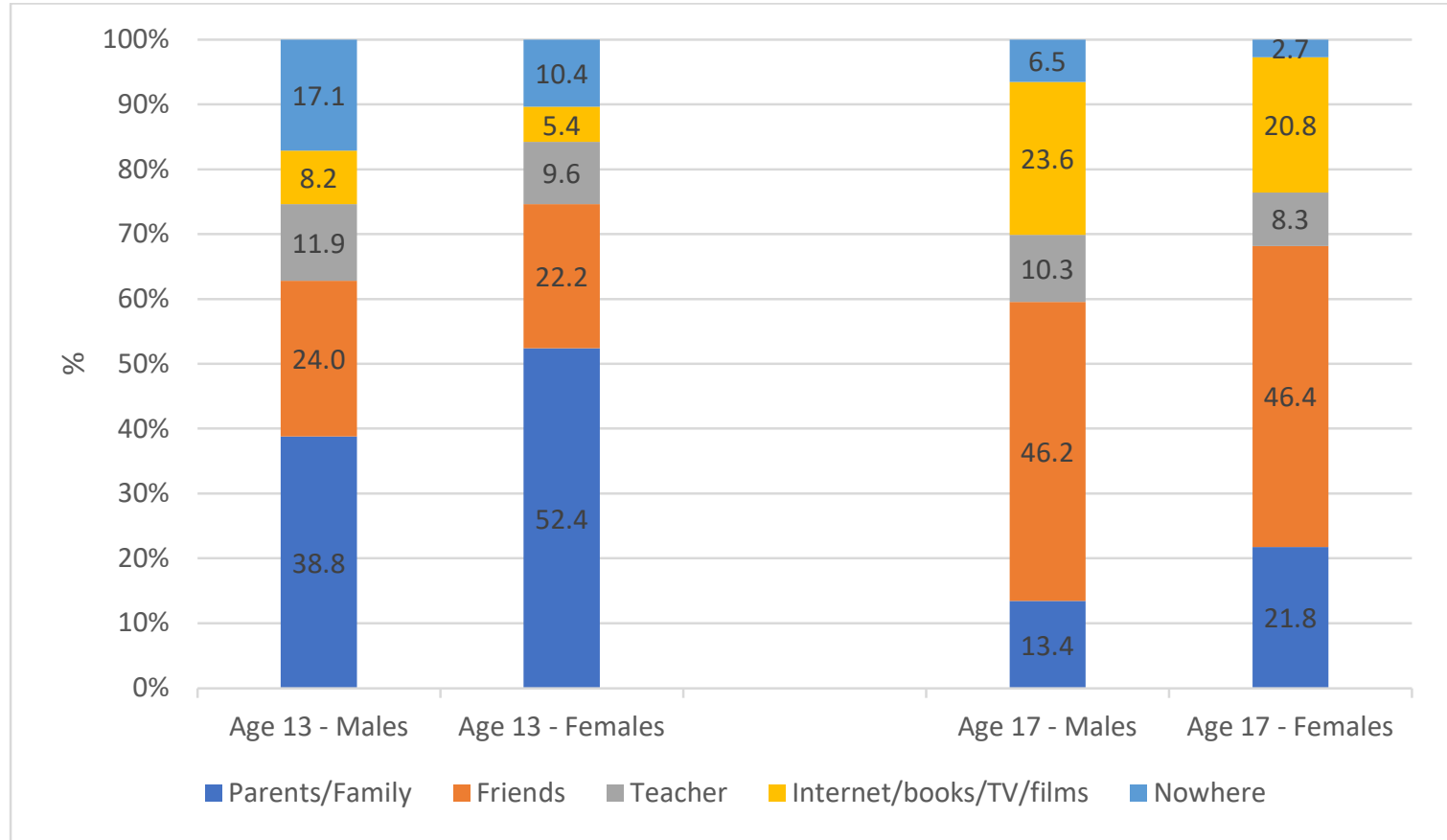

Source: GUI, '98 Cohort, waves 2 (age 13) and 3 (age 17).

Note: $\quad$ Population weights are employed.

In order to examine the variation in main source of sex information by key individual and family characteristics, we run multinomial logit models (full results presented in Appendix Tables A3.11 and A3.12). At age 13, relative to citing parents/family as their main source, young women were significantly less likely than males to cite all other sources. Those who were in second year (rather than first year) were more likely to cite their teacher. There was little significant variation by family background, except that young people from lower income families were more likely to cite 'nowhere'. Having a close relationship with their mother was an important predictor of source of information on sex, with those with close relationships with their mothers significantly less likely to choose all other sources over their parents/family. The quality of peer relationships mattered too, particularly for reliance on the internet, with those displaying greater alienation from their peers, and lower trust with their peers, significantly more likely to choose the internet as their main source at 13.

By age 17, the differences between young men and women were much less evident, with young women only significantly less likely than young men to choose teacher and 'nowhere' as their main source. Those from higher income families were significantly more likely to cite the internet as their main source at age 17. Closeness with the mother at age 13 was insignificant, although this was likely 
mediated by the strong effect for maternal intimacy at age $17 .{ }^{25}$ The quality of peer relationships was somewhat significant, with those with higher alienation from their peers significantly more likely to cite the internet as their main source at 17 .

Given the patterns identified in Section 3.2 in relation to variation in RSE across schools, it is instructive to examine in particular whether citing a teacher as the main source of information on sex is also related to school characteristics. A multivariate mode ${ }^{26}$ indicates that at 13 , males and those in second year were more likely to name their teacher as the main source of information on sex. None of the school-level characteristics were associated with the choice of teacher as the main source of sex education at age 13 . At 17, young people with a SEN were more likely to cite their teacher as the main source of information, while this was less prevalent among those from lone-parent families and those who had left school. Reliance on the teacher did not vary by type of school or the school's social or gender mix (see Appendix Table A13).

\subsection{SUMMARY}

In this chapter, we examined how, when and where young people receive information about relationships and sex. By age 17, the majority of young people had reported RSE at school, with females slightly more likely to report receipt than males. The proportions receiving RSE at both ages 13 and 17 varied significantly across individual schools. However, the school-level characteristics available in the Growing Up in Ireland (GUI) data were generally non-significant, suggesting that schools differ in the timing of RSE provision, but not due to school size, ethos, gender mix or DEIS status.

By age 17, nearly 60 per cent of young people reported that they had discussed sex and/or relationship issues with their parents. The quality of the relationship between the mother and child emerged as a key determinant of parental discussions at both ages 13 and 17, as did pubertal stage, suggesting that puberty operated as a prompt for parental discussions with their children about sex and relationships.

A significant minority of 13-year-olds - a third of males and almost a quarter of females - were not receiving sex education at home or at school. This group was disproportionately from disadvantaged backgrounds (in terms of maternal

25 The (Spearman) correlation between the measure of primary caregiver (PCG) closeness at age 13 and maternal intimacy at age 17 is 0.209 (and it is statistically significant at the 0.1 per cent level). Excluding maternal intimacy at age 17 from the models increases the size and significance of some of the negative relative risk ratios for PCG closeness at age 13 (particularly those for choosing friends, and the internet).

26 Multilevel models would not converge, most likely because of the small size of the group that indicated their teacher was the main source of information on sex education. 
education and household income). School characteristics did not make a difference but there was variation in lack of access to information across individual schools, suggesting an important role for policy and leadership at school level.

Less than 5 per cent of young people reported no RSE or parental discussions by the age of 17 . However, young men were significantly more likely to belong to this group ( 5 per cent vs 3 per cent). In addition, a very significant group - over 40 per cent of males and over 30 per cent of females - were solely reliant on sex education at school. This was more common for those living in rural areas and for the lowest income groups.

There was a clear gender divide in reports of ease of discussions with parents about sex; young women found it easier to talk to their mothers, while young men found to easier to talk to their fathers. However, nearly 60 per cent of young men reported finding it difficult or very difficult to talk openly with their fathers about sex. The quality of the parental relationship emerged once again as a key predictor of ease of discussions. Similar patterns were evident when examining reports of parental discussions from the perspectives of parents - mothers were more likely to talk to their daughters about key sex and relationship issues, while fathers were more likely to talk to their sons, and the quality of the parent-child relationship was again significant. One consistent finding across all five issues (sex; sexual feelings; contraception; safer sex; sexual orientation) was that rural fathers were significantly less likely to discuss these issues with their children than urban fathers.

Finally, this chapter examined the main sources of information used by young people in learning about sex. While parents/family were the main source at age 13, by age 17 , friends were the most commonly cited source (by nearly 50 per cent of young people). Teachers were cited by approximately 10 per cent of young people at both ages 13 and 17. At age 17, nearly a quarter of young men, and 21 per cent of young women, cited the internet/books/TV/films, etc. as their main source of information on sex. The quality of peer relationships emerged as a key predictor of reporting the internet as the main source; those who were more alienated from their peers were significantly more likely to cite the internet rather than their parents/family as their main source at age 17.

In Chapter 4 we examine sexual competency and behaviours for the subsample of 17-year-olds who have had sex, focusing in particular on the role, if any, of how and where young people have received information on sex and relationships in shaping these patterns. 


\section{CHAPTER 4}

\section{Sexual competence and sexual health behaviours}

\subsection{INTRODUCTION}

In this chapter we focus on the young people at the age of 17 who have had sexual intercourse, and examine their sexual competence at first sex, as well as their current sexual health behaviours. While Growing Up in Ireland (GUI) does not contain the full set of indicators used to construct an index of sexual competence, information on timing regret and contraceptive use at first sex is available and can be used to assess these dimensions of sexual competence. Lack of sexual competence at first sex has been shown to be associated with poor subsequent sexual health, as defined by self-reported sexually transmitted infection (STI) diagnosis, Human Papilloma Virus (HPV) positive status, lower sexual function, unplanned pregnancy and experience of non-volitional sex (Palmer et al., 2019). Before examining the sexual competence of young people who have had sex by age 17, we first examine the prevalence of sexual intercourse by age 17 , as this group forms the sample for the subsequent analyses in this chapter.

\subsection{SEXUAL ACTIVITY}

At age 17, the young person was asked about whether they had engaged in various types of sexual activity, ranging from holding hands to sexual intercourse. Overall, 33 per cent of the young people had had sexual intercourse by the time of their wave 3 interview. ${ }^{27}$ Those who were 18 years of age were much more likely to report having had sexual intercourse (38 per cent) than those who were 16 or 17 years of age ( 32 per cent), as were those who had left second-level school (45 per cent vs 34 per cent for those in sixth year and 27 per cent for those in fifth year). Young men were slightly more likely to report sexual intercourse than women (34 vs 32 per cent) (see Figure 4.1).

27 Data from the Irish Study of Sexual Health and Relationships (ISSHR) found that the median age for first (vaginal) sexual intercourse was 17 years among those aged 18-25 years in 2004 (Layte et al., 2006). More recently, data from the Health Behaviour in School-Aged Children (HBSC) study indicated that in 2018, 28 per cent of 15-17-year-old boys and 20 per cent of 15-17-year-old girls reported having had sexual intercourse (Költő et al., 2020). Of those in Senior Cycle who responded to the 2018 My World survey, 30 per cent reported having had sex (Dooley et al., 2019). 


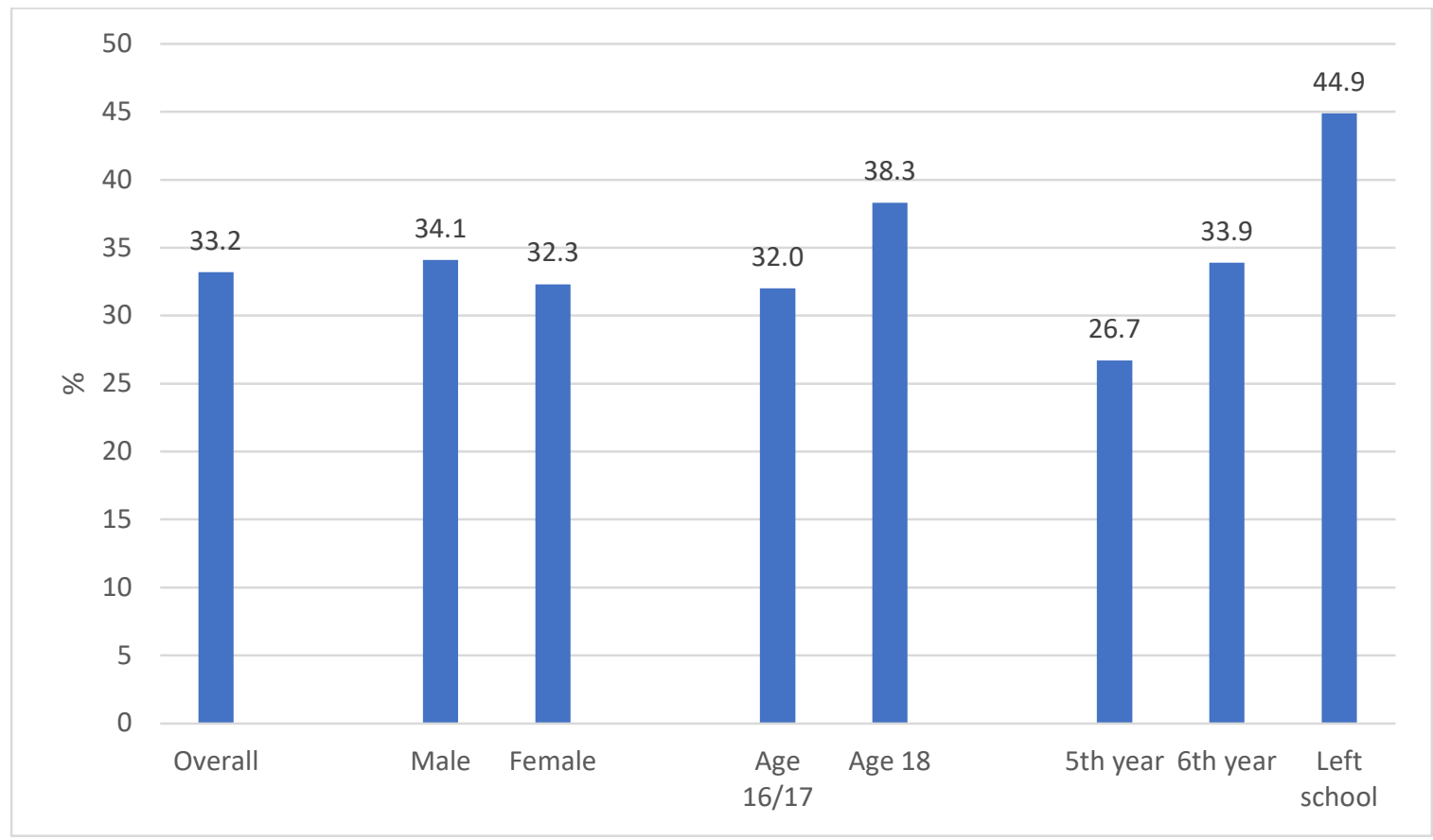

Source: GUI, '98 Cohort, wave 3 (age 17).

Note: $\quad$ Population weights are employed.

In order to investigate the extent to which sexual intercourse was associated with how and when young people received information on sex and their family background, and also varied across second-level schools, a multilevel model was estimated. The results showed that the proportion who had had sexual intercourse varied across second-level schools, even controlling for gender and family background $(p<.05)$, but this difference is modest (less than 2 per cent of total variation). None of the school characteristics are significant. The probability of having sexual intercourse is higher among males, those who are older and those from lone-parent families and lower among those with graduate mothers. Rates are much lower among those with a special education need (SEN). There are large differences by stage, with much higher rates among those who have left school (and the lowest level among fifth years). Timing of Relationships and Sexuality Education (RSE) receipt makes no difference, so there is no evidence that provision of sex education at school delays (or accelerates) sexual initiation. However, this may because the quality of such provision matters more (and there are no measures of such quality in GUI). Alternatively, the modest scale of provision in schools (DES, 2017) likely makes other sources of information more important. Other aspects of information receipt did matter, with those who were more reliant on their friends as a source of information much more likely to have had intercourse. Puberty by 13 has a large positive effect. Those who had discussed sex 
with their parents by 13 had higher rates, while rates were also significantly higher for those who had a conflictual relationship with their mothers at 13 (though the difference was small in scale).

In terms of school experiences, the probability of having sexual intercourse was lower among those who had achieved higher Junior Certificate grades. Rates were higher among those who had a negative relationship with their teachers at 13 but did not vary by attitudes to school, taking account of these other school factors. School factors accounted for most of the initial gender difference in the likelihood of having had sexual intercourse by 17 . Those who had larger friendship networks at 13 were more likely to have intercourse, but the age composition of the friendship group made no difference (see Appendix Table A14).

While subsequent analyses in this chapter focus just on the subsample of young people who reported sexual intercourse, it is instructive also to examine other sexual behaviours. The multilevel models were repeated to examine the profile of those who had had oral sex and/or sexual intercourse. Significant between-school variation is evident $(p<.01)$, which persists even controlling for a range of individual and family background factors. However, between-school variation is no longer significant when other factors, including the receipt of information from parents or school and the main sources of information on sex, are taken into account, suggesting that this variation between schools reflects differences in the nature and/or quality of information.

Having had sex is more common among males, older groups, those in the highest three income quintiles and those from lone-parent families. It is less common among those with a SEN and those living in rural areas. Levels are highest among those who have left school and lowest among those in fifth year. There is no significant variation by school characteristics. Those reliant on friends, the internet or books/magazines/TV are more likely to have had sex, as are (slightly) those who have a conflictual relationship with their mother (at 13) and more negative relationships with teachers. Those who had larger friendship networks are more likely to have had sex (see Appendix Table A15).

Information was also collected on whether young people felt that their friends had had sex. Those who reported 'most' or 'all' were combined for the purpose of a multilevel logistic regression model. Between-school variation in reports was significant $(p<.001)$, with around 6 per cent of the variation at the school rather than the individual level; school-level variation remained significant even taking account of individual and family background characteristics. Females and those from lone-parent families were more likely to report a sexually active friendship network, while those from more educated families were much less likely to do so. 
These differences were substantial, with those with graduate mothers 66 per cent less likely than those whose mothers had Junior Certificate or lower education to report most or all of their friends having had sex. As with own sexual activity, those who had left school were much more likely to report sexually active friends, with those in fifth year least likely to do so.

School characteristics made no significant difference but significant variation remained between individual schools, suggesting variation in peer culture across schools. The pattern did not vary by timing of RSE receipt. However, those who mainly received their information on sex from friends were more likely to report a sexually active friendship network. This may mean that young people seek out advice if they feel their friends are well informed. Alternatively, it may reflect the establishment of norms around sexual activity in friendship groups, which are reinforced through the exchange of advice and information. Those who had negative relationships with their teachers and who hated school were more likely to have sexually active friends (while the opposite was the case for those with higher Junior Certificate exam grades). This cannot be a direct causal relationship but is likely to reflect the friendship choices of those who are more disaffected from school. The influence of parental conflict is indirect and mediated through the size of the friendship network. In other words, those who have more conflict with their parents seem to seek out larger friendship groups. Between-school variation remains highly significant when all of these factors are taken into account (see Appendix Table A16); even taking account of a range of family and peer factors, schools account for 4 per cent of the total variation in having a sexually active friendship group.

\subsection{SEXUAL COMPETENCE AT FIRST SEX}

As noted in Chapter 1, the concept of sexual competence has been developed by researchers working on the British NATSAL surveys. Individuals are generally classified as sexually competent at first intercourse if they reported that the event was characterised by contraceptive protection, autonomy of decision, equal willingness of both partners, and that it had occurred 'at the right time'. For those who have had sexual intercourse (1792 or 33 per cent of the GUI young people), we have information on contraceptive protection and whether they felt that first sex had occurred 'at the right time'.

Looking first at contraceptive protection, Figure 4.2 shows how the proportion of those reporting that they used contraception at first sex varies by age, sex and school stage. Overall, 89 per cent of young people reported using contraception at first sex, and there were no significant differences by age, sex or school stage. 


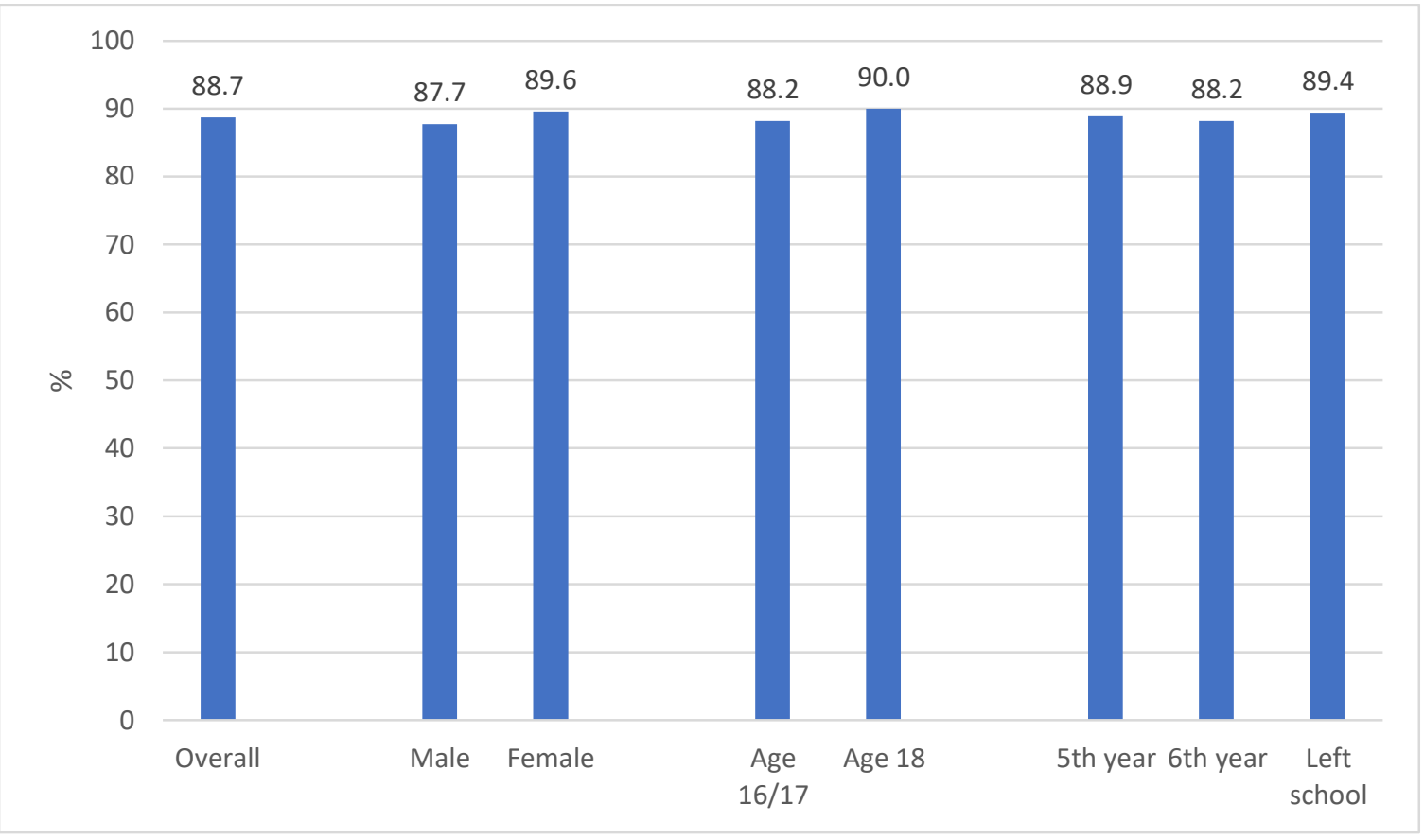

Source: GUI, '98 Cohort, wave 3 (age 17).

Note: $\quad$ Population weights are employed.

A multilevel model showed that contraceptive use at first sex did not vary across schools, either before or after controlling for individual, peer and school factors. Contraceptive use at first sex varied little by individual or family factors but was somewhat greater among those who had left school. There was no variation by school characteristics or by the timing of receipt of RSE. Contraceptive use was higher where young people had talked to their parents about sex at 13 and somewhat higher where they had already reached puberty at 13 . Those who relied on their friends as the main source of information were much less likely to use contraception at first sex. Those who had achieved higher Junior Certificate grades were more likely to have used contraception at first sex while those who had negative relationships with their teachers were less likely to do so. Patterns did not vary by attitudes to school or the size and age composition of the peer group. However, those who reported that most or all of their friends had had sex were much less likely to have used contraception when they first had sex (see Appendix Table A17).

Moving on to regret over the timing of first sex, Figure 4.3 illustrates the proportion of those who have had sex who reported regret over the timing (i.e. that they should have waited longer before having sex with anyone). Overall, 23 per cent of young people expressed regret over the timing, and this proportion did not differ 
by age or school stage (note that we cannot identify when the young person first had sex). However, there was a clear gender divide, with nearly a third of young women reporting regret over the timing of first sex (the corresponding proportion among young men was 16 per cent).

\section{FIGURE 4.3 PREVALENCE OF TIMING REGRET AT FIRST SEX BY AGE, SEX AND SCHOOL STAGE}

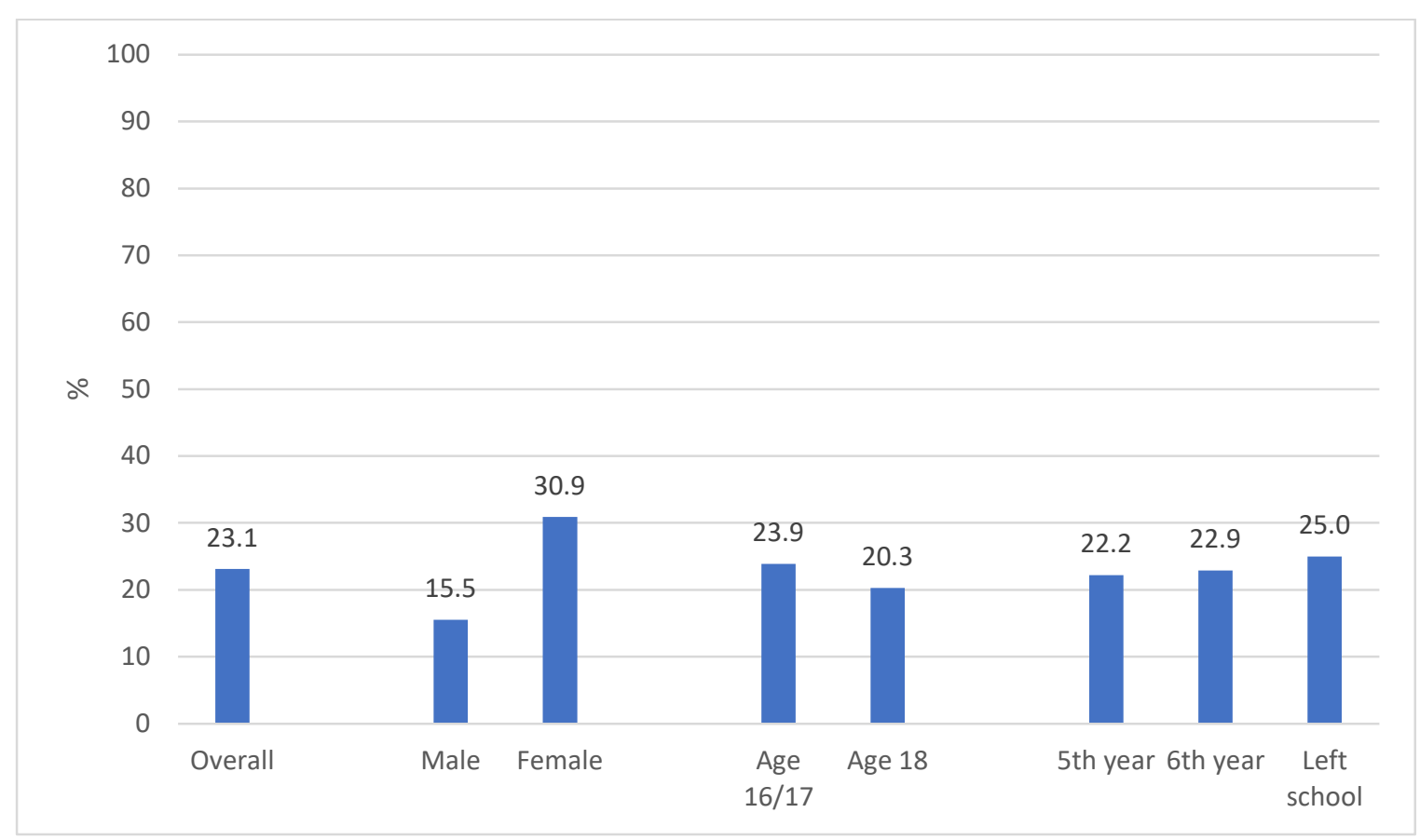

Source: GUI, '98 Cohort, wave 3 (age 17).

Note: $\quad$ Population weights are employed.

Analyses used a multilevel logistic regression model to look at timing regret. Before taking account of other factors, between-school variation was only significant at the 10 per cent level and dropped to below significance when other characteristics were examined. Thus, levels of regret were fairly similar across schools. Young women were somewhat more likely to express regret than young men, while those with a SEN were less likely to do so. However, there was no systematic association with any of the other background measures or school characteristics. There was no variation by RSE receipt timing, having talked to their parents about sex at 13 , puberty timing, source of information on sex (at 13) and closeness with their mother at 13. Only parental conflict was significantly associated with regret, but the effect was small. Regret was lower among those with higher Junior Certificate grades but did not vary by other school experiences. Number and age of friends did not make a difference. Interestingly, there was no variation by the sexual activity of their friendship network (see Appendix Table A18). 


\subsection{CURRENT SEXUAL HEALTH BEHAVIOURS}

In this section, we focus on those who have had sexual intercourse and are currently sexually active. We examine two key aspects of their sexual behaviour, use of condoms and contraception. Figure 4.4 shows that overall, 56 per cent of young people report that they use a condom 'all the time'. This proportion varies significantly by gender and school stage, with females and those who have left school less likely to report using condoms all the time.

\section{FIGURE 4.4 PREVALENCE OF CONDOM USE BY AGE, SEX AND SCHOOL STAGE}

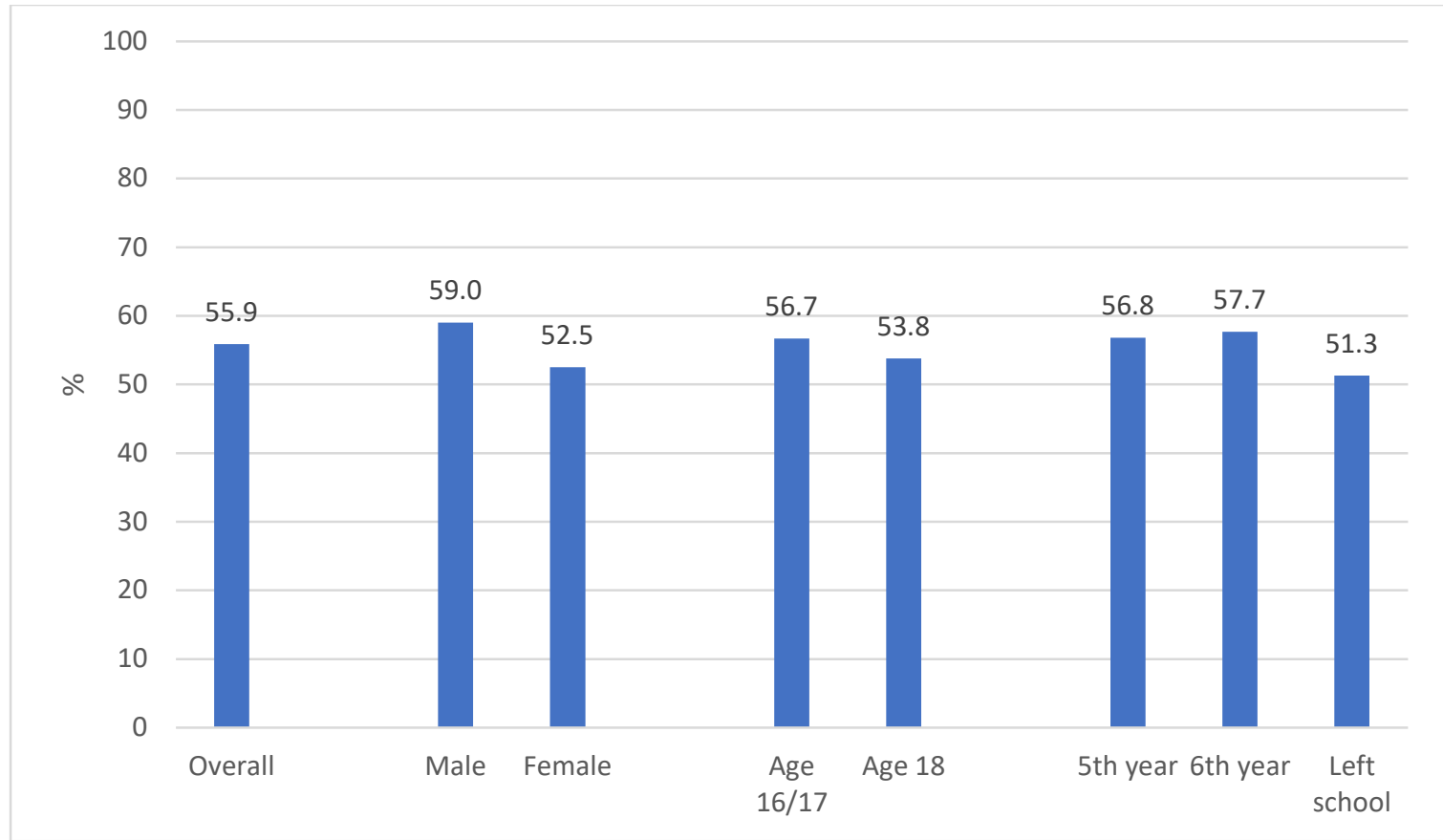

Source: GUI, '98 Cohort, wave 3 (age 17).

Note: $\quad$ Population weights are employed.

A multilevel model indicates that the proportion who report always using a condom does not vary significantly across schools. There is little variation by individual characteristics but usage patterns are lower for females and among those from lone-parent families and somewhat higher among those in rural areas before school stage, school characteristics and source of information on sex are taken into account. There is little variation by school characteristics, having left school or engagement with school. However, those with higher Junior Certificate grades are more likely to always use a condom while those with negative relationships with teachers are less likely to do so. Source of information or the nature of peer groups are not significantly associated with condom use on an ongoing basis, in contrast to the pattern for contraceptive use at first sex. Results from the multilevel model are presented in Appendix Table A19. 
Moving on to contraceptive use, for those who have had sex, Figure 4.5 shows that overall, just under 80 per cent of young people report that they 'always' use contraception. This proportion did not vary significantly by gender, age or school stage.

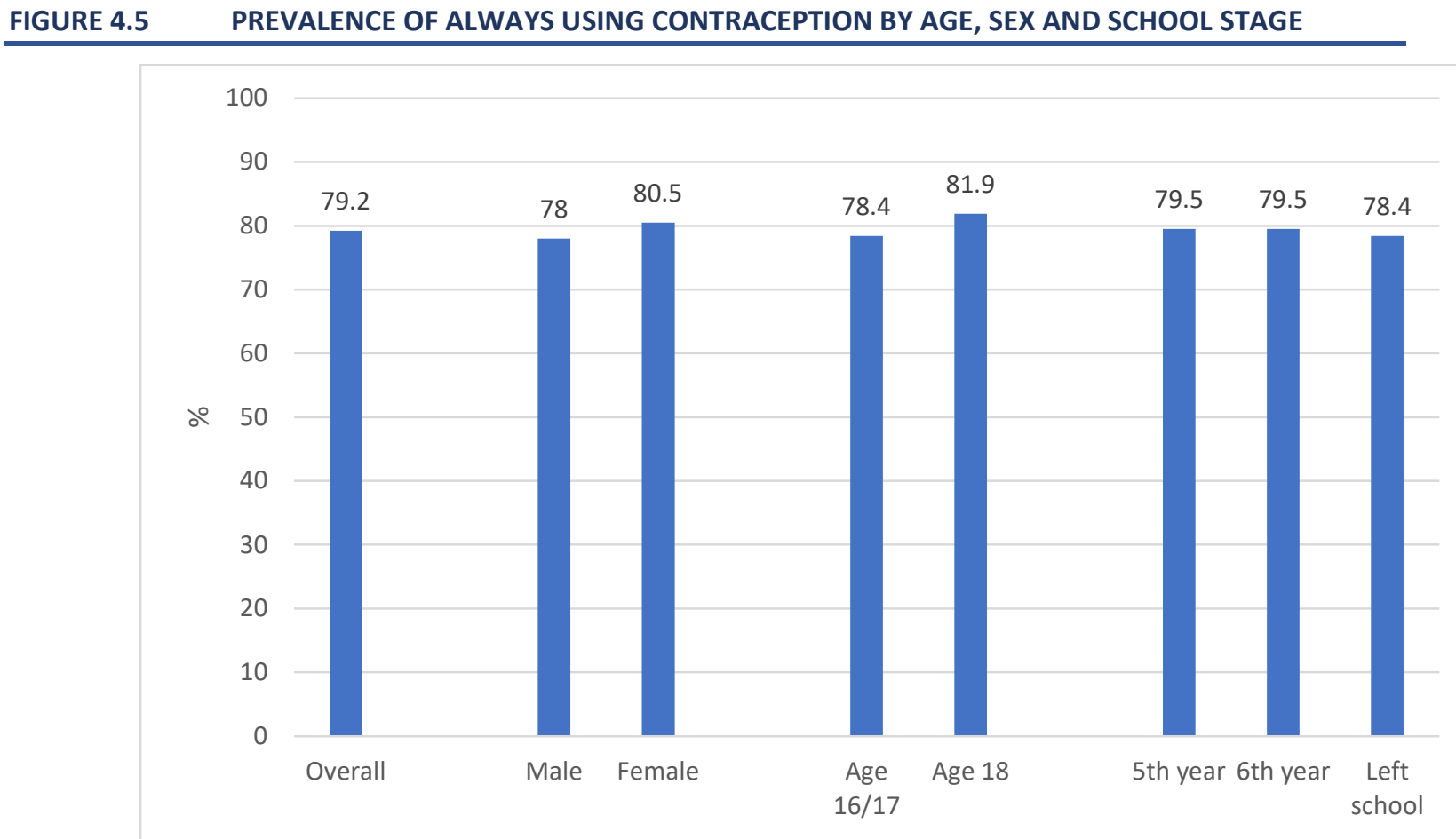

Source: GUI, '98 Cohort, wave 3 (age 17).

Note: Population weights are employed.

As with condom use, contraceptive use did not vary across individual second-level schools. There was no systematic variation by individual or school characteristics, school engagement, source of information on sex or nature of the peer group. However, young people who achieved higher grades at the Junior Certificate were more likely to always use contraception (see Appendix Table A20). Additional analyses (not shown here) suggest that having friends that are mostly sexually active was associated with lower levels of contraceptive use.

\subsection{SUMMARY}

In this chapter, we have focused on the subsample of 17-year-olds (approximately one-third) who have reported having had sexual intercourse. Having had sexual intercourse is more prevalent among males, those who are older and those from lone-parent families and lower among those with graduate mothers. Rates are much lower among those with a SEN. There are large differences by school stage, 
with much higher rates among those who have left school and the lowest level among fifth years, suggesting an association between stage in the educational career and self-perceived independence or maturity. There is a modest but significant variation in the proportion who have had sexual intercourse across second-level schools, even controlling for gender and family background. This difference is not due to the type of school or to the timing of receipt of RSE, suggesting some role for other factors such as the quality of sex education and/or the nature of the peer culture.

While GUI does not contain the full set of items that are generally used to construct a measure of sexual competence, the evidence here showed that, consistent with other research, females were significantly more likely to express regret over the timing of their first sexual intercourse experience. In terms of contraceptive use at first sex, there was evidence that those who had discussed sex and relationships with their parents at age 13 were significantly more likely to have used contraception at first sex. Furthermore, those who sourced most of their information on sex from their friends were significantly less likely to use contraception at first sex. With the prevalence of contraceptive use at first sex at nearly 90 per cent, it was perhaps unsurprising that so few other variables emerged as significant predictors of contraceptive use at first sex. There was no significant school-level variation in sexual competence and no relationship with the timing of RSE receipt. Similarly, for those who are currently sexually active, there was no significant school-level variation in use of condoms and/or contraception. While nearly 90 per cent of young people reported using contraception the first time they had sex, for those who are currently sexually active this proportion had dropped to below 80 per cent. 



\section{CHAPTER 5}

\section{Discussion and policy implications}

\subsection{SUMMARY}

Sexual activity is an important component of physical and mental health and wellbeing. The development of positive sexual health behaviours during adolescence lays the foundation for healthy relationships throughout the life course. One of the three key goals of the national sexual health strategy is to ensure that everyone has access to appropriate sexual health education and information. This report has drawn on rich information from the Growing Up in Ireland (GUI) study to look at sources of information on sex and sexual behaviour among 17-year-olds, thus providing an important evidence base for policy development.

\subsubsection{Sources of information on sex}

This report focused in the first instance on how, when and where young people source their information on sex and relationships. By age 17, nearly 60 per cent of young people reported that they had discussed sex and/or relationship issues with their parents. The quality of the relationship between the mother and child emerged as a key determinant of parental discussions at both ages 13 and 17, as did pubertal stage, suggesting that puberty operated as a prompt for parental discussions with their children about sex and relationships. Less than 5 per cent of young people reported no school-based Relationships and Sexuality Education (RSE) or parental discussions by the age of 17 . However, young men were significantly more likely to belong to this group ( 5 per cent compared with 3 per cent).

There was a clear gender divide in reports of ease of discussions with parents about sex: young women found it easier to talk to their mothers, while young men found it easier to talk to their fathers. However, nearly 60 per cent of young men reported finding it difficult or very difficult to talk openly with their fathers about sex. The quality of the parental relationship emerged once again as a key predictor of ease of discussion. Similar patterns were evident when examining reports of parental discussions from the perspectives of parents: mothers were more likely to talk to their daughters about key sex and relationship issues, while fathers were more likely to talk to their sons, and the quality of the parent-child relationship was again significant. One consistent finding in parental discussion of various issues (sex; sexual feelings; contraception; safer sex; sexual orientation) was that rural fathers were significantly less likely to discuss these issues with their children than urban fathers. 
By age 17, over 90 per cent of young men and women had received RSE at school but young people were found to vary in the timing of receipt of school-based RSE, depending on the school they attended. Variation was not evident by school characteristics such as size, ethos or gender mix, suggesting the important role of policy and leadership at the school level.

Looking at findings on the receipt of sex education at school or home together, two key patterns are evident. Firstly, a significant minority of 13-year-olds - a third of males and almost a quarter of females - had not received sex education at home or at school. Secondly, around a third of 17-year-olds were wholly dependent on school-based provision rather than discussions with their parents. This group was significantly more likely to be male, in the lowest two income quintiles and from a two-parent family, and to live in a rural area. While a reliance on school-based information is not problematic per se, the relatively modest time allocation given to Social, Personal and Health Education (SPHE) in general and RSE in particular (see below) may lead to gaps in information and support for these young people.

Young people were asked about their main source of information on sex at both 13 and 17 years of age. While parents/family were the main source at age 13 , by age 17 friends were the most commonly cited source (by nearly 50 per cent of young people). At both ages, young people were more likely to cite their parents/family as their main source where they had a positive relationship with their mother. Teachers were cited by approximately 10 per cent of young people at both ages and were more frequently mentioned by young people with a special educational need (SEN). At age 17, nearly a quarter of young men, and just over 20 per cent of young women, cited the internet/books/TV/films etc. as their main source of information on sex. The quality of peer relationships emerged as a key predictor of reporting the internet as the main source; those who were more alienated from their peers were significantly more likely to cite the internet as their main source at age 17 .

\subsubsection{Sexual behaviour}

The report then focused on the sexual behaviour of 17-year-olds. Approximately one-third had had sexual intercourse while four in ten had had oral sex and/or intercourse. The group of young people who had oral and/or penetrative sex were more likely to be male, older and from a lone-parent family, and less likely to have a SEN or live in a rural area. School stage was important, with sexual activity levels higher among those who had left school. Those reliant on friends, the internet or books/magazines/TV were more likely to be sexually active as were (slightly) those who had a conflictual relationship with their mother (at 13) and more negative relationships with teachers. Those who had larger friendship networks were more likely to have had sex. Significant between-school variation was evident in the 
proportion of young people who had had oral sex and/or intercourse, even controlling for a range of individual and family background factors. This was not related to school characteristics such as gender and social mix, suggesting a role for peer culture and broader school climate in influencing sexual behaviour.

The probability of having had sexual intercourse was higher among males, those who were older and those from lone-parent families, and lower among those with graduate mothers. Rates were much lower among those with a SEN. Earlier puberty was associated with a greater likelihood of having had intercourse. Those who were more reliant on their friends as a source of information were much more likely to have had intercourse, as were those who had larger friendship networks at 13.

Between-school differences were found in the proportion of 17-year-olds who had had intercourse but these differences were largely accounted for by school stage, with much higher rates among those who had left school (and the lowest level among fifth years). Other aspects of school experience also mattered, with higher rates among those who had a negative relationship with their teachers and lower rates among those who achieved higher Junior Certificate grades.

International research has increasingly focused not on age of sexual initiation but on a broader notion of sexual competence or readiness, which encompasses contraceptive protection, making a free choice, both partners being equally willing, and feeling it was the right time (rather than regretting the timing). While GUI does not contain the full set of items that are generally used to construct a measure of sexual competence, the evidence here showed that, consistent with other research, females were significantly more likely to express regret over the timing of their first sexual intercourse experience. The GUI survey did not collect information on the reasons for such regret. However, previous research (Layte and McGee, 2007) points to the role of context and circumstances in regret: in particular, not being in a steady relationship, it being a spur of the moment decision rather than planned, and feeling coerced. ${ }^{28}$ In terms of contraceptive use at first sex, there was evidence that those who had discussed sex and relationships with their parents at age 13 were significantly more likely to have used contraception at first sex. In contrast, those mainly reliant on their friends as a source of information on sex had lower levels of contraceptive use at first sex. However, with the prevalence of contraceptive use at first sex at nearly 90 per cent, it was perhaps unsurprising that so few variables emerged as significant predictors of contraceptive use at first sex.

28 In this context, it should be noted that the GUI questionnaire asked only about 'things which happened with your consent'. 
There was no significant school-level variation in sexual competence. Similarly, for those who are currently sexually active, there was no significant school-level variation in use of condoms and/or contraception and the timing of RSE was not associated with use of contraception. However, young people who had higher levels of academic achievement were less likely to express regret over the timing of sexual initiation and were more likely to use condoms or other contraception at first sex and/or currently. While nearly 90 per cent of young people reported using contraception the first time they had sex, for those who were currently sexually active, this proportion had dropped to below 80 per cent.

\subsection{STRENGTHS AND LIMITATIONS}

It is worth highlighting the strengths and limitations of this analysis before discussing the main results and inferring implications for policy and practice.

First, in terms of limitations, the data are all self-reported, by either the young person or their parents. The potential for recall and social desirability bias associated with self-reported data on sexual behaviour is well documented (DiClemente et al., 2013). However, the use of a self-completion questionnaire format in GUI maximises response rates, while also allowing for respondents to answer truthfully in a confidential setting. ${ }^{29}$ A comparison of data on the proportion of young people who have reported having had sex by age 17 from GUI shows good agreement with data reported in other surveys in Ireland (and elsewhere). ${ }^{30}$

Second, the absence of data on age of sexual initiation prevented us from analysing early sexual initiation, its antecedents and its consequences. In particular, information on early initiation would have been useful in understanding variation in sexual competence at first sex, as previous research has demonstrated that earlier initiation is associated with lower levels of sexual competence (Wellings et al., 2001).

29 Using a 'common cohort analysis' on NATSAL 2 and NATSAL 3, Prah et al. (2014) find that changes in the reporting of sexual behaviours and attitudes over time observed in the wider NATSAL 3 study largely reflected real changes in behaviours rather than recall or other types of bias (e.g. social desirability). Where any differences were observed, they were more pronounced for women, but in the opposite direction to what might be expected from increased liberal social attitudes (e.g. women were less likely in NATSAL 3 than in NATSAL 2 to say that they had a child before the age of 20).

30 The 2010 HBSC study found that among those aged 15-18 years, 27 per cent of men and 16 per cent of women were 'sexually initiated' (based on a positive response to the question 'have you ever had sexual intercourse?'). Data from the ISSHR indicate that the median age of sexual initiation for those aged 18-24 years in 2004 was 17 (whereas for those aged 60-64 it was 22/23) (Layte et al., 2006). Data from the Longitudinal Study of Australian Children (LSAC), which uses a similar research design to GUI, show that one third of 16-17-year-olds had had sexual intercourse (Warren and Swami, 2019). 
Third, as noted, GUI contains information on only two of the four components of sexual competence, namely timing regret and contraceptive use, meaning that a direct comparison with existing research using NATSAL could not be undertaken. Similarly, while GUI contains data on RSE receipt, no information is available on the quantity or quality of provision, an issue discussed further below. In the GUI study, young people were not directly asked about pornography as a source of information on sex (though some may have included it under 'the internet'). However, three years later, almost two-thirds (64 per cent) of males from this cohort reported using the internet for pornography (compared to 13 per cent of females). Finally, sample size restrictions prevented us from disaggregating these patterns by the young person's sexual orientation.

Despite these limitations, it is important to highlight that the information collected in GUI represents the first time that comprehensive information on how young people learn about sex and relationships, and whether they make positive and healthy sexual health choices, is available from a nationally representative sample of young adults. While the HBSC surveys collect valuable information on sexual health and behaviours, the data are limited to those attending school; GUI captures all young people, even those who have left school. In addition, the availability of data on RSE, parental discussions and information sources at two time points (age 13 and age 17) allows us to identify potentially vulnerable groups who have not received any information, or delayed information, on sex and relationships at age 17. The availability of detailed longitudinal data on different dimensions of young people's lives (demographic characteristics, family background, cognitive skills and school-level factors) facilitates an analysis of the relative importance of these factors for the variety of outcomes considered in this study. The existence of comprehensive data on the young person's second-level school also allows for the use of multilevel analysis to examine the role, if any, of school-level characteristics in influencing RSE receipt in particular.

\subsection{DISCUSSION AND POLICY IMPLICATIONS}

\subsubsection{Comparative findings}

While it is difficult to compare the findings in this report with existing Irish and international research due to differences in data sources, survey methods, variable definitions and reference periods, a number of broad observations can be made. First, it appears as if Irish parents are more willing than in the past to talk to their adolescent children about sex and relationship issues. At age 17, 53 per cent of young men and 66 per cent of young women in the GUI cohort reported that they had discussed sex and relationship issues with their parents; data from the 2004 ISSHR study showed that among men aged 18-24, just 21 per cent had received sex education in the home, although the proportion among women was higher at 
38 per cent. Second, the clear gender divide in experience of regret over the timing of first sex reported in this study is replicated in previous research in Ireland and internationally. For example, data from the UK NATSAL 3 study (carried out over the period 2010-2012) found that 40 per cent of women and 27 per cent of men aged 17-24 reported that first sex had not occurred at the right time (Palmer et al., 2019). Layte et al. (2006) found that less than 20 per cent of men but around a quarter of women aged 18-24 regretted the timing of their first sexual experience. Finally, in terms of sexual health behaviours, our findings in relation to contraceptive use at first sex (which was reported by 90 per cent of the GUI cohort who had had sex) are in broad agreement with previous data in Ireland from Healthy Ireland (Department of Health, 2015a) and ISSHR (Layte et al., 2006). Comparing statistics on condom use is more difficult, given differences in the underlying question used to gather the data in studies such as the HBSC (Young et al., 2018) and Healthy Ireland (Department of Health, 2015a).

\subsubsection{Policy implications}

Focusing first on RSE, the findings indicate that by age 17, over 90 per cent of young men and women have received RSE at school. At age 13, just over half had received RSE. Schools differ in the timing of RSE provision, but not for reasons of school size, ethos or gender mix, suggesting that policy and leadership at the school level play an important role in the timing of RSE provision. This is consistent with previous Irish research, which highlighted the importance of school leadership and teacher professional development in successful RSE provision (Mayock et al., 2007) but pointed to constraints in the form of teacher discomfort, the low status of SPHE, exam pressures and a significant reliance on external providers for RSE classes (NCCA, 2008; DES, 2009, 2013, 2017).

The study findings point to little relationship between receiving RSE or not and young people's sexual behaviour and competence. However, as discussed above, GUI did not collect information on the quantity or, perhaps more importantly, the quality of the sex education received. The requirement within second-level education is for six RSE class sessions as part of SPHE per year. Evidence suggests that only a quarter of schools are meeting this target (DES, 2017). ${ }^{31}$ Consultation undertaken for the NCCA review of RSE has highlighted some issues around the quality of provision. Young people were especially critical of the focus on biological processes to the neglect of broader issues of relationships and emotions, alongside a concern with risks rather than a positive view of sexual relationships (NCCA, 2019a, 2019b; see also Hyde and Howlett, 2004). ${ }^{32}$ The review highlighted the

31 This is based on the online Life Skills survey of schools conducted by DES in 2015; the response rate for second-level schools was 33 per cent.

32 Qualitative research in Ireland has also indicated that parent-child discussion tends to focus on risks rather than emotions or sexual pleasure (Hyde et al., 2009). 
importance of provision being student-centred, holistic, inclusive, age/developmentally appropriate and based on a whole-school approach. It indicated the need to create an integrated curriculum for SPHE/RSE as one subject and to review the content of, and time allocated to, this domain. Addressing consent and diversity were seen as key components of a reframed curriculum. School leadership and teacher professional development were highlighted as crucial ingredients in the successful implementation of RSE.

The review of RSE and the broader context of the Framework for Junior Cycle (DES, 2015), which designated wellbeing as a new area of learning at Junior Cycle with 400 timetabled hours, provides an opportunity to reconsider the place of RSE within the broader curriculum. The emphasis of the Wellbeing Policy Statement and Framework for Practice 2018-2023 (DES, 2018) is on a whole-school approach to promoting wellbeing, which could be used to move away from a treatment of sex education as a 'stand-alone' set of classes to looking at sexual wellbeing as part of broader physical and psychological wellbeing.

However, there is a limit to what even intensive, high-quality school-based sex education can achieve. As noted by Hirst (2008), RSE is only one aspect of the portfolio of skills and competencies that can assist young people to protect their sexual health and ensure positive sexual experiences (together with, for instance, a strong sense of agency, communication between sexual partners and access to sexual health services). The National Sexual Health Strategy highlights the responsibility of parents in providing their children with the information, education and support necessary to prepare them for a lifetime of positive sexual health and wellbeing, tasking the HSE, the Department of Children and Youth Affairs and parents' organisations with providing supports and resources for parents in engaging with this role. Our research shows that the quality of the relationship between parents and their children is a key determinant of both whether discussions about sex and relationships take place and how easy young people find it to speak to their parents about sex. In this context, there may be lessons from initiatives elsewhere designed to foster communication between parents and children about sex (see for example Kesterton and Coleman, 2010;33 Schuster et al., 2008 ${ }^{34}$ ). In Ireland, the HSE Sexual Health and Crisis Pregnancy Programme has websites (b4udecide.ie and sexualwellbeing.ie) providing information to parents, among others, and links to training programmes offered by the Irish Family Planning Association and the National Parents' Council Primary. Broader initiatives

33 The Family Planning Association Speakeasy course in the UK was designed to be delivered in local community settings to support parental confidence and knowledge in speaking to their children about sex. Research pointed to an increase in self-reported knowledge, confidence and openness after taking the course (Kesterton and Coleman, 2010), which is also run by the Irish Family Planning Association.

34 A randomised control trial of the Talking Parents, Healthy Teens found that the provision of eight one-hour sessions delivered at workplaces to parents of 11-15-year-olds resulted in greater ability to communicate and more open discussion around sex (Schuster et al., 2008). 
to support parents in developing positive communication skills may be expected to have broader benefits in terms of discussions about sex and relationships. However, given the difficulty felt by many young people in discussing sex with their parents and parents' own reluctance to broach these topics, a more targeted approach may be necessary. The NCCA review's consultation with parents (2019a, $2019 b)$ would also suggest the potential for greater communication between school and home around the provision of sex education.

The study findings highlight a significant group of young people who are not receiving information or advice from their parents on relationships and sex. Young men are much less likely to discuss sex with their parents than young women, and males from low-income families living in rural areas emerge as a potentially vulnerable group in relation to the lack of advice and information from parents. In the absence of parental discussion, young people appear to turn to their friends for information, increasingly so as they move through adolescence. However, the findings point to some risks associated with (over-)reliance on friends, with lower levels of contraceptive/condom use among this group. In addition, 20 per cent of young people at age 17 rely on the internet/TV/films etc. as their main source of information on sex, a pattern that is more common in the absence of good-quality friendships. This suggests that initiatives to target quality sex education via these media should be considered. International research (Simon and Daneback, 2013) has pointed to the potential role of online sources of sex education, while also highlighting the varied quality of such information and the digital divide among young people.

Overall, the findings are positive in relation to sexual competence and behaviour, with low levels of regret about the timing of first intercourse and high levels of contraceptive or condom use at first sex. In keeping with international research (Schubotz et al., 2004), young women are more likely than young men to express regret about the timing of sexual initiation, a quarter doing so compared to one in six of young men: a pattern that may reflect gendered social norms. Currently, a number of initiatives around consent have been introduced in the Irish higher education sector (Department of Education and Skills, 2019). These findings suggest that the issue could usefully be addressed within school-based RSE, placing it, as young people themselves suggest (NCCA, 2019b), in the context of the broader (power) dynamics of relationships.

Rates of contraceptive use at first sex are high, though at 90 per cent not universal. There appears to be a lower level of usage at the time of the survey than at first sex, with less than four-fifths always using contraception and much fewer (56 per cent) always using a condom. The findings therefore suggest the necessity for a multi-pronged approach involving school-based RSE, parental support and public health campaigns to support safe sex practices. Given the widespread reliance of 
young people on their friends for information and advice, there would appear to be considerable potential to use peer mentoring to encourage condom use (Petosa and Smith, 2014).

The cohort of young people in this study were followed up again at the age of 20. This provides a crucial opportunity to look at the transition to sexual activity among the broader group of young people. These data could be used to explore whether earlier contraceptive/condom use is predictive of ongoing use and the extent to which it reflects the broader quality of young people's intimate relationships.

To conclude, it is worth reiterating that the collection and analysis of high-quality, nationally representative data are crucial components of effective policy on sexual health and relationships. Indeed, one of the three key goals of the current National Sexual Health Strategy 2015-2020 is the provision of good-quality data to guide service provision (Department of Health, 2015b). Much of our information on the sexual health, attitudes and behaviours of adults in Ireland relies on the comprehensive Irish Study of Sexual Health and Relationships (ISSHR), carried out over 15 years ago. ${ }^{35}$ In terms of young people, while there are important ethical issues around reporting and analysis of sexual health data, this needs to be balanced against the value of this information for policy development and service provision, particularly on neglected topics such as the consumption of pornography, sexual initiation, consent and sexual violence. In this context, it is welcome that the Central Statistics Office (CSO) will carry out a new Survey on Sexual Violence (SSV) in the next few years. 

TABLE A1 MULTILEVEL LOGISTIC REGRESSION MODEL OF HAVING RECEIVED SCHOOL-BASED RELATIONSHIPS AND SEXUALITY EDUCATION BY AGE 13 (ODDS RATIOS)

\begin{tabular}{|c|c|}
\hline & Coefficient \\
\hline \multicolumn{2}{|l|}{ Fixed effects } \\
\hline Female & $1.166^{*}$ \\
\hline Age at time of survey & 1.232 \\
\hline Has a SEN & 0.995 \\
\hline \multicolumn{2}{|l|}{ Mother's education (ref. lower secondary or less) } \\
\hline Upper second-level & 1.012 \\
\hline Post-secondary & 0.932 \\
\hline Degree or higher & 1.080 \\
\hline \multicolumn{2}{|l|}{ Household equivalised income (ref. lowest quintile) } \\
\hline 2nd quintile & 1.081 \\
\hline 3rd quintile & 0.999 \\
\hline 4th quintile & 1.041 \\
\hline 5th (highest) quintile & $1.221+$ \\
\hline Migrant family & 0.978 \\
\hline Lone-parent family & $1.186+$ \\
\hline Rural area (ref. urban) & $0.897+$ \\
\hline In second year (ref. first year) & $2.194^{* * *}$ \\
\hline DEIS school & 1.090 \\
\hline Fee-paying school & 1.055 \\
\hline \multicolumn{2}{|l|}{ Gender mix of the school (ref. coeducational) } \\
\hline Single-sex boys' & 0.939 \\
\hline Single-sex girls' & 1.108 \\
\hline \multicolumn{2}{|l|}{ School size (ref. <200) } \\
\hline $\begin{array}{c}\text { School size (ref. <200) } \\
200-399\end{array}$ & 1.189 \\
\hline $400-599$ & 1.092 \\
\hline $600+$ & 1.278 \\
\hline \multicolumn{2}{|l|}{ School sector (ref. voluntary secondary) } \\
\hline ETB & 0.882 \\
\hline Community/comprehensive & 0.937 \\
\hline School has Roman Catholic ethos & 0.832 \\
\hline Random effects & \\
\hline Between-school variation & $0.224 * * *$ \\
\hline McFadden pseudo $\mathrm{R}^{2}$ & 0.09 \\
\hline Number of schools & 608 \\
\hline Number of young people & 5183 \\
\hline
\end{tabular}

Source: GUI, '98 Cohort, wave 2 (age 13).

Note: $\quad * * * p<.001 ;{ }^{* *} p<.01 ; * p<.05 ;+p<.10$. 
TABLE A2 MULTILEVEL LOGISTIC REGRESSION MODEL OF HAVING RECEIVED SCHOOL-BASED RELATIONSHIPS AND SEXUALITY EDUCATION BY AGE 17 (ODDS RATIOS)

\begin{tabular}{|c|c|}
\hline & Coefficients \\
\hline \multicolumn{2}{|l|}{ Fixed effects } \\
\hline Female & $1.334 *$ \\
\hline Age at time of survey & 0.931 \\
\hline Has a SEN & 0.791 \\
\hline \multicolumn{2}{|c|}{ Mother's education (ref. lower secondary or less) } \\
\hline Upper second-level & 0.773 \\
\hline Post-secondary & 0.869 \\
\hline Degree or higher & $0.720+$ \\
\hline \multicolumn{2}{|c|}{ Household equivalised income (ref. lowest quintile) } \\
\hline 2nd quintile & $1.797 * *$ \\
\hline 3rd quintile & 1.190 \\
\hline 4th quintile & $1.395+$ \\
\hline 5th (highest) quintile & 1.327 \\
\hline Migrant family & 1.057 \\
\hline Lone-parent family & 0.953 \\
\hline Rural area (ref. urban) & 0.844 \\
\hline \multicolumn{2}{|l|}{ Year group (ref. fifth year) } \\
\hline Sixth year & 1.148 \\
\hline Has left school & $1.391+$ \\
\hline DEIS school & $1.492+$ \\
\hline Fee-paying school & $1.779+$ \\
\hline \multicolumn{2}{|c|}{ Gender mix of the school (ref. coeducational) } \\
\hline Single-sex boys' & 1.229 \\
\hline Single-sex girls' & 1.137 \\
\hline \multicolumn{2}{|l|}{ School size (ref. <200) } \\
\hline $200-399$ & 0.983 \\
\hline $400-599$ & 0.808 \\
\hline $600+$ & 1.137 \\
\hline \multicolumn{2}{|l|}{ School sector (ref. voluntary secondary) } \\
\hline ETB & 0.687 \\
\hline Community/comprehensive & 1.343 \\
\hline School has Roman Catholic ethos & 0.712 \\
\hline Random effects & \\
\hline Between-school variation & $0.762^{* * *}$ \\
\hline McFadden pseudo $\mathrm{R}^{2}$ & 0.10 \\
\hline Number of schools & 616 \\
\hline Number of young people & 6459 \\
\hline
\end{tabular}

Source: GUI, '98 Cohort, waves 2 (13 years) and 3 (17 years).

Note: $\quad{ }^{* * *} p<.001 ;{ }^{* *} p<.01 ;{ }^{*} p<.05 ;+p<.10$. 
TABLE A3 MULTILEVEL LOGISTIC REGRESSION MODELS OF HAVING RECEIVED SCHOOL-BASED RELATIONSHIPS AND SEXUALITY EDUCATION AT AGE 13 AND/OR 17 (ODDS RATIOS); BASE CATEGORY - RECEIVED RSE AT BOTH AGES

\begin{tabular}{|c|c|c|c|}
\hline & Late advice & Early advice & Neither age \\
\hline \multicolumn{4}{|l|}{ Fixed effects } \\
\hline Female & $0.856+$ & 0.946 & $0.521 * *$ \\
\hline Age at time of survey & $0.539 *$ & 0.760 & 1.002 \\
\hline Has a SEN & 0.984 & 0.860 & 1.372 \\
\hline \multicolumn{4}{|c|}{ Mother's education (ref. lower secondary or less) } \\
\hline Upper second-level & 0.865 & 1.077 & 1.323 \\
\hline Post-secondary & 0.962 & 0.820 & 1.355 \\
\hline Degree or higher & $0.799+$ & 1.066 & 1.425 \\
\hline \multicolumn{4}{|c|}{$\begin{array}{l}\text { Household equivalised income (ref. lowest } \\
\text { quintile) }\end{array}$} \\
\hline 2nd quintile & 0.925 & $0.509 *$ & 0.626 \\
\hline 3rd quintile & 0.972 & 0.780 & 0.991 \\
\hline 4th quintile & 0.946 & 0.598 & 0.871 \\
\hline 5th (highest) quintile & 0.873 & 0.875 & 0.669 \\
\hline Migrant family & 1.071 & 1.221 & 0.709 \\
\hline Lone-parent family & $0.775^{*}$ & 1.369 & 0.615 \\
\hline Rural area (ref. urban) & 1.057 & 1.057 & 1.349 \\
\hline \multicolumn{4}{|l|}{ Year group (ref. fifth year) } \\
\hline Sixth year & $0.515^{* * *}$ & $0.684^{*}$ & $0.651^{*}$ \\
\hline Has left school & $0.463 * * *$ & $0.413^{* *}$ & 0.688 \\
\hline DEIS school & 0.932 & $0.491 *$ & 0.832 \\
\hline Fee-paying school & 0.829 & $0.405^{*}$ & 0.670 \\
\hline \multicolumn{4}{|c|}{ Gender mix of the school (ref. coeducational) } \\
\hline Single-sex boys' & 0.992 & 0.705 & 0.883 \\
\hline Single-sex girls' & 0.809 & $0.586+$ & 1.074 \\
\hline \multicolumn{4}{|l|}{ School size (ref. <200) } \\
\hline 200-399 & 0.736 & 1.155 & 1.687 \\
\hline 400-599 & 0.793 & 1.166 & 2.815 \\
\hline $600+$ & 0.712 & 1.042 & 1.486 \\
\hline \multicolumn{4}{|l|}{ School sector (ref. voluntary secondary) } \\
\hline ETB & 1.033 & 1.559 & 1.744 \\
\hline Community/comprehensive & 0.978 & 0.881 & 0.523 \\
\hline School has Roman Catholic ethos & 1.107 & 1.452 & 1.706 \\
\hline \multicolumn{4}{|l|}{ Random effects } \\
\hline Between-school variation & $0.203^{* * *}$ & $0.767^{* * *}$ & $1.601^{* * *}$ \\
\hline McFadden pseudo $\mathrm{R}^{2}$ & 0.09 & 0.100 & 0.11 \\
\hline Number of schools & 594 & 541 & 546 \\
\hline Number of young people & 4577 & 2750 & 2777 \\
\hline
\end{tabular}

Source: GUI, '98 Cohort, waves 2 (13 years) and 3 (17 years).

Note: $\quad * * * p<.001 ; * * p<.01 ; * p<.05 ;+p<.10$. 
TABLE A4 LOGIT REGRESSION MODEL OF PARENT/CHILD DISCUSSIONS ABOUT SEX, AGES 13 AND 17 (ODDS RATIOS)

\begin{tabular}{|c|c|c|}
\hline & Age 13 & Age 17 \\
\hline Female & $1.46 * * *$ & 1.13 \\
\hline Age at time of survey & 1.02 & 1.10 \\
\hline Has a SEN & 0.77 & 1.02 \\
\hline \multicolumn{3}{|l|}{ Mother's education (ref. lower second-level or less) } \\
\hline Upper second-level & 0.99 & 0.94 \\
\hline Post-secondary & $1.33^{*}$ & 1.18 \\
\hline Degree or higher & $1.39 *$ & 1.05 \\
\hline \multicolumn{3}{|l|}{ Household equivalised income (ref. lowest quintile) } \\
\hline 2nd quintile & 0.86 & 1.01 \\
\hline 3rd quintile & 1.02 & 0.99 \\
\hline 4th quintile & 1.21 & 1.01 \\
\hline 5th (highest) quintile & $1.34 *$ & 0.99 \\
\hline Migrant family & 1.15 & 1.21 \\
\hline Lone-parent family & 1.15 & $1.53^{* *}$ \\
\hline Rural area (ref. urban) & 1.09 & 0.88 \\
\hline In second year (ref. first year) & -0.02 & $\mathrm{n} / \mathrm{a}$ \\
\hline School stage (ref. 5th year) & $\mathrm{n} / \mathrm{a}$ & \\
\hline 6 th year & $\mathrm{n} / \mathrm{a}$ & 0.88 \\
\hline Left school & $\mathrm{n} / \mathrm{a}$ & 1.05 \\
\hline Pianta PCG - closeness (age 13) & $1.04 * *$ & 1.02 \\
\hline Pianta PCG - conflict (age 13) & 1.00 & 1.00 \\
\hline Stattin-Kerr PCG - monitoring (age 13) & 0.99 & 1.01 \\
\hline Stattin-Kerr young person - disclosure (age 13) & 1.01 & 1.02 \\
\hline PCG network of relationship - intimacy (age 17) & $\mathrm{n} / \mathrm{a}$ & $1.41 * * *$ \\
\hline PCG network of relationship - conflict (age 17) & $\mathrm{n} / \mathrm{a}$ & 1.00 \\
\hline Had reached puberty at 13 & $1.38 * * *$ & $1.32 * *$ \\
\hline McFadden pseudo $\mathrm{R}^{2}$ & 0.02 & 0.09 \\
\hline Number of young people & 4665 & 4250 \\
\hline
\end{tabular}

Source: GUI, '98 Cohort, waves 2 (age 13) and 3 (age 17).

Note: $\quad * * * p<.001 ; * * p<.01 ; * p<.05 ;+p<.10$. 


\begin{tabular}{|c|c|}
\hline & Marginal effects \\
\hline Female & $0.84+$ \\
\hline Age at time of survey & 0.91 \\
\hline Has a SEN & 0.94 \\
\hline \multicolumn{2}{|l|}{ Mother's education (ref. lower second-level or less) } \\
\hline Upper second-level & 1.18 \\
\hline Post-secondary & 0.98 \\
\hline Degree or higher & 0.95 \\
\hline \multicolumn{2}{|l|}{ Household equivalised income (ref. Lowest quintile) } \\
\hline 2nd quintile & 0.89 \\
\hline 3rd quintile & 0.95 \\
\hline 4th quintile & 0.78 \\
\hline 5th (highest) quintile & $0.75+$ \\
\hline Migrant family & $0.75^{*}$ \\
\hline Lone parent family & $0.54 * * *$ \\
\hline Rural area (ref. urban) & 0.99 \\
\hline \multicolumn{2}{|l|}{ School stage (ref. 5th year) } \\
\hline 6 th year & 1.18 \\
\hline Left school & 0.98 \\
\hline Pianta PCG - closeness (age 13) & $0.96^{*}$ \\
\hline Pianta PCG - conflict (age 13) & 1.00 \\
\hline Stattin-Kerr PCG - monitoring (age 13) & 1.00 \\
\hline Stattin-Kerr young person - disclosure (age 13) & 0.98 \\
\hline PCG network of relationship - intimacy (age 17) & $0.73 * * *$ \\
\hline PCG network of relationship - conflict (age 17) & $0.93^{* *}$ \\
\hline Had reached puberty at 13 & $0.70 * * *$ \\
\hline McFadden pseudo $\mathrm{R}^{2}$ & 0.08 \\
\hline Number of young people & 4364 \\
\hline
\end{tabular}

Source: GUI, '98 Cohort, waves 2 (age 13) and 3 (age 17).

Note: $\quad * * * p<.001 ; * * p<.01 ; * p<.05 ;+p<.10$. 
TABLE A6 MULTILEVEL LOGISTIC REGRESSION MODEL OF LIKELIHOOD OF A 13-YEAR-OLD NOT HAVING RECEIVED SCHOOL-BASED RELATIONSHIPS AND SEXUALITY EDUCATION OR DISCUSSED SEX WITH THEIR PARENTS (ODDS RATIOS)

\begin{tabular}{|c|c|}
\hline & Coefficients \\
\hline \multicolumn{2}{|l|}{ Fixed effects } \\
\hline Female & $0.728 * *$ \\
\hline Age at time of survey & $0.607 \dagger$ \\
\hline Has a SEN & 0.748 \\
\hline \multicolumn{2}{|c|}{ Mother's education (ref. Lower secondary or less) } \\
\hline Upper second-level & 0.845 \\
\hline Post-secondary & 0.864 \\
\hline Degree or higher & $0.699 * *$ \\
\hline \multicolumn{2}{|c|}{ Household equivalised income: (ref. Lowest quintile) } \\
\hline 2nd quintile & 0.902 \\
\hline 3rd quintile & 1.021 \\
\hline 4th quintile & 0.973 \\
\hline 5th (highest) quintile & $0.757^{*}$ \\
\hline Migrant family & 0.995 \\
\hline Lone-parent family & $0.716^{* *}$ \\
\hline Rural area (ref. urban) & 1.081 \\
\hline In second year (ref. first year) & $0.508 * * *$ \\
\hline DEIS school & 0.848 \\
\hline Fee-paying school & 0.911 \\
\hline \multicolumn{2}{|c|}{ Gender mix of the school (ref. coeducational) } \\
\hline Single-sex boys' & 1.042 \\
\hline Single-sex girls' & 0.833 \\
\hline \multicolumn{2}{|l|}{ School size (ref. <200) } \\
\hline 200-399 & 1.062 \\
\hline $400-599$ & 1.042 \\
\hline $600+$ & 0.881 \\
\hline \multicolumn{2}{|l|}{ School sector (ref. voluntary secondary) } \\
\hline ETB & 1.038 \\
\hline Community/comprehensive & 0.961 \\
\hline School has Roman Catholic ethos & 1.148 \\
\hline \multicolumn{2}{|l|}{ Random effects } \\
\hline Between-school variation & $0.175 * * *$ \\
\hline McFadden pseudo $\mathrm{R}^{2}$ & 0.10 \\
\hline Number of schools & 589 \\
\hline Number of young people & 4090 \\
\hline
\end{tabular}

Source: GUI, '98 Cohort, waves 2 (13 years) and 3 (17 years).

Note: $\quad * * * *<.001 ;{ }^{* *} p<.01 ;{ }^{*} p<.05 ;+p<.10$. 


\begin{tabular}{|c|c|}
\hline & Coefficients \\
\hline Constant & 1.915 \\
\hline Female & $0.598 * * *$ \\
\hline Age at time of survey & 0.768 \\
\hline Has a SEN & 1.048 \\
\hline \multicolumn{2}{|c|}{ Mother's education: (ref. lower secondary or less) } \\
\hline Upper second-level & 0.946 \\
\hline Post-secondary & 0.897 \\
\hline Degree or higher & 0.989 \\
\hline \multicolumn{2}{|c|}{ Household equivalised income: (ref. Lowest quintile) } \\
\hline 2nd quintile & 0.918 \\
\hline 3rd quintile & $0.664 * * *$ \\
\hline 4th quintile & $0.732 * *$ \\
\hline 5th (highest) quintile & $0.660 * * *$ \\
\hline Migrant family & 0.993 \\
\hline Lone-parent family & $0.748^{* *}$ \\
\hline Rural area (ref. urban) & $1.155^{*}$ \\
\hline In second year (ref. first year) & 1.029 \\
\hline DEIS school & 0.946 \\
\hline Fee-paying school & 1.163 \\
\hline \multicolumn{2}{|c|}{ Gender mix of the school (ref. coeducational) } \\
\hline Single-sex boys' & 1.048 \\
\hline Single-sex girls' & 1.011 \\
\hline \multicolumn{2}{|l|}{ School size (ref. <200) } \\
\hline 200-399 & 1.225 \\
\hline $400-599$ & 1.102 \\
\hline $600+$ & 1.084 \\
\hline \multicolumn{2}{|l|}{ School sector (ref. voluntary secondary) } \\
\hline ETB & 1.441 \\
\hline Community/comprehensive & $1.619 *$ \\
\hline School has Roman Catholic ethos & $1.735^{* *}$ \\
\hline McFadden pseudo $\mathrm{R}^{2}$ & 0.10 \\
\hline Number of schools & 603 \\
\hline Number of young people & 5018 \\
\hline
\end{tabular}

Source: GUI, '98 Cohort, waves 2 (13 years) and 3 (17 years).

Note: $\quad{ }^{* * *} p<.001 ;{ }^{* *} p<.01 ;{ }^{*} p<.05 ;+p<.10$. 

(ODDS RATIOS)

\begin{tabular}{|c|c|c|}
\hline & Mother & Father \\
\hline Female & $1.50 * * *$ & $0.17 * * *$ \\
\hline Age at time of survey & 0.93 & 1.10 \\
\hline Has a SEN & 1.14 & 1.02 \\
\hline \multicolumn{3}{|c|}{$\begin{array}{l}\text { Mother's education (ref. lower secondary or } \\
\text { less) }\end{array}$} \\
\hline Upper second-level & 1.10 & 1.29 \\
\hline Post-secondary & 0.84 & 0.79 \\
\hline Degree or higher & 1.01 & 0.98 \\
\hline
\end{tabular}

Household equivalised income (ref. lowest quintile)

\begin{tabular}{|c|c|c|}
\hline 2nd quintile & 1.01 & 0.79 \\
\hline 3rd quintile & 0.90 & $0.46^{* * *}$ \\
\hline 4th quintile & 0.80 & $0.64+$ \\
\hline 5th (highest) quintile & $0.73^{+}$ & 0.81 \\
\hline Migrant family & 1.04 & 0.95 \\
\hline Lone-parent family & $1.75^{* * *}$ & 0.83 \\
\hline Rural area (ref. urban) & 0.98 & 0.95 \\
\hline \multicolumn{3}{|l|}{ School stage (ref. 5th year) } \\
\hline 6th year & 1.04 & 1.15 \\
\hline Left school & 1.25 & 1.13 \\
\hline Pianta PCG/SCG - closeness (age 13) & 1.02 & $1.06^{*}$ \\
\hline Pianta PCG/SCG - conflict (age 13) & 1.01 & $1.02+$ \\
\hline Stattin-Kerr PCG/SCG- monitoring (age 13) & 1.00 & 0.99 \\
\hline $\begin{array}{l}\text { Stattin-Kerr young person - disclosure (age } \\
\text { 13) }\end{array}$ & 1.02 & 1.01 \\
\hline $\begin{array}{l}\text { PCG/SCG network of relationship - intimacy } \\
\text { (age 17) }\end{array}$ & $1.60^{* * *}$ & $1.29 * * *$ \\
\hline $\begin{array}{l}\text { PCG/SCG network of relationship - conflict } \\
\text { (age 17) }\end{array}$ & $0.85^{* * *}$ & $0.81^{* * *}$ \\
\hline Had reached puberty at 13 & 1.20 & 0.97 \\
\hline McFadden pseudo $\mathrm{R}^{2}$ & 0.17 & 0.13 \\
\hline Number of young people & 4181 & 3824 \\
\hline
\end{tabular}

Source: GUI, '98 Cohort, wave 3 (age 17).

Note: $\quad * * * p<.001{ }^{* *} p<.01 ; * p<.05 ;+p<.10$. For the fathers' models, the Pianta, Stattin-Kerr and network of relationship inventory measures are those recorded by the secondary caregiver (SCG) (generally the father). 


\begin{tabular}{|c|c|c|c|c|c|}
\hline & $\begin{array}{c}\text { Sexual } \\
\text { intercourse }\end{array}$ & $\begin{array}{c}\text { Sexual } \\
\text { feelings/ } \\
\text { relationships }\end{array}$ & Contraception & Safer sex & $\begin{array}{c}\text { Sexual } \\
\text { orientation }\end{array}$ \\
\hline Female & $1.42^{* * *}$ & $1.42 * *$ & $1.58^{* * *}$ & $1.47^{* * *}$ & $1.57^{* * *}$ \\
\hline Age at time of survey & 1.18 & 1.05 & $0.76^{*}$ & 0.96 & 0.96 \\
\hline Has a SEN & 1.16 & 0.86 & 0.87 & 0.97 & 0.98 \\
\hline \multicolumn{6}{|l|}{$\begin{array}{l}\text { Mother's education (ref. lower } \\
\text { secondary or less) }\end{array}$} \\
\hline Upper second-level & 1.23 & 1.18 & 0.81 & 1.09 & $1.34 *$ \\
\hline Post-secondary & $1.73 * *$ & $1.72 * *$ & 0.89 & 1.04 & $1.49 * *$ \\
\hline Degree or higher & $1.77^{* * *}$ & $1.71 * *$ & 0.84 & 1.06 & $1.74 * * *$ \\
\hline \multicolumn{6}{|l|}{$\begin{array}{l}\text { Household equivalised income } \\
\text { (ref. Lowest quintile) }\end{array}$} \\
\hline 2nd quintile & 1.29 & 1.22 & 1.18 & 1.13 & $1.37 \dagger$ \\
\hline 3rd quintile & 1.29 & 1.31 & 1.06 & 1.17 & 1.21 \\
\hline 4th quintile & 1.20 & 1.16 & 1.05 & 1.02 & 1.23 \\
\hline 5th (highest) quintile & 1.14 & 1.04 & 1.01 & 1.00 & 1.17 \\
\hline Migrant family & 0.86 & $0.69 *$ & 0.80 & 0.85 & 0.83 \\
\hline Lone parent family & 1.25 & 1.31 & $1.77^{* * *}$ & $1.90^{* * *}$ & $1.82^{* * *}$ \\
\hline Rural area (ref. urban) & 0.98 & 0.97 & 1.02 & 1.00 & 0.91 \\
\hline \multicolumn{6}{|l|}{ School stage (ref. 5th year) } \\
\hline 6th year & 0.93 & 0.91 & 1.04 & 1.00 & 0.96 \\
\hline Left school & 0.83 & 0.80 & $1.38^{\dagger}$ & 1.26 & 0.81 \\
\hline Pianta PCG - closeness (age 13) & 1.02 & $1.07^{* * *}$ & $1.06^{* * *}$ & $1.06 * *$ & $1.06^{* * *}$ \\
\hline Pianta PCG - conflict (age 13) & 0.99 & 1.00 & 1.01 & 1.00 & 1.00 \\
\hline $\begin{array}{l}\text { Stattin-Kerr PCG - monitoring } \\
\text { (age 13) }\end{array}$ & 1.01 & 1.00 & 1.02 & 1.01 & 1.00 \\
\hline $\begin{array}{l}\text { Stattin-Kerr young person - } \\
\text { disclosure (age 13) }\end{array}$ & 1.02 & $1.02+$ & 1.01 & $1.04^{* *}$ & $1.06+$ \\
\hline $\begin{array}{l}\text { PCG network of relationship - } \\
\text { intimacy (age 17) }\end{array}$ & $1.09 * * *$ & $1.20^{* * *}$ & $1.12^{* * *}$ & $1.11^{* * *}$ & $1.42^{* * *}$ \\
\hline $\begin{array}{l}\text { PCG network of relationship - } \\
\text { conflict (age 17) }\end{array}$ & $1.10 * *$ & $1.10^{* * *}$ & $1.07^{*}$ & $1.06^{*}$ & $0.01 *$ \\
\hline Had reached puberty at 13 & $1.40^{* * *}$ & $1.43^{* *}$ & $1.62^{* * *}$ & $1.40^{* * *}$ & $-0.07 * * *$ \\
\hline McFadden pseudo $\mathrm{R}^{2}$ & 0.04 & 0.06 & 0.06 & 0.05 & 0.04 \\
\hline Number of young people & 4317 & 4315 & 4313 & 4311 & 4312 \\
\hline
\end{tabular}

Source: $\quad$ GUI, '98 Cohort, wave 3 (age 17).

Note: $\quad * * * p<.001 ;{ }^{* *} p<.01 ;{ }^{*} p<.05 ;+p<.10$. 
TABLE A10 LOGIT REGRESSION MODEL OF FATHERS' REPORTS OF DISCUSSIONS WITH YOUNG PERSON AT AGE 17 (ODDS RATIOS)

\begin{tabular}{|c|c|c|c|c|c|}
\hline & $\begin{array}{c}\text { Sexual } \\
\text { intercourse }\end{array}$ & $\begin{array}{c}\text { Sexual } \\
\text { feelings/ } \\
\text { relationships }\end{array}$ & Contraception & Safer sex & $\begin{array}{c}\text { Sexual } \\
\text { orientation }\end{array}$ \\
\hline Female & $0.30^{* * *}$ & $0.60^{* * *}$ & $0.34^{* * *}$ & $0.37^{* * *}$ & $0.69 * * *$ \\
\hline Age at time of survey & 1.11 & 1.14 & 1.02 & 1.00 & 1.00 \\
\hline Has a SEN & 0.95 & 1.21 & 0.97 & 1.17 & 1.11 \\
\hline \multicolumn{6}{|l|}{$\begin{array}{l}\text { Mother's education (ref. lower } \\
\text { secondary or less) }\end{array}$} \\
\hline Upper second-level & 0.85 & 0.95 & 0.81 & 0.75 & 0.93 \\
\hline Post-secondary & 1.13 & 0.97 & 0.72 & $0.68^{\dagger}$ & 0.90 \\
\hline Degree or higher & 1.27 & 1.37 & 0.80 & 0.89 & 1.05 \\
\hline \multicolumn{6}{|l|}{$\begin{array}{l}\text { Household equivalised income } \\
\text { (ref. lowest quintile) }\end{array}$} \\
\hline 2nd quintile & 1.37 & 1.08 & 1.07 & $1.49+$ & 1.23 \\
\hline 3rd quintile & $1.84^{* *}$ & $1.45^{\dagger}$ & $1.55^{\dagger}$ & 1.45 & $1.53^{*}$ \\
\hline 4th quintile & 1.43 & 1.06 & 1.02 & 1.03 & 1.31 \\
\hline 5th (highest) quintile & $1.70^{*}$ & 1.32 & 1.28 & 1.31 & $1.47^{\dagger}$ \\
\hline Migrant family & 1.14 & 1.27 & 1.11 & 1.23 & 1.28 \\
\hline Rural area (ref. urban) & $0.67^{* * *}$ & $0.64^{* * *}$ & $0.62^{* * *}$ & $0.67^{* * *}$ & $0.66^{* * *}$ \\
\hline \multicolumn{6}{|l|}{ School stage (ref. 5th year) } \\
\hline 6th year & 1.16 & 1.11 & 1.11 & 0.98 & 1.04 \\
\hline Left school & $1.56^{*}$ & 1.00 & 1.27 & 1.26 & $1.42+$ \\
\hline Pianta SCG - closeness (age 13) & $1.05^{*}$ & $1.06^{* * *}$ & $1.04 *$ & 1.03 & $1.07^{* * *}$ \\
\hline Pianta SCG - conflict (age 13) & 1.01 & 1.01 & 1.02 & $1.02^{\dagger}$ & 1.01 \\
\hline $\begin{array}{l}\text { Stattin-Kerr SCG - monitoring } \\
\text { (age 13) }\end{array}$ & $1.07^{* * *}$ & $1.04 * *$ & $1.03^{\dagger}$ & $1.04^{* *}$ & $1.04 *$ \\
\hline $\begin{array}{l}\text { Stattin-Kerr young person - } \\
\text { disclosure (age 13) }\end{array}$ & 1.00 & 1.02 & 1.01 & 1.02 & 1.01 \\
\hline $\begin{array}{l}\text { SCG network of relationship - } \\
\text { intimacy (age 17) }\end{array}$ & $1.13^{* * *}$ & $1.16^{* * *}$ & $1.18^{* * *}$ & $1.17^{* * *}$ & $1.13^{* * *}$ \\
\hline $\begin{array}{l}\text { SCG network of relationship - } \\
\text { conflict (age 17) }\end{array}$ & 1.05 & 0.98 & 1.01 & 1.02 & 1.00 \\
\hline Had reached puberty at 13 & 1.09 & 1.11 & 1.21 & 0.24 & $1.29 *$ \\
\hline McFadden pseudo $\mathrm{R}^{2}$ & 0.09 & 0.05 & 0.08 & 0.07 & 0.05 \\
\hline Number of young people & 2602 & 2603 & 2603 & 2603 & 2603 \\
\hline
\end{tabular}

Source: GUI, '98 Cohort, wave 3 (age 17).

Note: $\quad * * * p<.001 ;{ }^{* *} p<.01 ;{ }^{*} p<.05 ;+p<.10$. 

SEX, AGE 13 (ODDS RATIOS, RELATIVE TO PARENTS/FAMILY)

\begin{tabular}{|c|c|c|c|c|}
\hline & Friends & Teacher & $\begin{array}{l}\text { Internet/ } \\
\text { TV/books/ } \\
\text { films }\end{array}$ & Nowhere \\
\hline Female & $0.72 * *$ & $0.59 * * *$ & $0.51 * * *$ & $0.59 * * *$ \\
\hline Age at time of survey & 1.70 & 0.95 & 2.24 & 1.14 \\
\hline Has a SEN & $0.67+$ & 0.86 & 0.55 & 1.39 \\
\hline \multicolumn{5}{|l|}{ Mother's education (ref. lower secondary or less) } \\
\hline Upper second-level & $1.55^{*}$ & $1.56^{*}$ & 1.53 & 0.93 \\
\hline Post-secondary & 1.22 & 1.31 & $2.36^{* *}$ & 0.74 \\
\hline Degree or higher & 1.27 & 1.49 & 1.37 & 0.93 \\
\hline \multicolumn{5}{|l|}{$\begin{array}{l}\text { Household equivalised income (ref. lowest } \\
\text { quintile) }\end{array}$} \\
\hline 2nd quintile & 0.83 & 1.40 & 0.98 & 0.94 \\
\hline 3rd quintile & 0.94 & 0.90 & 1.20 & $0.63^{*}$ \\
\hline 4th quintile & 0.99 & 0.83 & 1.34 & 0.74 \\
\hline 5th (highest) quintile & 1.23 & 0.86 & $1.74 \dagger$ & $0.66^{*}$ \\
\hline Migrant family & 0.98 & 0.82 & 1.23 & 1.04 \\
\hline Lone-parent family & $0.75+$ & 1.08 & 1.37 & 1.16 \\
\hline Rural area (ref. urban) & $0.83+$ & 0.80 & 1.11 & $0.78+$ \\
\hline In 2nd year (ref. 1st year) & $1.02+$ & $1.44^{* *}$ & 1.06 & 0.91 \\
\hline Pianta PCG - closeness (age 13) & $0.92 * * *$ & $0.94 *$ & $0.95+$ & $0.90 * * *$ \\
\hline Pianta PCG - conflict (age 13) & $1.02 * * *$ & 0.99 & 1.01 & 1.00 \\
\hline Stattin-Kerr PCG - monitoring (age 13) & 1.02 & $0.97+$ & 1.01 & 1.01 \\
\hline Stattin-Kerr young person - disclosure (age 13) & 1.01 & 1.01 & 1.01 & 1.01 \\
\hline Peer relationships - alienation (age 13) & 1.02 & 0.97 & $1.04^{*}$ & 1.00 \\
\hline Peer relationships - trust (age 13) & 0.99 & 1.00 & $0.96^{*}$ & $0.97 * *$ \\
\hline Had reached puberty at 13 & $1.48 * * *$ & 0.85 & 1.21 & $0.65 * * *$ \\
\hline McFadden pseudo $\mathrm{R}^{2}$ & \multicolumn{4}{|c|}{0.04} \\
\hline Number of young people & \multicolumn{4}{|c|}{4594} \\
\hline
\end{tabular}

Source: GUI, '98 Cohort, wave 2 (age 13).

Note: $\quad * * * p<.001 ; * * p<.01 ; * p<.05 ;+p<.10$. 
TABLE A12 MULTINOMIAL LOGIT REGRESSION MODEL OF MAIN SOURCE OF INFORMATION ON SEX, AGE 17 (ODDS RATIOS, RELATIVE TO PARENTS/FAMILY)

\begin{tabular}{|c|c|c|c|c|}
\hline & Friends & Teacher & $\begin{array}{l}\text { Internet/ } \\
\text { TV/Books/ } \\
\text { Films }\end{array}$ & Nowhere \\
\hline Female & 0.96 & $0.711^{\dagger}$ & 0.89 & $0.61+$ \\
\hline Age at time of survey & 0.98 & 0.74 & 1.05 & 0.78 \\
\hline Has a SEN & $0.55^{* *}$ & 1.26 & $0.49 *$ & 0.77 \\
\hline \multicolumn{5}{|l|}{$\begin{array}{l}\text { Mother's education (ref. Lower secondary or } \\
\text { less) }\end{array}$} \\
\hline Upper second-level & 0.96 & $0.64{ }^{\dagger}$ & 0.75 & 1.68 \\
\hline Post-secondary & 1.13 & $0.59 \dagger$ & 0.83 & 1.22 \\
\hline Degree or higher & 1.33 & 0.69 & 1.04 & $2.14^{\dagger}$ \\
\hline \multicolumn{5}{|l|}{$\begin{array}{l}\text { Household equivalised income (ref. Lowest } \\
\text { quintile) }\end{array}$} \\
\hline 2nd quintile & 0.97 & 1.15 & $1.61^{\dagger}$ & 1.18 \\
\hline 3rd quintile & 1.10 & 0.77 & $2.04 * *$ & 1.21 \\
\hline 4th quintile & 1.21 & 1.53 & $2.21^{* *}$ & 1.12 \\
\hline 5th (highest) quintile & 1.30 & 0.91 & $2.16^{* *}$ & 0.92 \\
\hline Migrant family & $0.74{ }^{\dagger}$ & 0.75 & 1.00 & 1.01 \\
\hline Lone-parent family & $0.66 *$ & $0.63^{\dagger}$ & 0.94 & 0.72 \\
\hline Rural area (ref. urban) & 0.85 & 0.84 & 1.13 & 1.16 \\
\hline \multicolumn{5}{|l|}{ School stage (ref. 5th year) } \\
\hline 6th year & 1.26 & 0.86 & $1.39 *$ & $1.74 \dagger$ \\
\hline Left school & 1.06 & 0.67 & 0.90 & $2.51^{*}$ \\
\hline Pianta PCG - closeness (age 13) & 0.97 & 0.99 & $0.95^{\dagger}$ & 1.01 \\
\hline Pianta PCG - conflict (age 13) & 0.99 & 0.98 & 0.98 & $1.04+$ \\
\hline Stattin-Kerr PCG - monitoring (age 13) & 0.99 & 0.99 & 1.00 & 0.99 \\
\hline Stattin-Kerr young person - disclosure (age 13) & 0.99 & 1.02 & 1.00 & 0.96 \\
\hline PCG network of relationship - intimacy (age 17) & $0.68^{* * *}$ & $0.75^{* * *}$ & $0.69 * * *$ & $0.66^{* * *}$ \\
\hline PCG network of relationship - conflict (age 17) & $1.08^{*}$ & 1.03 & $1.09+$ & $0.74 * *$ \\
\hline Peer relationships - alienation (age 13) & 1.01 & 0.98 & $1.04+$ & 0.99 \\
\hline Peer relationships - trust (age 13) & 1.01 & 1.00 & 1.00 & $0.96^{*}$ \\
\hline Had reached puberty at 13 & 1.10 & $0.69+$ & $1.43 * *$ & 0.94 \\
\hline McFadden pseudo $\mathrm{R}^{2}$ & \multicolumn{4}{|c|}{0.06} \\
\hline Number of young people & \multicolumn{4}{|c|}{3786} \\
\hline
\end{tabular}

Source: GUI, '98 Cohort, wave 3 (age 17).

Note: $\quad * * * p<.001 ; * * p<.01 ;{ }^{*} p<.05 ;{ }^{\dagger} p<.10$. 


\begin{tabular}{|c|c|c|}
\hline & Age 13 & Age 17 \\
\hline Constant & 0.006 & 27.605 \\
\hline Female & $0.623^{* *}$ & 0.823 \\
\hline Age at time of survey & 1.465 & 0.551 \\
\hline Has a SEN & 0.845 & $1.610 *$ \\
\hline \multicolumn{3}{|c|}{ Mother's education (ref. lower secondary or less) } \\
\hline Upper second-level & 0.956 & 0.828 \\
\hline Post-secondary & 0.969 & 0.946 \\
\hline Degree or higher & 1.030 & 0.629 \\
\hline \multicolumn{3}{|c|}{ Household equivalised income (ref. lowest quintile) } \\
\hline 2nd quintile & 0.805 & 0.970 \\
\hline 3rd quintile & 1.099 & 0.624 \\
\hline 4th quintile & 0.821 & 0.868 \\
\hline 5th (highest) quintile & 0.712 & 0.801 \\
\hline Migrant family & 0.959 & 0.905 \\
\hline Lone-parent family & 0.861 & $0.479 * *$ \\
\hline Rural area (ref. urban) & 0.815 & $-0.295^{*}$ \\
\hline In second year (ref. first year) & $1.399 * *$ & \\
\hline In sixth year (ref. fifth year) & & 0.765 \\
\hline Left school & & $0.576^{*}$ \\
\hline DEIS school & 0.759 & 1.158 \\
\hline Fee-paying school & 1.334 & 0.649 \\
\hline \multicolumn{3}{|c|}{ Gender mix of the school: (ref. coeducational) } \\
\hline Single-sex boys' & 0.676 & 0.796 \\
\hline Single-sex girls' & 1.156 & 0.910 \\
\hline \multicolumn{3}{|l|}{ School size (ref. <200) } \\
\hline 200-399 & 0.789 & 0.967 \\
\hline $400-599$ & 0.746 & 1.223 \\
\hline $600+$ & 0.734 & 0.978 \\
\hline \multicolumn{3}{|l|}{ School sector (ref. voluntary secondary) } \\
\hline ETB & 1.492 & 1.728 \\
\hline Community/comprehensive & 1.394 & 2.123 \\
\hline School has Roman Catholic ethos & 1.376 & 1.694 \\
\hline McFadden pseudo $\mathrm{R}^{2}$ & 0.01 & 0.03 \\
\hline Number of young people & 6644 & 6695 \\
\hline
\end{tabular}

Source: GUI, '98 Cohort, waves 2 (age 13) and 3 (age 17).

Note: $\quad * * * p<.001{ }^{* *} p<.01{ }^{*} p<.05 ;{ }^{\dagger} p<.10$. 

INTERCOURSE AT AGE 17 (ODDS RATIOS)

\begin{tabular}{|c|c|}
\hline & Coefficient \\
\hline \multicolumn{2}{|l|}{ Fixed effects } \\
\hline Female & $0.839+$ \\
\hline Age at survey & $2.016^{*}$ \\
\hline Has a SEN & $0.655^{* *}$ \\
\hline \multicolumn{2}{|c|}{ Mother's education (ref. lower secondary or less) } \\
\hline Upper second-level & 0.968 \\
\hline Post-secondary & 0.842 \\
\hline Degree or higher & $0.798+$ \\
\hline \multicolumn{2}{|c|}{ Household equivalised income (ref. lowest quintile) } \\
\hline 2nd quintile & 1.208 \\
\hline 3rd quintile & $1.448^{*}$ \\
\hline 4th quintile & $1.493 * *$ \\
\hline 5th (highest) quintile & 1.275 \\
\hline Migrant family & 1.060 \\
\hline Lone-parent family & $1.631^{* * *}$ \\
\hline Living in a rural area & 1.031 \\
\hline Sixth year & 1.190 \\
\hline Left school & $1.809^{* * *}$ \\
\hline DEIS school & 0.992 \\
\hline Fee-paying school & 0.944 \\
\hline \multicolumn{2}{|l|}{ Gender mix of school: } \\
\hline Single-sex boys' & 0.952 \\
\hline Single-sex girls' & 0.935 \\
\hline \multicolumn{2}{|l|}{ School size } \\
\hline 200-399 & 0.770 \\
\hline $400-599$ & 0.849 \\
\hline $600+$ & 0.887 \\
\hline \multicolumn{2}{|l|}{ School sector } \\
\hline ETB & 0.791 \\
\hline Community/comprehensive & 0.967 \\
\hline Roman Catholic ethos & 0.911 \\
\hline Receipt of RSE & \\
\hline Late & 0.979 \\
\hline Early & 0.827 \\
\hline None & 0.824 \\
\hline Discussed sex with parents at 13 & $1.230 *$ \\
\hline Reached puberty by 13 & $1.347^{* *}$ \\
\hline
\end{tabular}




\section{Coefficient}

Source of most information on sex at age 13

\begin{tabular}{|c|c|}
\hline Friends & $1.611 * * *$ \\
\hline Teacher & 0.957 \\
\hline Internet & 0.759 \\
\hline Books/magazines/TV & 0.715 \\
\hline Nowhere & 0.984 \\
\hline Closeness with PCG & 0.995 \\
\hline Conflict with PCG & $1.013+$ \\
\hline Junior Certificate grade point average & $0.899 * *$ \\
\hline Positive interaction with teachers & 0.972 \\
\hline Negative interaction with teachers & $1.320 * * *$ \\
\hline \multicolumn{2}{|l|}{ Attitude to school } \\
\hline Like it quite a bit & 0.977 \\
\hline Like it a bit & 0.906 \\
\hline Don't like it & 0.882 \\
\hline Hate it & 0.836 \\
\hline Size of friendship network & $1.373 * * *$ \\
\hline Some friends more than two years older & 0.895 \\
\hline Most/all friends more than two years older & 0.791 \\
\hline \multicolumn{2}{|l|}{ Random effects } \\
\hline Between-school variation & 0.030 \\
\hline McFadden pseudo $\mathrm{R}^{2}$ & 0.38 \\
\hline No. of schools & 576 \\
\hline Number of young people & 3856 \\
\hline
\end{tabular}

Source: GUI, '98 Cohort, waves 2 (age 13) and 3 (age 17).

Note: $\quad{ }^{* * *} p<.001 ;{ }^{* *} p<.01 ;{ }^{*} p<.05 ;+p<.10$. 

SEXUAL INTERCOURSE AT AGE 17 (ODDS RATIOS)

\begin{tabular}{|c|c|}
\hline & Coefficient \\
\hline \multicolumn{2}{|l|}{ Fixed effects } \\
\hline Constant & 0.002 \\
\hline Female & $0.740^{* *}$ \\
\hline Age at time of survey & 1.415 \\
\hline Has a SEN & $0.686^{* *}$ \\
\hline \multicolumn{2}{|c|}{ Mother's education (ref. lower secondary or less) } \\
\hline Upper second-level & 0.995 \\
\hline Post-secondary & 0.863 \\
\hline Degree or higher & 0.884 \\
\hline \multicolumn{2}{|c|}{ Household equivalised income (ref. lowest quintile) } \\
\hline 2nd quintile & 1.228 \\
\hline 3rd quintile & $1.374^{*}$ \\
\hline 4th quintile & $1.366^{*}$ \\
\hline 5th (highest) quintile & 1.309 \\
\hline Migrant family & 1.021 \\
\hline Lone-parent family & $1.650 * * *$ \\
\hline Rural area (ref. urban) & 0.941 \\
\hline In sixth year (ref. fifth year) & $1.210^{*}$ \\
\hline Left school & $1.636^{* * *}$ \\
\hline DEIS school & 0.969 \\
\hline Fee-paying school & 1.117 \\
\hline \multicolumn{2}{|c|}{ Gender mix of the school (ref. coeducational) } \\
\hline Single-sex boys' & 1.196 \\
\hline Single-sex girls' & 1.049 \\
\hline \multicolumn{2}{|l|}{ School size (ref. <200) } \\
\hline $200-399$ & 1.525 \\
\hline 400-599 & 1.527 \\
\hline $600+$ & 1.426 \\
\hline \multicolumn{2}{|l|}{ School sector (ref. voluntary secondary) } \\
\hline ETB & 1.376 \\
\hline Community/comprehensive & 1.087 \\
\hline School has Roman Catholic ethos & 1.040 \\
\hline Receipt of RSE & \\
\hline Late receipt & 1.013 \\
\hline Early receipt & 1.004 \\
\hline No receipt & 1.125 \\
\hline Discussed sex with parents at 13 & 1.153 \\
\hline
\end{tabular}


Coefficient

Reached puberty by 13

1.169

Main source of information on sex

Friends

$1.559 * * *$

Teacher

0.995

Internet

$1.675^{* *}$

Books/magazines/TV

$1.534^{*}$

Nowhere

0.951

Closeness with PCG at 13

0.998

Conflict with PCG at 13

$1.015^{*}$

Junior Certificate grade point average

0.969

Positive interaction with teachers at 13

0.972

Negative interaction with teachers at 13

$1.309 * * *$

Attitude to school (ref. like it very much)

\begin{tabular}{|l|r|}
\hline \multicolumn{1}{|c|}{ Like it quite a bit } & 1.001 \\
\hline \multicolumn{1}{|c|}{ Like it a bit } & 0.971 \\
\hline \multicolumn{1}{|c|}{ Don't like it very much } & 1.168 \\
\hline Size of friendship network & 0.868 \\
\hline Some friends more than two years older (ref. none) & $1.350 * * *$ \\
\hline Most or all friends more than two years older & 1.026 \\
\hline Random effects & 1.031 \\
\hline Between-school variation & 0.028 \\
\hline McFadden pseudo R & 0.38 \\
\hline Number of schools & 576 \\
\hline Number of young people & 3856 \\
\hline
\end{tabular}

Source: GUI, '98 Cohort, waves 2 (age 13) and 3 (age 17).

Note: $\quad * * * p<.001{ }^{* *} p<.01 ;{ }^{*} p<.05 ;+p<.10$. 

FRIENDS HAD HAD SEX (ODDS RATIOS)

\begin{tabular}{|c|c|}
\hline & Coefficient \\
\hline \multicolumn{2}{|l|}{ Fixed effects } \\
\hline Female & $1.562 * * *$ \\
\hline Age at survey & 1.035 \\
\hline Has a SEN & $0.719 *$ \\
\hline \multicolumn{2}{|c|}{ Mother's education (ref. lower secondary or less) } \\
\hline Upper second-level & 0.932 \\
\hline Post-secondary & $0.757^{*}$ \\
\hline Degree or higher & 0.000 \\
\hline \multicolumn{2}{|c|}{ Household equivalised income (ref. lowest quintile) } \\
\hline 2nd quintile & 1.091 \\
\hline 3rd quintile & 1.151 \\
\hline 4th quintile & 1.283 \\
\hline 5th (highest) quintile & 1.189 \\
\hline Migrant family & 0.916 \\
\hline Lone-parent family & $1.332 *$ \\
\hline Living in a rural area & 0.962 \\
\hline Sixth year & $1.721 * * *$ \\
\hline Left school & $4.768 * * *$ \\
\hline DEIS school & 1.022 \\
\hline Fee-paying school & 0.910 \\
\hline \multicolumn{2}{|l|}{ Gender mix of school } \\
\hline Single-sex boys' & 1.125 \\
\hline Single-sex girls' & 1.070 \\
\hline \multicolumn{2}{|l|}{ School size } \\
\hline $200-399$ & 1.359 \\
\hline 400-599 & 1.484 \\
\hline $600+$ & 1.376 \\
\hline \multicolumn{2}{|l|}{ School sector } \\
\hline ETB & 0.816 \\
\hline Community/comprehensive & 0.787 \\
\hline Roman Catholic ethos & 0.732 \\
\hline Receipt of RSE & \\
\hline Late & 0.914 \\
\hline Early & 1.168 \\
\hline None & 1.183 \\
\hline Discussed sex with parents at 13 & 0.999 \\
\hline Reached puberty by 13 & 0.856 \\
\hline
\end{tabular}




\section{Coefficient}

Source of most information on sex at age 13

\begin{tabular}{|c|c|}
\hline Friends & $1.220+$ \\
\hline Teacher & 0.822 \\
\hline Internet & 1.004 \\
\hline Books/magazines/TV & 1.186 \\
\hline Nowhere & 1.116 \\
\hline Closeness with PCG & 1.012 \\
\hline Conflict with PCG & 1.013 \\
\hline Junior Certificate grade point average & $0.791 * * *$ \\
\hline Positive interaction with teachers & 1.010 \\
\hline Negative interaction with teachers & $1.209 * * *$ \\
\hline \multicolumn{2}{|l|}{ Attitude to school } \\
\hline Like it quite a bit & 1.058 \\
\hline Like it a bit & 1.191 \\
\hline Don't like it & $1.443^{*}$ \\
\hline Hate it & $2.136^{*}$ \\
\hline Size of friendship network & $1.459 * * *$ \\
\hline Some friends more than two years older & $1.249 *$ \\
\hline Most/all friends more than two years older & 1.331 \\
\hline \multicolumn{2}{|l|}{ Random effects } \\
\hline Between-school variation & $0.121 * *$ \\
\hline McFadden pseudo $\mathrm{R}^{2}$ & 0.39 \\
\hline Number of schools & 572 \\
\hline Number of young people & 3666 \\
\hline
\end{tabular}

Source: GUI, '98 Cohort, waves 2 (13 years) and 3 (age 17).

Note: $\quad{ }^{* * *} p<.001 ;{ }^{* *} p<.01 ;{ }^{*} p<.05 ;+p<.10$. 
TABLE A17 MULTILEVEL LOGISTIC REGRESSION MODEL OF USE OF CONTRACEPTION AT FIRST SEXUAL INTERCOURSE (ODDS RATIOS)

\begin{tabular}{|c|c|}
\hline & Coefficients \\
\hline \multicolumn{2}{|l|}{ Fixed effects } \\
\hline Female & 1.035 \\
\hline Age at survey & 1.229 \\
\hline Has a SEN & 1.716 \\
\hline \multicolumn{2}{|c|}{ Mother's education (ref. lower secondary or less) } \\
\hline Upper second-level & 1.073 \\
\hline Post-secondary & 1.183 \\
\hline Degree or higher & 0.706 \\
\hline \multicolumn{2}{|c|}{ Household equivalised income (ref. lowest quintile) } \\
\hline 2nd quintile & 0.981 \\
\hline 3rd quintile & 1.560 \\
\hline 4th quintile & 1.717 \\
\hline 5th (highest) quintile & 1.373 \\
\hline Migrant family & 0.962 \\
\hline Lone-parent family & 0.999 \\
\hline Living in a rural area & 0.952 \\
\hline Sixth year & 1.207 \\
\hline Left school & $2.083+$ \\
\hline DEIS school & 0.738 \\
\hline Fee-paying school & 0.789 \\
\hline \multicolumn{2}{|l|}{ Gender mix of school } \\
\hline Single-sex boys' & 1.197 \\
\hline Single-sex girls' & 0.991 \\
\hline \multicolumn{2}{|l|}{ School size } \\
\hline 200-399 & 0.374 \\
\hline $400-599$ & 0.338 \\
\hline $600+$ & 0.481 \\
\hline \multicolumn{2}{|l|}{ School sector } \\
\hline ETB & 0.855 \\
\hline Community/comprehensive & 0.726 \\
\hline Roman Catholic ethos & 0.744 \\
\hline \multicolumn{2}{|l|}{ Receipt of RSE } \\
\hline Late & 1.069 \\
\hline Early & 0.649 \\
\hline None & 1.153 \\
\hline Discussed sex with parents at 13 & $1.682^{*}$ \\
\hline Reached puberty by 13 & $1.747 \dagger$ \\
\hline
\end{tabular}


Coefficients

Source of most information on sex at age 13

\begin{tabular}{|l|c|}
\hline Friends & $0.596^{*}$ \\
\hline Teacher & 1.402 \\
\hline Internet & 0.626 \\
\hline Books/magazines/TV & 1.822 \\
\hline Nowhere & $2.512 \dagger$ \\
\hline Closeness with PCG & 0.964 \\
\hline Conflict with PCG & 0.974 \\
\hline Junior Certificate grade point average & $1.430 * * *$ \\
\hline Positive interaction with teachers & 1.018 \\
\hline Negative interaction with teachers & $0.837 *$ \\
\hline Attitude to school & \\
\hline \multicolumn{1}{|c|}{ Like it quite a bit } & 1.020 \\
\hline \multicolumn{1}{|c|}{ Like it a bit } & 0.904 \\
\hline Don't like it & 1.510 \\
\hline Hate it & 1.597 \\
\hline Size of friendship network & 1.046 \\
\hline Some friends more than two years older & 0.829 \\
\hline Most/all friends more than two years older & 1.293 \\
\hline Number & $0.480 * *$ \\
\hline Mand friends have had sex & \\
\hline
\end{tabular}

Source: GUI, '98 Cohort, waves 2 (age 13) and 3 (age 17).

Note: $\quad * * * p<.001{ }^{* *} p<.01 ;{ }^{*} p<.05 ;+p<.10$. 
MULTILEVEL LOGISTIC REGRESSION MODEL OF REGRET AT TIMING OF FIRST SEXUAL INTERCOURSE (ODDS RATIOS)

\begin{tabular}{|c|c|}
\hline & Coefficient \\
\hline \multicolumn{2}{|l|}{ Fixed effects } \\
\hline Female & $1.408^{\dagger}$ \\
\hline Age at survey & 1.471 \\
\hline Has a SEN & $0.611^{\dagger}$ \\
\hline \multicolumn{2}{|c|}{ Mother's education (ref. lower secondary or less) } \\
\hline Upper second-level & 0.861 \\
\hline Post-secondary & 0.882 \\
\hline Degree or higher & 1.122 \\
\hline \multicolumn{2}{|c|}{ Household equivalised income (ref. lowest quintile) } \\
\hline 2nd quintile & 1.471 \\
\hline 3rd quintile & 1.443 \\
\hline 4th quintile & 1.022 \\
\hline 5th (highest) quintile & 1.143 \\
\hline Migrant family & 1.121 \\
\hline Lone-parent family & 0.876 \\
\hline Living in a rural area & 0.951 \\
\hline Sixth year & 0.952 \\
\hline Left school & 0.910 \\
\hline DEIS school & 1.119 \\
\hline Fee-paying school & 1.000 \\
\hline \multicolumn{2}{|l|}{ Gender mix of school } \\
\hline Single-sex boys' & 0.757 \\
\hline \multirow{2}{*}{\multicolumn{2}{|c|}{$\begin{array}{l}\text { Single-sex girls } \\
\text { School size }\end{array}$}} \\
\hline & \\
\hline 200-399 & 0.582 \\
\hline $400-599$ & 0.535 \\
\hline $600+$ & 0.679 \\
\hline \multicolumn{2}{|l|}{ School sector } \\
\hline ETB & 0.759 \\
\hline Community/comprehensive & 0.690 \\
\hline Roman Catholic ethos & 0.866 \\
\hline Receipt of RSE & \\
\hline Late & 1.133 \\
\hline Early & 0.844 \\
\hline None & 1.281 \\
\hline Discussed sex with parents at 13 & 1.208 \\
\hline Reached puberty by 13 & 0.918 \\
\hline
\end{tabular}




\section{Coefficient}

Source of most information on sex at age 13

\begin{tabular}{|c|c|}
\hline Friends & 1.135 \\
\hline Teacher & 0.904 \\
\hline Internet & 1.380 \\
\hline Books/magazines/TV & 0.578 \\
\hline Nowhere & 0.949 \\
\hline Closeness with PCG & 1.014 \\
\hline Conflict with PCG & $1.038 * *$ \\
\hline Junior Certificate grade point average & $0.875^{*}$ \\
\hline Positive interaction with teachers & 0.960 \\
\hline Negative interaction with teachers & 0.982 \\
\hline Attitude to school & \\
\hline Like it quite a bit & 1.028 \\
\hline Like it a bit & $1.468^{*}$ \\
\hline Don't like it & 1.169 \\
\hline Hate it & 1.047 \\
\hline Size of friendship network & 1.113 \\
\hline Some friends more than two years older & 1.162 \\
\hline Most/all friends more than two years older & 0.679 \\
\hline Most/all friends have had sex & 1.102 \\
\hline Random effects & \\
\hline Between-school variation & 0.108 \\
\hline McFadden pseudo $\mathrm{R}^{2}$ & 0.32 \\
\hline Number of schools & 460 \\
\hline Number of young people & 1262 \\
\hline
\end{tabular}

Source: GUI, '98 Cohort, waves 2 (age 13) and 3 (age 17).

Note: $\quad{ }^{* * *} p<.001 ;{ }^{* *} p<.01 ;{ }^{*} p<.05 ;+p<.10$. 


\begin{tabular}{|c|c|}
\hline & Coefficient \\
\hline \multicolumn{2}{|l|}{ Fixed effects } \\
\hline Female & 0.834 \\
\hline Age at survey & 0.604 \\
\hline Has a SEN & 1.157 \\
\hline \multicolumn{2}{|c|}{ Mother's education (ref. lower secondary or less) } \\
\hline Upper second-level & 0.975 \\
\hline Post-secondary & 1.110 \\
\hline Degree or higher & 1.005 \\
\hline \multicolumn{2}{|c|}{ Household equivalised income (ref. lowest quintile) } \\
\hline 2nd quintile & 0.745 \\
\hline 3rd quintile & 0.964 \\
\hline 4th quintile & 0.825 \\
\hline 5th (highest) quintile & 0.881 \\
\hline Migrant family & 0.968 \\
\hline Lone-parent family & 0.776 \\
\hline Living in a rural area & 1.239 \\
\hline Sixth year & 0.979 \\
\hline Left school & 0.968 \\
\hline DEIS school & 1.029 \\
\hline Fee-paying school & 1.230 \\
\hline \multicolumn{2}{|l|}{ Gender mix of school } \\
\hline Single-sex boys' & 1.120 \\
\hline Single-sex girls' & 1.611 \\
\hline \multicolumn{2}{|l|}{ School size } \\
\hline 200-399 & 0.598 \\
\hline $400-599$ & 0.788 \\
\hline $600+$ & 0.827 \\
\hline \multicolumn{2}{|l|}{ School sector } \\
\hline ETB & 1.013 \\
\hline Community/comprehensive & 0.899 \\
\hline Roman Catholic ethos & 0.972 \\
\hline Receipt of RSE & \\
\hline Late & 1.022 \\
\hline Early & 0.899 \\
\hline None & $1.716^{\dagger}$ \\
\hline Discussed sex with parents at 13 & 0.873 \\
\hline Reached puberty by 13 & 0.836 \\
\hline
\end{tabular}




\section{Coefficient}

Source of most information on sex at age 13

\begin{tabular}{|c|c|}
\hline Friends & 0.986 \\
\hline Teacher & 1.196 \\
\hline Internet & 0.658 \\
\hline Books/magazines/TV & 1.289 \\
\hline Nowhere & 1.251 \\
\hline Closeness with PCG & 1.017 \\
\hline Conflict with PCG & $0.974 *$ \\
\hline Junior Certificate grade point average & $1.198 * *$ \\
\hline Positive interaction with teachers & 1.040 \\
\hline Negative interaction with teachers & $0.889 *$ \\
\hline \multicolumn{2}{|l|}{ Attitude to school } \\
\hline Like it quite a bit & 0.824 \\
\hline Like it a bit & 0.934 \\
\hline Don't like it & 1.122 \\
\hline Hate it & 0.792 \\
\hline Size of friendship network & 0.987 \\
\hline Some friends more than two years older & 0.839 \\
\hline Most/all friends more than two years older & 0.696 \\
\hline \multicolumn{2}{|l|}{ Random effects } \\
\hline Between-school variation & 0.111 \\
\hline McFadden pseudo $\mathrm{R}^{2}$ & 0.32 \\
\hline Number of schools & 457 \\
\hline Number of young people & 1216 \\
\hline
\end{tabular}

Source: GUI, '98 Cohort, waves 2 (age 13) and 3 (age 17).

Note: $\quad{ }^{* * *} p<.001 ;{ }^{* *} p<.01 ;{ }^{*} p<.05 ;+p<.10$. 

AGE 17 (ODDS RATIOS)

\begin{tabular}{|c|c|}
\hline & Coefficient \\
\hline \multicolumn{2}{|l|}{ Fixed effects } \\
\hline Female & 1.018 \\
\hline Age at survey & 0.588 \\
\hline Has a SEN & 1.181 \\
\hline \multicolumn{2}{|c|}{ Mother's education (ref. lower secondary or less) } \\
\hline Upper second-level & 0.866 \\
\hline Post-secondary & 1.111 \\
\hline Degree or higher & 0.824 \\
\hline \multicolumn{2}{|c|}{ Household equivalised income (ref. lowest quintile) } \\
\hline 2nd quintile & 0.948 \\
\hline 3rd quintile & 0.861 \\
\hline 4th quintile & 1.499 \\
\hline 5th (highest) quintile & 1.592 \\
\hline Migrant family & 0.910 \\
\hline Lone-parent family & 1.033 \\
\hline Living in a rural area & 1.128 \\
\hline Sixth year & 1.035 \\
\hline Left school & 1.037 \\
\hline DEIS school & 0.891 \\
\hline Fee-paying school & 1.230 \\
\hline \multicolumn{2}{|l|}{ Gender mix of school: } \\
\hline Single-sex boys' & 1.091 \\
\hline \multirow{2}{*}{\multicolumn{2}{|c|}{$\begin{array}{l}\text { Single-sex girls' } \\
\text { School size }\end{array}$}} \\
\hline & \\
\hline $200-399$ & 0.527 \\
\hline $400-599$ & 0.480 \\
\hline $600+$ & 0.536 \\
\hline \multicolumn{2}{|l|}{ School sector } \\
\hline ETB & 1.013 \\
\hline Community/comprehensive & 0.899 \\
\hline Roman Catholic ethos & 0.972 \\
\hline Receipt of RSE & \\
\hline Late & 1.038 \\
\hline Early & 0.580 \\
\hline None & 3.059 \\
\hline Discussed sex with parents at 13 & 1.107 \\
\hline Reached puberty by 13 & $0.836+$ \\
\hline
\end{tabular}




\section{Coefficient}

Source of most information on sex at age 13

\begin{tabular}{l|c}
\hline Friends & 0.812 \\
\hline Teacher & 0.926 \\
\hline Internet & 0.791 \\
\hline Books/magazines/TV & 0.763 \\
\hline Nowhere & 0.985 \\
\hline Closeness with PCG & 1.006 \\
\hline Conflict with PCG & 0.974 \\
\hline Junior Certificate grade point average & $1.198 *$ \\
\hline Positive interaction with teachers & 1.037 \\
\hline Negative interaction with teachers & 1.014
\end{tabular}

Attitude to school (Ref. like it very much)

Like it quite a bit

Like it a bit

0.934

Don't like it

1.267

Hate it

1.260

Size of friendship network

1.006

Some friends more than two years older

0.832

Most/all friends more than two years older

1.334

Random effects

Between-school variation

McFadden pseudo $\mathrm{R}^{2}$

0.29

Number of schools

Number of young people

1192

Source: GUI, '98 Cohort, waves 2 (age 13) and 3 (age 17).

Note: $\quad{ }^{* * *} p<.001 ;{ }^{* *} p<.01 ;{ }^{*} p<.05 ;+p<.10$. 



\section{REFERENCES}

Belsky, J., L. Steinberg, R.M. Houts, and B. L. Halpern-Felsher (2010). 'The development of reproductive strategy in females: early maternal harshness $\rightarrow$ earlier menarche $\rightarrow$ increased sexual risk taking', Developmental Psychology, Vol. 46, No. 1, pp. 120128.

Blenkinsop, S., P. Wade, T. Benton, M. Gnaldi, and S. Schagen (2004). Evaluation of the APAUSE SRE Programme, London: Teenage Pregnancy Unit.

Bonell, C., E. Allen, V. Strange, A. Oakley, A. Copas, A. Johnson, and J. Stephenson (2006). 'Influence of family type and parenting behaviours on teenage sexual behaviour and conceptions ', Journal of Epidemiology \& Community Health, Vol. 60, No. 6. https://doi.org/10.1136/jech.2005.042838

Burke, L., S. Nic Gabhainn, and C. Kelly (2018). 'Socio-Demographic, Health and Lifestyle Factors Influencing Age of Sexual Initiation among Adolescents', International Journal of Environmental Research and Public Health, Vol. 15, No. 9, p. 1851.

Coleman, L. and A. Testa (2007). 'Sexual health knowledge, attitudes and behaviours among an ethnically diverse sample of young people in the UK', Health Education Journal, Vol. 66, No. 1, pp. 68-81.

Conlon, C. (2018). Supporting parents communicating with children aged 4-9 years about relationships, sexuality and growing Up, HSE Sexual Health and Crisis Pregnancy Programme Report No. 27, Dublin: HSE.

de Looze, M., A. Madkour, T. Huijts, N. Moreau, and C. Currie (2019). 'Country-level gender equality and adolescents' contraceptive use in Europe, Canada and Israel: findings from 33 countries', Perspectives on Sexual and Reproductive Health, Vol. 51, No. 1, pp. 43-53.

de Looze, M., T. ter Bogt, Q. Raaijmakers, W. Pickett, E. Kuntsche, and W. Vollebergh (2014). 'Cross-national evidence for the clustering and psychosocial correlates of adolescent risk behaviours in 27 countries', European Journal of Public Health, Vol. 25, No. 1, pp. 50-56.

Department of Children and Youth Affairs (2014). Better Outcomes, Brighter Futures, Dublin: Stationery Office.

Department of Education and Science (2009). Social, Personal and Health Education (SPHE) in the primary school: Inspectors' evaluation studies, Dublin: Inspectorate Evaluation and Support Unit, DES.

Department of Education and Skills (2013). Looking at Social, Personal and Health Education: Teaching and learning in post-primary schools, Dublin: DES.

Department of Education and Skills (2015). Framework for Junior Cycle, Dublin: DES.

Department of Education and Skills (2017) Lifeskills Survey, Dublin: DES.

Department of Education and Skills (2018) Wellbeing Policy Statement and Framework for Practice. Dublin: Department of Education and Skills. 
Department of Education and Skills (2019). Safe, respectful, supportive and positive: Ending sexual violence and harassment in Irish higher education institutions, Dublin: DES.

Department of Health (2015a). Healthy Ireland Survey 2015, Dublin: Department of Health.

Department of Health (2015b). National Sexual Health Strategy 2015-2020, Dublin: Department of Health.

Department of Health (2016). Healthy Ireland Survey 2016, Dublin: Department of Health.

Department of Health (2017). Healthy Ireland Survey 2017, Dublin: Department of Health.

Department of Health (2018). Healthy Ireland Survey 2018, Dublin: Department of Health.

DiClemente, R.J., A.L. Swartzendruber, and J.L. Brown, (2013). 'Improving the validity of self-reported sexual behavior: no easy answers', Sexually Transmitted Diseases, Vol. 40, No. 2, pp. 111-112.

Dooley, B., C. O'Connor, A. Fitzgerald, and A. O'Reilly (2019). My World Survey 2: The National Survey of Youth Mental Health, Dublin: UCD.

European Commission (2017). Eurobarometer Report 449: Gender-based violence, Brussels: European Commission.

European Commission (2019). Eurobarometer on Discrimination 2019: The social acceptance of LGBTI people in the EU, Brussels: European Commission.

Ezer, P., L. Kerr, C.M. Fisher, W. Heywood, and J. Lucke (2019). 'Australian students' experiences of sexuality education at school', Sex Education, Vol. 19, No. 5, pp. 597-613.

Fahey, T., H. Russell, and H. Whelan (2007). Best of times? The social impact of the Celtic Tiger, Dublin: Institute for Public Administration.

Goldstein, H. (2003). Multilevel statistical models, London: Edward Arnold.

Hale, D.R., P. Patalay, N. Fitzgerald-Yau, D.S. Hargreaves, L. Bond, A. Görzig, et al. (2014). 'School-level variation in health outcomes in adolescence: analysis of three longitudinal studies in England', Prevention Science, Vol. 15, No. 4, pp. 600-610.

Hale, D. and R. Viner (2012). 'Policy responses to multiple risk behaviours in adolescents', Journal of Public Health, Vol. 34, Suppl. 1, pp. i11-i19.

Henderson, M., I. Butcher, D. Wight, L. Williamson, and G. Raab (2008). What explains between-school differences in rates of sexual experience? BMC Public Health, Vol. 8, No. 53. https://doi.org/10.1186/1471-2458-8-53

Hirst, J. (2008). 'Developing sexual competence? Exploring strategies for the provision of effective sexualities and relationships education', Sex Education, Vol. 8, No. 4, pp. 399-413.

House, L. D., Bates, J., Markham, C. M., \& Lesesne, C. (2010). Competence as a predictor of sexual and reproductive health outcomes for youth: A systematic review. Journal of Adolescent Health, 46(3), S7-S22. 
HSE Health Protection Surveillance Centre (2019). STI provisional slideset 2018. https://www.hpsc.ie/a-z/sexuallytransmittedinfections/publications/stireports/

Hyde, A., M. Carney, J. Drennan, M. Butler, M. Lohan, and E. Howlett (2009). Parents' approaches to educating their pre-adolescent and adolescent children about sexuality, Report No. 21, Dublin: Crisis Pregnancy Agency.

Hyde, A. and E. Howlett (2004). Understanding teenage sexuality in Ireland, Dublin: Crisis Pregnancy Agency.

Jackson, C., Geddes, R., Haw, S., \& Frank, J. (2012a). Interventions to prevent substance use and risky sexual behaviour in young people: a systematic review. Addiction, 107(4), 733-747.

Jackson, C., H. Sweeting, and S. Haw (2012b). 'Clustering of substance use and sexual risk behaviour in adolescence: analysis of two cohort studies', BMJ Open, Vol. 2, No. 1, e000661.

Jones, K. (1992). 'Using multilevel models for survey analysis, in A. Westlake et al. (eds), Survey and statistical computing, Amsterdam: North-Holland.

Keating, S., M. Morgan, and B. Collins (2018). Relationships and Sexuality Education (RSE) in primary and post-primary Irish schools, Dublin: NCCA.

Kesterton, D. and L. Coleman (2010). 'Speakeasy: a UK-wide initiative raising parents' confidence and ability to talk about sex and relationships with their children', Sex Education, Vol. 10, No. 4, pp. 437-448.

Költő, A., A. Gavin, M. Molcho, C. Kelly, L. Walker, and S. Nic Gabhainn, (2020). Health Behaviour in School-aged Children (HBSC) Ireland study 2018, Galway: Health Promotion Research Centre, NUIG.

Layte, R., and H. McGee (2007). Regret about the timing of first sexual intercourse: the role of age and context, ESRI Working Paper No. 217, Dublin: The Economic and Social Research Institute.

Layte, R., H. McGee, A. Quail, K. Rundle, G. Cousins, C. Donnelly, F. Mulcahy, and R. Conroy (2006). The Irish Study of Sexual Health and Relationships, Dublin: Department of Health and Children.

Lewis, R., C. Tanton, C. Mercer, K. Mitchell, M. Palmer, W. Macdowall, and K. Wellings (2017). 'Heterosexual practices among young people in Britain: evidence from three national surveys of sexual attitudes and lifestyles', Journal of Adolescent Health, Vol. 61, No. 6, pp. 694-702.

Lindberg, L.D. and I. Maddow-Zimet (2012). 'Consequences of sex education on teen and young adult sexual behaviors and outcomes', Journal of Adolescent Health, Vol. 51, No. 4, pp. 332-338.

Lopez, L. M., Bernholc, A., Chen, M., \& Tolley, E. E. (2016a). School-based interventions for improving contraceptive use in adolescents. Cochrane Database of Systematic Reviews, (6). 
Lopez, L. M., Grey, T. W., Tolley, E. E., \& Chen, M. (2016b). Brief educational strategies for improving contraception use in young people. Cochrane Database of Systematic Reviews, (3).

Macdowall, W., K. Jones, C. Tanton, S. Clifton, A. Copas, C. Mercer, M. Palmer, R. Lewis, J. Datta, K. Mitchell, N. Field, P. Sonnenberg, A. Johnson, and K. Wellings (2015). 'Associations between source of information about sex and sexual health outcomes in Britain: findings from the third National Survey of Sexual Attitudes and Lifestyles (Natsal-3)', BMJ Open, Vol. 5, No. 3, e007837.

Madkour, A.S., Farhat, T., Halpern, C. T., Godeau, E., \& Gabhainn, S. N. (2010). Early adolescent sexual initiation as a problem behavior: a comparative study of five nations. Journal of Adolescent Health, 47(4), 389-398.

Mayock, P., K. Kitching, and M. Morgan (2007). Relationships and Sexuality Education (RSE) in the context of Social, Personal and Health Education (SPHE), Dublin: Crisis Pregnancy Agency.

McBride, O., K. Morgan, and H. McGee (2012). Irish Contraception and Crisis Pregnancy Study 2010, Dublin: Crisis Pregnancy Programme.

Mercer, C.H., C. Tanton, P. Prah, B. Erens, P. Sonnenberg, S. Clifton, W. Macdowall, R. Lewis, N. Field, J. Datta, A.J. Copas, A. Phelps, K. Wellings, and A.M. Johnson (2013). 'Changes in sexual attitudes and lifestyles in Britain through the life course and over time: findings from the National Surveys of Sexual Attitudes and Lifestyles (Natsal)', The Lancet, Vol. 382, No. 9907, pp. 1781-1794.

Moreau, N., A. Költő, H. Young, F. Maillochon, and E. Godeau (2019). 'Negative feelings about the timing of first sexual intercourse: findings from the Health Behaviour in School-aged Children study', International Journal of Public Health, Vol. 64, No. 2, pp. 219-227.

Morgan, M. (2000). Relationships and Sexuality Education: an evaluation and review of implementation, Dublin: Stationery Office.

Murphy, D., A. Quail, J. Williams, S. Gallagher, A. Murray, E. McNamara, and D. O'Mahony (2018). A summary guide to Wave 3 of the Child Cohort of Growing up in Ireland (at 17/18 years), Dublin: ESRI/TCD.

National Council for Curriculum and Assessment (2008). Primary Curriculum Review, Phase 2: Final report with recommendations, Dublin: NCCA.

National Council for Curriculum and Assessment (2019a). Draft report on the review of relationships and sexuality education (RSE) in primary and postprimary schools, Dublin: NCCA.

National Council for Curriculum and Assessment (2019b). Report on consultation with Comhairle na nÓg on Relationships and Sexuality Education, Dublin: NCCA.

Neville, F., J. McEachran, A. Aleman-Diaz, R. Whitehead, A. Cosma, D. Currie, and C. Currie (2017). 'Trends in the sexual behaviour of 15-year olds in Scotland: 2002-14', European Journal of Public Health, Vol. 27, No. 5, pp. 835-839.

Palmer, M. J., L. Clarke, G.B. Ploubidis, and K. Wellings (2019). 'Prevalence and correlates of "sexual competence" at first heterosexual intercourse among young people in 
Britain', BMJ Sexual \& Reproductive Health, Vol. 45, No. 2. https://doi.org/10.1136/bmjsrh-2018-200160

Peterson, A.J., M. Donze, E. Allen, and C. Bonell (2019). 'Effects of interventions addressing school environments or educational assets on adolescent sexual health: systematic review and meta-analysis', Perspectives on Sexual and Reproductive Health, Vol. 51, No. 2, pp. 91-107.

Petosa, R.L. and L.H. Smith (2014). 'Peer mentoring for health behavior change: a systematic review', American Journal of Health Education, Vol. 45, No. 6, pp. 351357.

Potard, C., R. Courtois, and E. Rusch (2008). 'The influence of peers on risky sexual behaviour during adolescence', European Journal of Contraception \& Reproductive Health Care, Vol. 13, No. 3, pp. 264-270.

Pound, P., S. Denford, J. Shucksmith, C. Tanton, A.M. Johnson, J. Owen, et al. (2017). 'What is best practice in sex and relationship education? A synthesis of evidence, including stakeholders' views', BMJ Open, Vol.7, No. 5. http://dx.doi.org/10.1136/bmjopen-2016-014791

Pound, P., R. Langford, and R. Campbell (2016). 'What do young people think about their school-based sex and relationship education? A qualitative synthesis of young people's views and experiences', BMJ Open, Vol. 6, No. 9. DOI: 10.1136/bmjopen2016-011329

Prah, P., A.J. Copas, C.H. Mercer, S. Clifton, B. Erens, A. Phelps, C. Tanton, P. Sonnenberg, W. Macdowall, K. Wellings, and A.M. Johnson (2014). 'Consistency in reporting sensitive sexual behaviours in Britain: change in reporting bias in the second and third National Surveys of Sexual Attitudes and Lifestyles (Natsal-2 and Natsal-3)', Sexually Transmitted Infections, Vol. 90, No. 2. https://doi.org/10.1136/sextrans2013-051360

Quail, A., J. Williams, C. McCrory, A. Murray, and M. Thornton (2011). A summary guide to Wave 1 of the Infant Cohort (at 9 months) of Growing Up in Ireland, Dublin: ESRI/TCD.

Quail, A., J. Williams, M. Thornton, and A. Murray (2014). A summary guide to Wave 2 of the Child Cohort (at 13 years) of Growing Up in Ireland, Dublin: ESRI/TCD.

Ramiro, L., B. Windlin, M. Reis, S.N. Gabhainn, S. Jovic, M.G. Matos, J. Magnusson, and E. Godeau (2015). 'Gendered trends in early and very early sex and condom use in 20 European countries from 2002 to 2010', European Journal of Public Health, Vol. 25, Suppl. 2, pp. 65-68.

Richter, M., M. Erhart, C.A. Vereecken, A. Zambon, W. Boyce, and S.N. Gabhainn (2009). 'The role of behavioural factors in explaining socio-economic differences in adolescent health: a multilevel study in 33 countries', Social Science and Medicine, Vol. 69, No. 3, pp. 396-403.

Rundle, K., C. Leigh, H. McGee, and R. Layte (2004). Irish Contraception and Crisis Pregnancy Study, Dublin: Crisis Pregnancy Agency. 
Sabia, J. (2006). Does sex education affect adolescent sexual behaviors and health? Journal of Policy Analysis and Management 25, 783-802

Schubotz, D., B. Rolston, and A. Simpson (2004). 'Sexual behaviour of young people in Northern Ireland: first sexual experience', Critical Public Health, vol. 14, no. 2, pp. 177-190.

Schuster, M.A., R. Corona, M.N. Elliott, D.E. Kanouse, K.L. Eastman, A.J. Zhou, and D.J. Klein (2008). 'Evaluation of Talking Parents, Healthy Teens, a new worksite based parenting programme to promote parent-adolescent communication about sexual health: randomised controlled trial', BMJ, Vol. 337, a308. https://doi.org/10.1136/bmj.39609.657581.25

Shiely, F., C. Kelleher, and M. Galvin (2004). Sexual health of the Irish population: Findings from SLAN, Dublin: Crisis Pregnancy Agency.

Simon, L. and K. Daneback (2013). 'Adolescents' use of the internet for sex education: a thematic and critical review of the literature', International Journal of Sexual Health, Vol. 25, No. 4, pp. 305-319.

Smyth, E. (1999). Do schools differ? Dublin: Oak Tree Press/The Economic and Social Research Institute.

Stattin, H. and M. Kerr, (2000). 'Parental monitoring: a reinterpretation', Child Development, Vol. 71, No. 4, pp. 1072-1085.

Takakura, M., N. Wake, and M. Kobayashi (2010). 'The contextual effect of school satisfaction on health-risk behaviors in Japanese high school students', Journal of School Health, Vol. 80, No. 11, pp. 544-551.

Thornton, M., J. Williams, C. McCrory, A. Murray, and A. Quail (2010). Guide to the datasets: Wave 1 of the Nine-Year Cohort of Growing Up in Ireland, Dublin: ESRI/TCD.

van den Akker, H., R. van der Ploeg, and P. Scheepers (2013). 'Disapproval of homosexuality: comparative research on individual and national determinants of disapproval of homosexuality in 20 European countries', International Journal of Public Opinion Research, Vol. 25, No. 1, pp. 64-86.

van Leeuwen, A.J. and R. Mace (2016). 'Life history factors, personality and the social clustering of sexual experience in adolescents', Royal Society Open Science, Vol. 3, No. 10, 160257.

Warren, D. and N. Swami, (2019). 'Teenagers and sex', in Growing Up In Australia - the Longitudinal Study of Australian Children, Annual Statistical Report 2018, Melbourne: Australian Institute of Family Studies.

Wellings, K., K. Nanchahal, W. Macdowall, S. McManus, B. Erens, C.H. Mercer, A.M. Johnson, A.J. Copas, C. Korovessis, K.A. Fenton, and J. Field (2001). 'Sexual behaviour in Britain: early heterosexual experience', The Lancet, Vol. 358, No. 9296, pp. 1843-1850.

Wellings, K., M.J. Palmer, K. Machiyama, and E. Slaymaker (2019). 'Changes in, and factors associated with, frequency of sex in Britain: evidence from three National Surveys of Sexual Attitudes and Lifestyles (Natsal)', BMJ, Vol. 365, I1525. https://doi.org/10.1136/bmj.|1525 
White, C.N. and L.A. Warner (2015). 'Influence of family and school-level factors on age of sexual initiation', Journal of Adolescent Health, Vol. 56, No. 2, pp. 231-237.

WHO (2006). Defining Sexual Health. New York: World Health Organization.

Wight, D., L. Williamson, and M. Henderson (2006). 'Parental influences on young people's sexual behaviour: a longitudinal analysis', Journal of Adolescence, Vol. 29, No. 4, pp. 473-494.

Young, H., L. Burke, and S. Nic Gabhainn (2018). 'Sexual intercourse, age of initiation and contraception among adolescents in Ireland: findings from the Health Behaviour in School-aged Children (HBSC) Ireland study', BMC Public Health, Vol. 18, No. 362. https://doi.org/10.1186/s12889-018-5217-z 
Whitaker Square,

Sir John Rogerson's Quay, Dublin 2

Telephone +35318632000

Email admin@esri.ie

Web www.esri.ie

Twitter @ESRIDublin

ISBN 978-0-7070-0540-9 